\title{
Enhancement of Shaft Capacity of Cast-in- Place Piles using a Hook System
}

\author{
by \\ Ghazi Abou El Hosn
}

A thesis submitted to the Faculty of Graduate and Postdoctoral Affairs in partial fulfillment of the requirements for the degree of:

\section{Master of Applied Science}

in

\section{Civil Engineering}

Carleton University, Ottawa, Ontario 


\begin{abstract}
*
This research investigates an innovative approach to improve the shaft bearing capacity of castin-place pile foundations by utilizing passive inclusions (Hooks) that will be mobilized if movement occurs in pile system. An extensive experimental program was developed to study the shaft bearing capacity of cast-in-place piles with and without hook system in soft clay and sand. First phase of the experiment was developed to investigate the effect of passive inclusion on pilesoil interface shear strength behaviour, employing a modified direct shear test apparatus. The interface strength obtained for pile-soil specimens was found to significantly increase when passive inclusions were implemented. Apparent residual friction angle for concrete-sand interface increased from $22^{\circ}$ to $29.5^{\circ}$ when two hook elements were used at the pile-soil interface. The pile-clay apparent adhesion was also increased from $19 \mathrm{kPa}$ to $34 \mathrm{kPa}$.
\end{abstract}

A series of pile-load testing at field were performed on cast-in-place in soft clay to investigate the effect of passive inclusions on pile bearing capacity. The pile-load tests were conducted at Gloucester test site. Four model piles were cast with steel cages along with hooks (P1- no hook, P2-7 hooks, P3- 5 hooks and P4- 5 hooks) installed on the exterior side of the steel cages prior to filling the hole with concrete. Results from these tests show a proportional increment of friction resistance compared to the number of hooks installed, also compared with those obtained using traditional pilling system (without hook). The interface apparent adhesion for concrete piles sheared against clay under static load test conditions increased about 38\% when 5 hooks were installed at the surface of the concrete.

*Patent Pending 


\section{ACKNOWLEDGMENTS}

I want to express my gratitude and sincere appreciation to Professor Mohammad Rayhani for his assistance, guidance and support in the preparation and completion of my graduate work. I thank also the members of the GRG graduate students: Abdulghader Aldaeef, Juan David Giraldo Velez and Amin Hosseini for their valuable help through my experimental program. I would like to thank the Civil and Environmental Engineering department at Carleton University who provided me with the needs, facility and financial help to complete my study. Finally a great appreciation and thanks to my wife and children for their encouragements and supports through this period to accomplish this project 


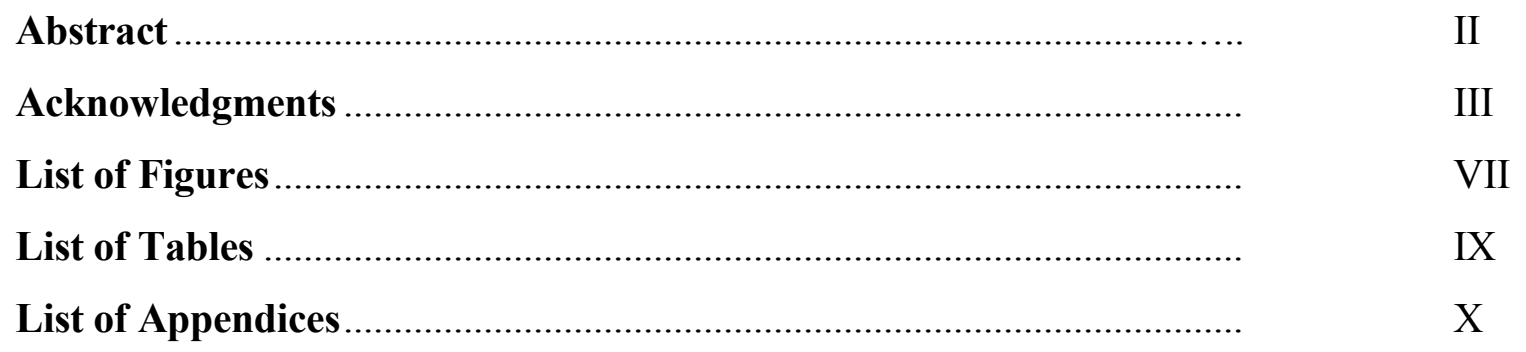

\section{CHAPTER 1}

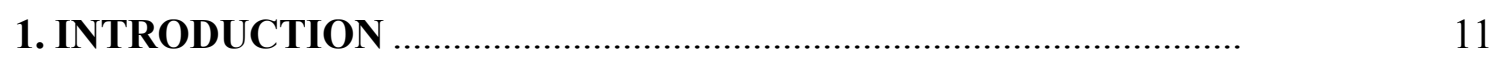

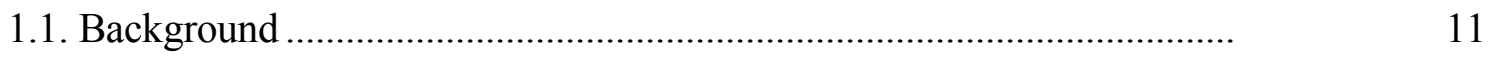

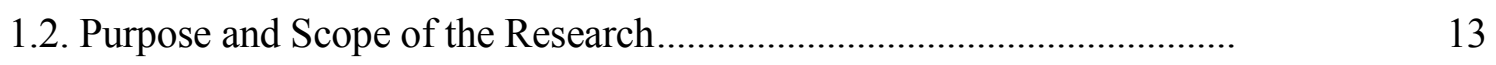

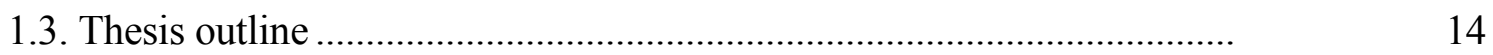

\section{CHAPTER 2}

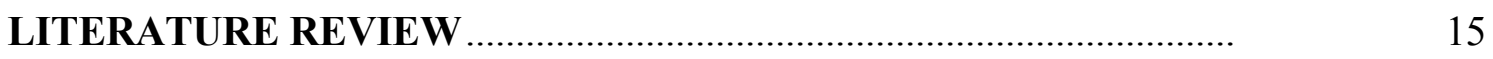

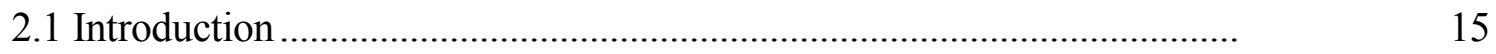

2.2 PILE INSTALLATION METHODS ....................................................

2.3 LOAD TRANSFER OF PILE FOUNDATION .......................................... 18

2.3.1 Determination of Shaft Capacity in Cohesion, Cohesionless Soils \& Rock 20

2.3.2 Methods to Determine Toe Capacity Cohesive, Cohesionless Soil \& Rock 24

2.3.3 Uplift Pile Capacity ......................................................................... 27

2.4 PILE LOAD TESTING ...................................................................... 27

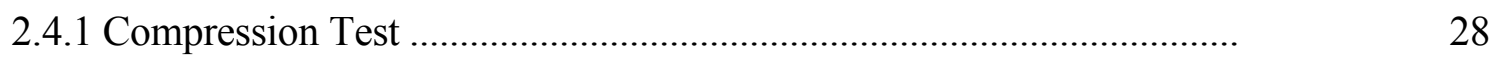

2.4.2 Uplift Pile Load Test............................................................................

2.5 SHAFT CAPACITY OF CAST-IN-PLACE-PILE .................................. 33

2.6 PILE CONCRETE-SOIL INTERFACE ............................ .. 36 
2.6.1 Concrete-Clay Interface Behavior ........................................................ 38

2.6.2 Concrete-Sand Interface Behavior ............................................................

2.6.3 Concrete-Rock Interface Behavior .........................................................

2.7 METHODS TO IMPROVE PILE SHAFT CAPACITY FOR C.I.P.P ... 43

2.7.1 Use of Expensive Concrete in Drilled Shaft Cast-in-place - Clay Soil. 43

2.7.2 Enlargement of Drilled Shaft Base........................................................

2.7.3 Shaft Load Transfer FRP Concrete Piles ................................................

2.7.4 Cutting Grooves into the Socket Wall ..................................................

2.7.5 The New Hooked Pile Method for Drilled Cast-In-Place Piles .............

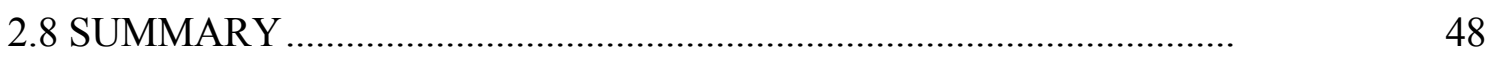

\section{CHAPTER 3}

HOOK SYSTEM PILE-SOIL INTERFACE STRENGTH (Cast in situ pile)

3.1 INTRODUCTION ...........................................................................

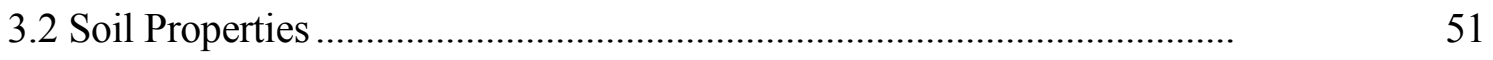

3.3 EXPERIMENTAL PROGRAM ........................................................ 53

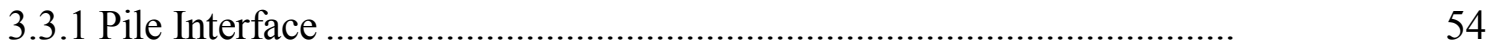

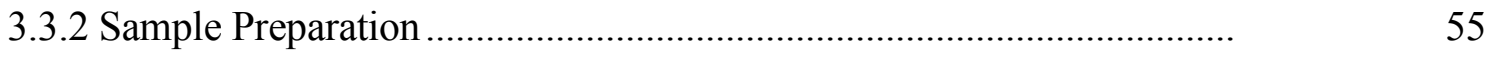

3.3.3 Testing Procedure ………………………………………………...

3.4 RESULTS AND ANALYSES .............................................................

3.4.1 Concrete-Clay Interface Shear Strength.................................................. 58

3.4.2 Concrete-Sand Interface Shear Strength ................................................ 62

3.4.3 Influence of Hook on Pile-Soil Interface Shear Strength ....................... 65

3.4.4 Performance of Hooked Pile Interface in Different Soils.........................

\section{CHAPTER 4}

LOAD TRANSFER OF HOOKED CAST-IN-PLACE CONCRETE PILES IN CLAY

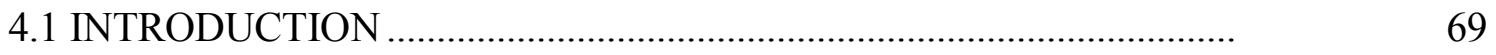

4.2 PILE BEARING CAPACITY ................................................................

4.3 EXPERIMENTAL PROGRAM ............................................................

4.3.1 Properties of the Hooked Model Piles ………………................................ 


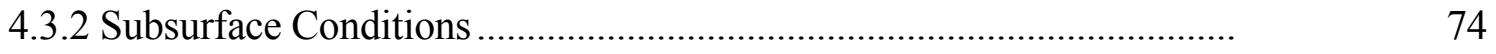

4.3.3 Pile Installation ...............................................................................

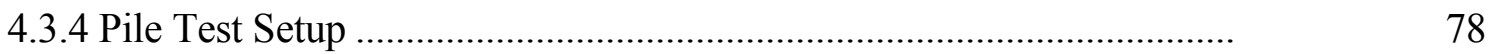

4.3.5 Pile Load Tests..................................................................................

4.4 PILE LOAD TEST RESULTS ............................................................

4.4.1 Results for Static Pile Load Test Conventional Pile (P1)......................

4.4.2 Results for Static Pile Compression Load Test on Modified Pile with 5 hooks 83

4.4.3 Results for Static Pile Compression Load Test on Modified Pile with 7 hooks 84

4.5 ANALYSIS AND DISCUSSION ...........................................................

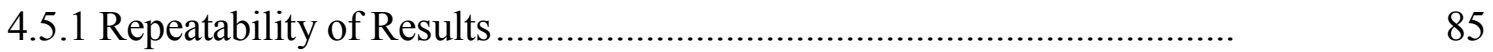

4.5.2 Effect of the Hook on the Shaft Resistance of the Piles ..........................

4.5.3 Effect of the Number of Hooks on Pile Bearing Capacity .....................

4.6 PERFORMANCE OF HOOKED PILE INTERFACE IN CLAY ........ 90

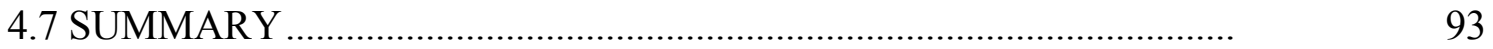

Chapter 5

CONCLUSIONS AND RECOMMENDATIONS

5.1 SUMMARY AND CONCLUSIONS .......................................................

5.2 RECOMMENDATIONS .................................................................

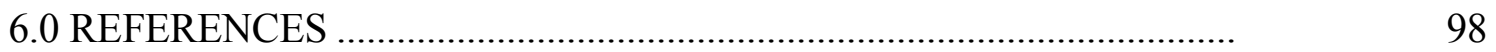




\section{LIST OF FIGURES}

Figure 2.1 Installation equipment for a driven pile.............................. 17

Figure 2.2 Installation techniques for cast-in-place piles ................................ 18

Figure 2.3 Load transfer distribution along the pile........................................ 20

Figure 2.4 Adhesion factors for piles in glacial till .......................................... 21

Figure 2.5 Relationship between standard penetration test $\mathrm{N}$-values

and angle of shearing resistance Friction angle ............................................. 22

Figure 2.6 Reduction factors for rock socket skin friction .............................

Figure 2.7 Reduction factors for discontinuities in rock mass .......................... 24

Figure 2.8 Wedge bearing capacity factors for foundations on rock .............. 26

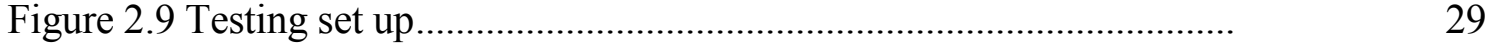

Figure 2.10 Typical load- settlement curves for CRP and ML ....................... 31

Figure 2.11 The pile test set up for uplift pile load test .................................. 33

Figure 2.12 Uplift load on test pile (ML test) diagrams .................................

Figure 2.13 Use of expensive cement in the concrete mix ..............................

Figure 2.14 The base enlargement of the toe .................................................

Figure 2.15 FRP piles used in harsh marine environments ............................. 46

Figure 2.16 Cutting grooves manually for short piles ....................................

Figure 3.1 Leda Clay and Sand grain size distribution ................................... 52

Figure 3.2 Modified shear box used for pile-soil interface testing................. 54

Figure 3.3 Surface interface and profile for concrete with hooks and without hooks 56

Figure 3.4 a) Shear Stress-strain readings from Shear Box tests for plain concrete-clay interface, b) Failure envelopes under undrained conditions in plain concrete-clay 59 
Figure 3.5 a) Shear Stress-strain readings from shear box tests for hooked concrete-clay interface, b) Failure envelopes under undrained conditions in hooked concrete-clay interface

Figure 3.6 a) Shear Stress-strain readings from shear box tests for plain concrete-sand; $b$ ) Failure envelopes under drained conditions in plain concrete-sand interface

Figure 3.7 a) Shear Stress-strain readings from shear box tests for hooked concrete-sand interface, b) Failure envelopes under drained conditions in hooked concrete-sand

Figure 3.8 a) Comparison of shear stress-strain curves for plain concrete- and hooked concrete-sand interface under $170 \mathrm{kPa}$ normal stresses; b) Failure envelopes under drained conditions for both plain concrete-and hooked concrete-sand interfaces; c) Failure envelopes under undrained conditions for both plain concrete-and hooked concrete-clay interfaces

Figure 4.1 Modified cast-in-place concrete pile shaft with Hook system

Figure 4.2 Modified cast-in-place concrete pile shaft with Hook system.......

Figure 4.3 Steel cages for cast-in-place piles .................................................

Figure 4.4 Preparation of cast-in-place piles in the field ................................

Figure 4.5 Test frame, reaction loads and schematic diagrams for load test..

Figure 4.6 a) Diagram of static load test up to working load for P1 (without hook),

b) Diagram of static load test up to failure load for P1 (without hook)..........

Figure 4.7 Load-settlement curves for Pile 3 under the design load (a) and failure load test (b)

Figure 4.8 Load-settlement curves for Pile 2 under the design load (a) and failure load test

Figure 4.9 Load-settlement curves for piles P3 and P4 under failure load tests $\quad 86$

Figure 4.10 Results of axial compression static load test up to failure load for P1\&P3 87

Figure 5.11 Load-settlement curves for piles with 5 hooks (P3) and 7 hooks (P2) 


\section{LIST OF TABLES}

Table 2.1 Values of the coefficient of horizontal soil stress, Ks ................... 22

Table 2.2 Loading sequence for proof load test to 100\% DVL plus 50\% SWL 30

Table 2.3 Drilled shaft capacity of different interpretation methods.............. 36

Table 2.4 Variation of coefficient of lateral earth pressure for different piles 41

Table 3.1 Index properties of soil samples ..................................................

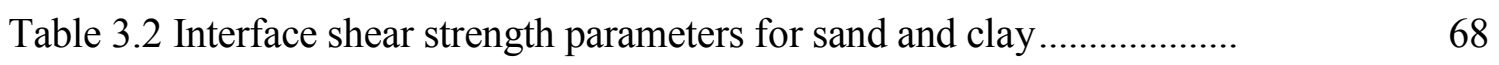

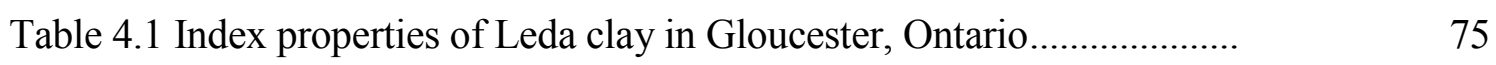

Table 4.2 The load increments used for pile load tests ...................................

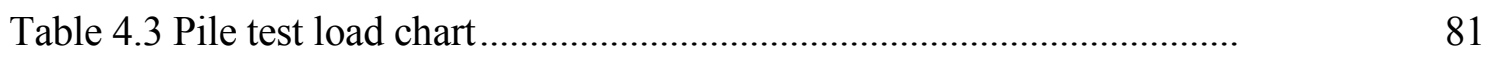

Table 4.4 Interface shear strength parameters for concrete/clay at field tests 94 


\section{LIST OF APPENDICES}

Appendix A: Laboratory and Field Tests Photos ..........................................

104 


\section{CHAPTER 1}

\section{INTRODUCTION}

\subsection{Background}

Pile foundation is one of the methods used during last century in a very large scale to ensure the stability, safety and the durability of the structure. Nowadays pile foundations are considered to be the preferred foundation system that is used extensively throughout the world to resist the upwards and downwards heavy load structures both onshore and offshore. Pile foundations are used when the upper soil stratum is weak and there is a need to transfer the loads to deeper strata and also when excessive settlement has to be prevented. In addition to axial load resistance, pile foundations are also used to withstand lateral forces and moments experienced in offshore structures and high-rise buildings. Pile foundation are normally installed either by driving through the ground strata or through drilling and filling the hole with reinforced concrete. Driven piles are the oldest type of pile foundations used in this industry and are installed through driving them into previously unexcavated soil by a hammer system. They were exclusively made of wood until the end of the nineteenth century. Reinforced concrete piles entered into the picture early in the twentieth century, as did the use of steel piling.

The load carrying capacity of pile foundations are provided by the toe bearing capacity as well as the pile shaft capacity through the interface pile-soil resistance. Interactions between piles and the surrounding soil are complex and installation of piles generally alters the 
characteristics of the soil. However localized strains are created near piles, while nonhomogeneity of the soil, the effects of pile groups and pile shape add further difficulties to understand the soil-pile interaction. Depending on the level of displacement generated by the pile during its installation process, the pile soil interface strength would be significantly different. Driven piles such as closed-end pipe piles and precast concrete pile can cause large displacement and hence better interface bonding, though it might also generate excess pore water pressure in saturated soils. The interface bonding for small displacement piles such as H-piles and open ended pipes would be lower, leading to lower interface strength. This interface strength for bored cast-in-place piles could even be lower due to a potential gap between the pile and soil, depending on the method of soil excavation.

Several techniques are used to improve the pile-soil interface strength and, hence, the shaft capacity of cast-in-place piles. These techniques include using expansive concrete to fill possible voids between the pile and the surrounding material, enlargement of the base of the pile to increase the uplift and base load capacity, and implementing cutting grooves around the pile's socket wall to increase the pile surface roughness and consequently the pile shaft capacity. Although some of these techniques are useful in certain applications, they are not widely implemented in the pilling industry due to their limitation and drawbacks. This research aims at developing a new methodology to enhance the pile-soil interface resistance and hence the pile shaft capacity applicable in a wide range of applications. A hook system is proposed to be implemented on the surface of the pile to improve the bonding between the pile and the surrounding material. The role of the hooks is to distribute the load reactions through transferring them from the pile shaft to the surrounding soil/rock by providing a passive force to the surrounding surfaces. Comparing the other types of enhancement approaches discussed 
above, the hook system is expected to play a central and direct role in terms of surface roughness.

\subsection{Purpose and Scope of the Research}

This research aims at developing a design methodology to enhance the shaft capacity of cast-inplace piles through improvement of the interface resistance between the pile and the surrounding ground materials. Potential gaps and cavities between the pile and the ground materials generated during the drilling process of the hole have shown to reduce the pile-soil interface strength and hence decrease the pile capacity. This could potentially increase the pile dimensions as well as the number of piles required for each project leading to higher cost of pilling.

In an attempt to address this problem, a new hook system is examined here to explore the possibility of increasing the pile shaft capacity. The hooks will be installed at the perimeter of the steel cages used in cast-in-place piles with the objective of improving the pile-soil interface resistance. This technique is expected to improve the resistance of the pile shaft under both compressive loads caused by superstructures as well as the uplift pressure and tension resistance resulting from high wind load or lateral loads without increasing the pile diameter and the shaft length. The target is to create a construction mechanism that improves the pile capacity and settlement, by increasing the frictional resistance of the pile. Implementation of the hook system along with the steel cage in a manner to create a hook anchoring with the surrounding soil requires a long term investigations program and multiple experiments that may result in understanding the behavior of the interface resistance between the hooked concrete surface and the surrounding soils. In order to achieve this, two stages of experiment were adopted here. In the first stage, the concrete-soil interface behaviour was investigated for both plain concrete 
surface and hooked surfaces using a modified direct shear box apparatus. In the second stage, compression static pile load tests were employed in the field to explore the impact of hook system on pile load capacity in a clay soil. The test procedures in both stages were carried out according to ASTM standard test methods.

\subsection{Thesis Outline}

The research procedure and the testing program in this thesis are presented in 5 chapters as follow:

Chapter 1 represents the general identity of pile foundations and the need for a research in this field along with the research objectives. Chapter 2 summarizes a review of pile foundations and their design procedure along with current research on pile-soil interface behaviour for different ground materials. Current improvement methods on pile shaft capacity are also discussed. This chapter also highlights the importance of this research in improving the frictional capacity of cast-in-place piles in pile industry. Chapter 3 reports a comprehensive evaluation of the interface shear resistance between cast-in-place piles and clay soils with and without hook system. Details of direct shear box testing on concrete-clay interface and concretesand with different hook configuration are discussed in this chapter along with the results and consequent analysis. In order to explore the role of hooks in improving the pile shaft capacity in field conditions, a series of pile load tests were conducted in Gloucester, ON. Chapter 4 presents these filed tests discussed the results of the pile load tests in order to evaluate the influence of the hooks on pile capacity. The results are also compared with those achieved through direct shear tests. Chapter 5 explains the final conclusions of the work and the recommendation for possible future research on the hook system. 


\section{CHAPTER 2}

\section{LITERATURE REVIEW}

\subsection{INTRODUCTION}

Piles are structural elements specifically used in foundation system when no adequate bearing soil strata exist at a shallow depth to allow an economic construction of strip footing or raft foundation. Pile foundation has the capacity of transmitting loads of the superstructure by means of side and toe bearing resistance through weak layers onto stiffer ground strata. Many types of piles exist nowadays and its selection is subject of the availability of the pile materials, conformity of site condition, the method of installation and many other reasons. Usually the pile installation methods play a major role on the pile's behavior and consequently its bearing capacity. Practically the pile load transfers to soils by means of the pile-soil interface shear strength along the shaft and the bearing resistance of the pile's tip. Many techniques have been employed to estimate the pile shaft and toe capacities in sandy and clayey soils to accurately achieve safe and economical results.

Piles were traditionally made of timber in foundation applications and progressed with time to steel, concrete and recently composite materials such as Fiber Reinforced Polymer (FRP) piles. Most of the standards code provisions and manuals (e.g., Canadian Foundation Engineering Manual, CGS 2007; European standards, BS 8004, 1986) categorized the pile foundations in three main groups of large displacement, small displacement and cast-in-place 
piles. Large displacement piles include hollow pipe with a closed end or precast concrete piles which are driven or jacked into the ground and therefore displace the soil. Small displacement piles mainly include steel piles with small sectional areas like $\mathrm{H}$ or I beam, hollow pipes, and box sections that are driven into the ground allowing the soils enter into the hollow box. These types of piles normally cause small soil displacement during driving unless plugged while driving and become large displacement piles. Replacement piles or cast-in-place piles are formed by filling the concrete in an excavated borehole in the site. Prefabricated element of steel, timber or concrete could be placed in drilled holes along with concrete fill.

Cast-in-place piles can be made in different diameters and lengths. The bearing capacity of these piles is mainly developed through the toe bearing resistance, as the shaft resistance could be affected by the concrete moisture content and the low concrete-soil interface strength unlike the driven piles. This chapter briefly reviews the background on pile capacity development for cast-in-place piles as well as previous research on improving pile shaft capacity in different soils.

\subsection{PILE INSTALLATION METHODS}

Most steel, timber and precast concrete piles are jacked or driven in the ground and cause various amount of displacement in the soil depending on the size of their cross section size. Large displacement piles (precast concrete piles and closed end steel pipes) generate large displacement in the soil as they are driven into the ground. Small displacement piles are also driven or jacked into the ground but have a relatively small cross-sectional area. They include rolled H or Isections, and pipe or box sections driven with an open end such that soil enters the hollow portion. Where these pile types are plugged with soil during driving, they become large displacement types. Drilled or Replacement piles are formed while removing the soil by boring 
using a wide range of drilling techniques. Drilled shafts can be executed using a continuous flight auger system CFA type and a temporary or permanent Caissons system. Some of the advantages for cast-in-place piles are: the flexibility in constructing the desired length and diameter of the pile required to safely resist the design load, the possibility of enlarging the pile toe base area, and to the possibility to install and fix additional devices like the Hook System or other energy saving tools. On the other side, the uncertainty of knowing the shape of the pile and the lack of possibility for pile inspection after concrete pouring are the disadvantages of this system. Figure 2.1 shows installation equipment for driven piles, and Figure 2.2 shows different installation technics used for drilled cast-in-place piles.

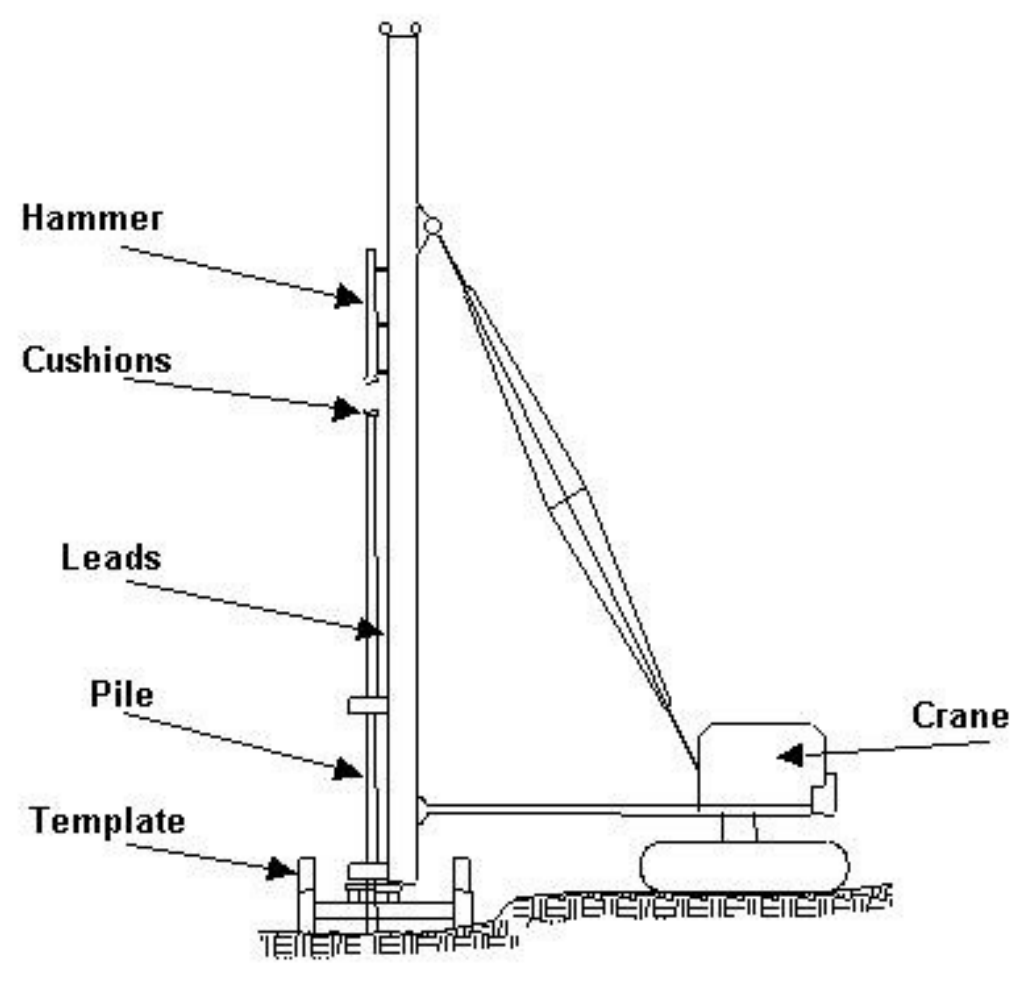

Figure 2.1: Installation equipment for a driven pile (Nationwide rock trenching) 


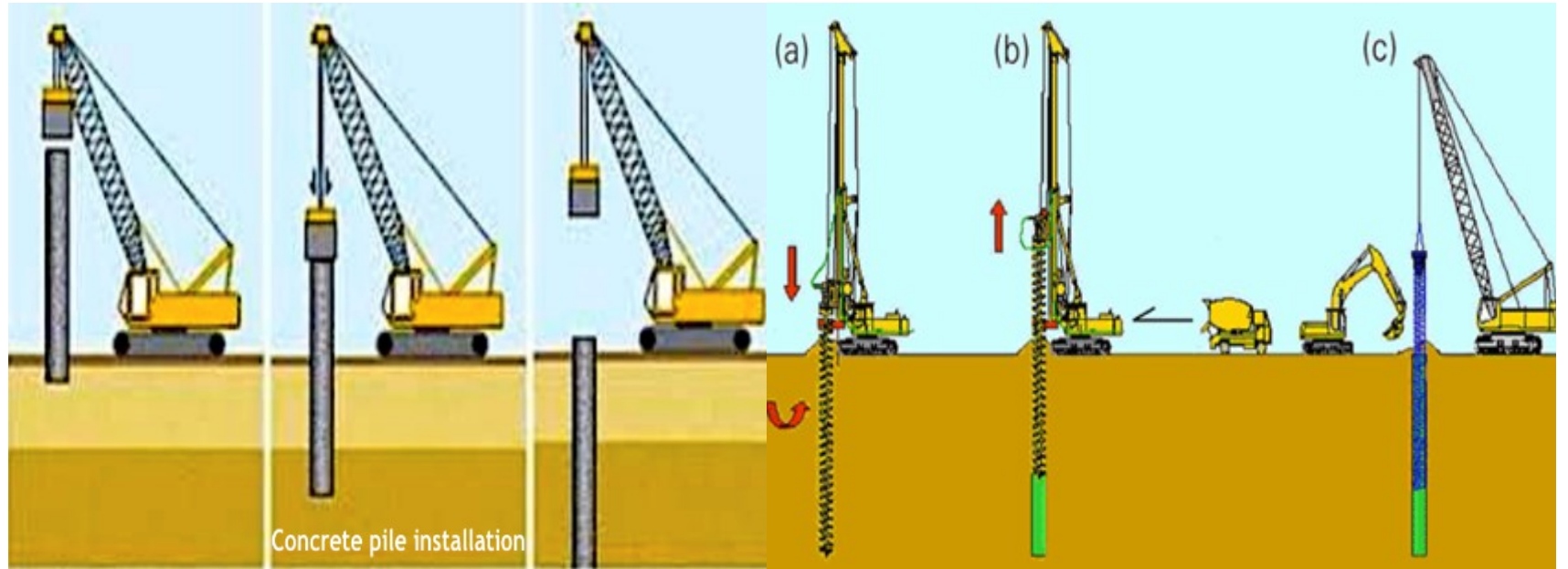

Bored cast-in-place pile Continuous flight auger CFA

Figure 2.2: Installation techniques for cast-in-place piles (Source: Bauer Maschinen)

\subsection{LOAD TRANSFER OF PILE FOUNDATIONS}

Many types of pile and their diversity in the methods of installation have been described in the previous section. Both drilling and driving could disturb and deform the soil surrounding the sides of the pile where the effects are significant on skin frictional resistance. The method of installation may improve or reduce the bearing capacity of pile foundations. The basic approaches used for the calculation of piles capacities are discussed here in terms of shaft and toe capacities in cohesive and cohesionless soils. A series of simple relationship between the effective overburden pressures, coefficient of earth pressure, the angle of the interface shearing and the average undrained shear strength of the soil are used to estimate the bearing capacity of the pile.

The load carrying capacity of a single pile, $Q$, is derived from frictional shaft resistance developed along the pile surface and bearing capacity of the toe of the pile. The contribution of each of these components depends on the soil properties, pile installation method, pile surface characteristics, material and geometry. The geotechnical axial capacity for single piles is 
determined by summing the shaft resistance (shear strength along the pile shaft) and the bearing capacity at the pile toe. The general expression for pile axial capacity is as follows:

$$
Q=\sum_{Z=0}^{L} Q_{s}+Q_{t}
$$

The shaft resistance $Q_{s}$ is given by:

$$
Q_{s}=C q_{s} \Delta z
$$

where, $C$, is the pile circumference, $L$ is the pile length, and $q_{s}$ is the average or unit shaft resistance at any given depth along the pile shaft. Toe bearing resistance, $Q_{t}$ is given by:

$$
Q_{t}=A_{t} q_{t}
$$

Where, $A_{t}$ is pile area at the toe, and $q_{t}$, is the bearing capacity of the pile toe.

In pilling practice, the carrying capacity of the pile is considered equivalent to the capacity of the pile tested considerably after the installation of the pile. The pile under progressively increasing load behaves elastically at starting of the load and changes to be more inelastic after reaching the movement required to mobilize the maximum skin friction which usually varies between 0.3 to $1 \%$ of the pile diameter and full mobilization occurs up to $10 \%$ of the base diameter where the pile plunges downwards with no further resistance and develops large settlements (Tomlinson, 1994). A combination of the maximum displacement contributed from the shaft and the toe of the pile may result in soil failure that causes intolerable distortion of the structure. Figure 2.3 illustrates the contribution of both shaft and toe resistance in bearing capacity of the pile.

The evaluation and determination of shaft capacity in cohesive soils, cohesionless soils and rock are influenced by the pile material, perimeter area, and the equipment used for the 
installation. The installation method can affect the soil properties like the apparent adhesion in clay and interface friction coefficient where frictional soil exist.

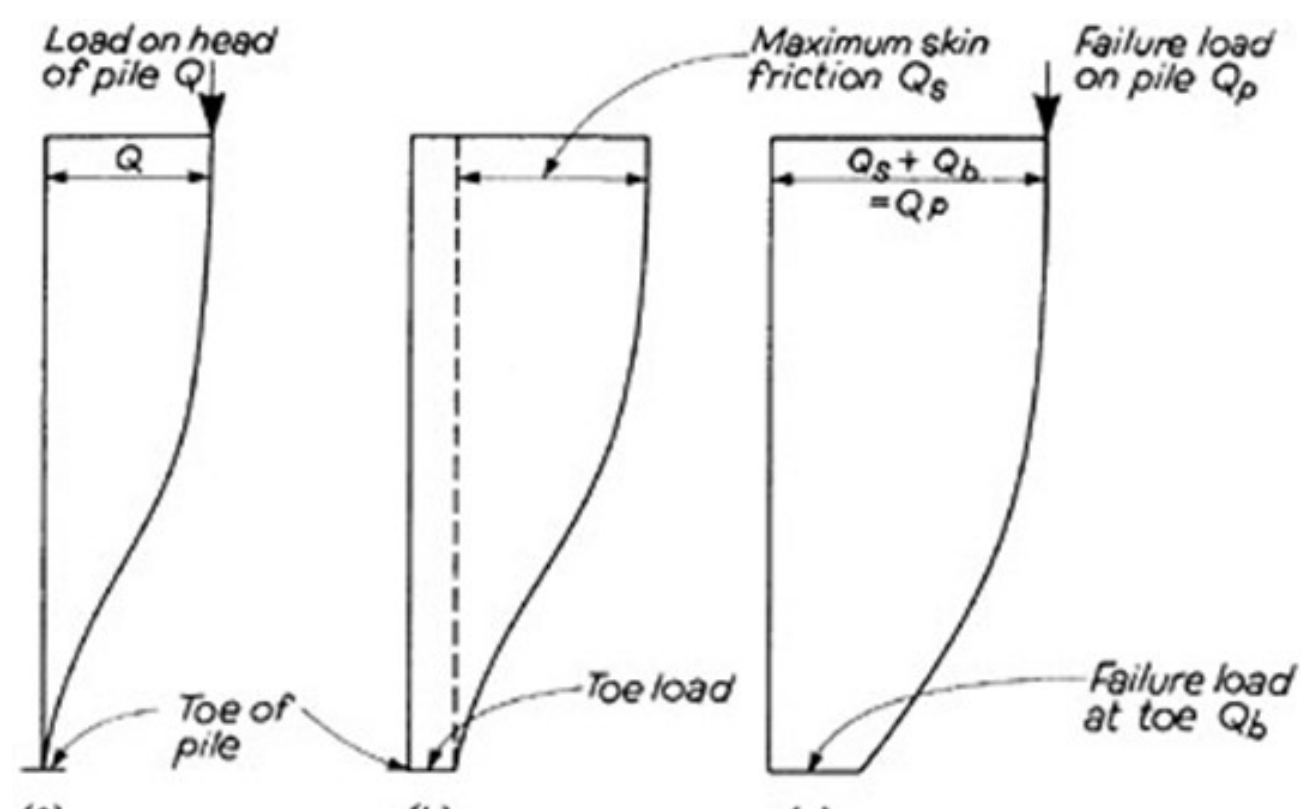

(a)

(b)

(c)

Fig. 2.3: Load transfer distribution along the pile (Tomlinson, 1994)

\subsubsection{Determination of Shaft Capacity in Different Ground Materials}

The average pile shaft capacity, $\mathrm{q}_{\mathrm{s}}$, in cohesive soils is a function of the adhesion phenomenon between the pile and soil. This adhesion in fine grained soils is proportional to undrained shear strength of the soil, $\mathrm{c}_{\mathrm{u}}$, as follow:

$$
\mathrm{q}_{\mathrm{s}}=\alpha C u
$$

Where $\mathrm{Cu}$ is the average undisturbed undrained shear strength of the soil surrounding the pile shaft, and $\alpha$ is an adhesion coefficient factor which is a function of the soil strength and pile displacement. The results of pile load tests carried out on driven and cast-in-place piles in glacial 
till (Weltman and Healy, 1978) produced a relation between $\alpha$ and $\mathrm{Cu}$ for both driven and castin-place piles as shown in Figure 2.4.

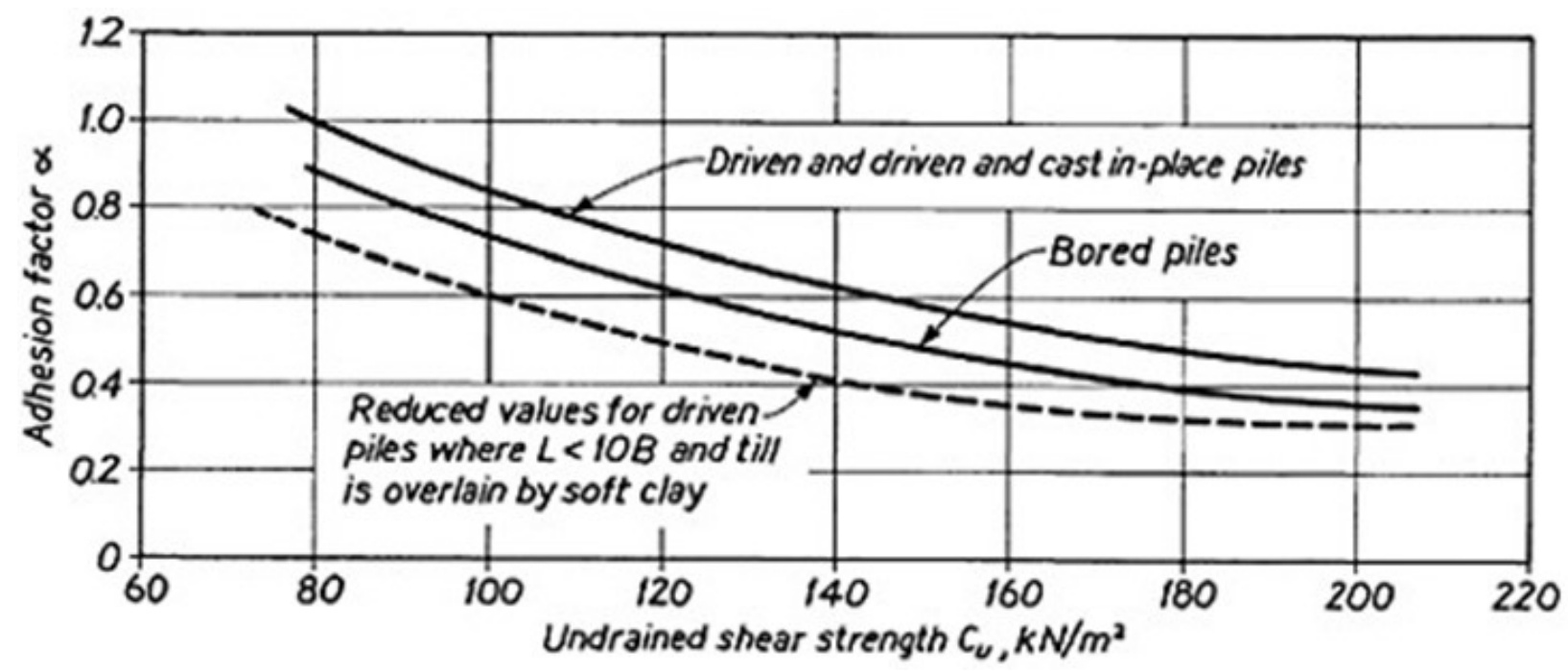

Fig. 2.4: Adhesion factors for piles in glacial till (after Weltman and Healy, 1978)

The pile shaft capacity in cohesionless soils is related to the interface friction angle and the horizontal normal stresses acting on the sides of the pile shaft. The horizontal earth pressure normal to the pile shaft is in turn a function of the confining pressure along the length of the pile and the coefficient of lateral earth pressure $K_{s .}$. The average shaft resistance $q_{s}$ can be represented by the following relationship proposed by Meyerhof, (1976):

$$
q_{s}=\sigma^{\prime}{ }_{v} K_{s} \tan \delta
$$

where, $\sigma_{v}^{\prime}$ is the vertical effective stress along the length of the pile, $K_{S}$ is the coefficient of lateral earth pressure and $\delta$ is the pile-soil interface friction angle. The coefficient of lateral earth pressure is dependent on the method of installation, soil properties and initial stress levels (Table 2.1). The pile-soil interface friction angle is also a function of pile surface roughness, soil particle size and 
pile installation methods. The pile-soil interface friction angle may vary between 0.7 to 1.0 of the soil effective internal friction angle (Figure 2.5).

Table 2.1: Values of the coefficient of horizontal soil stress, Ks (Tomlinson, 1994)

\begin{tabular}{|l|c|}
\hline \multicolumn{1}{|c|}{ Pile installation method } & $\mathrm{K}_{\mathrm{s}} / \mathrm{K}_{0}$ \\
\hline Driven piles, large displacement & $1.0-2.0$ \\
\hline Driven piles, small displacement & $0.75-1.25$ \\
\hline Bored and cast-in-place piles & $0.7-1.0$ \\
\hline Jetted piles & $0.5-0.7$ \\
\hline \multicolumn{1}{|c|}{$\mathrm{K}_{0}$ in normally consolidated sands } \\
\hline Loose sand & 0.5 \\
\hline Medium dense sand & 0.45 \\
\hline Dense sand & 0.35 \\
\hline
\end{tabular}

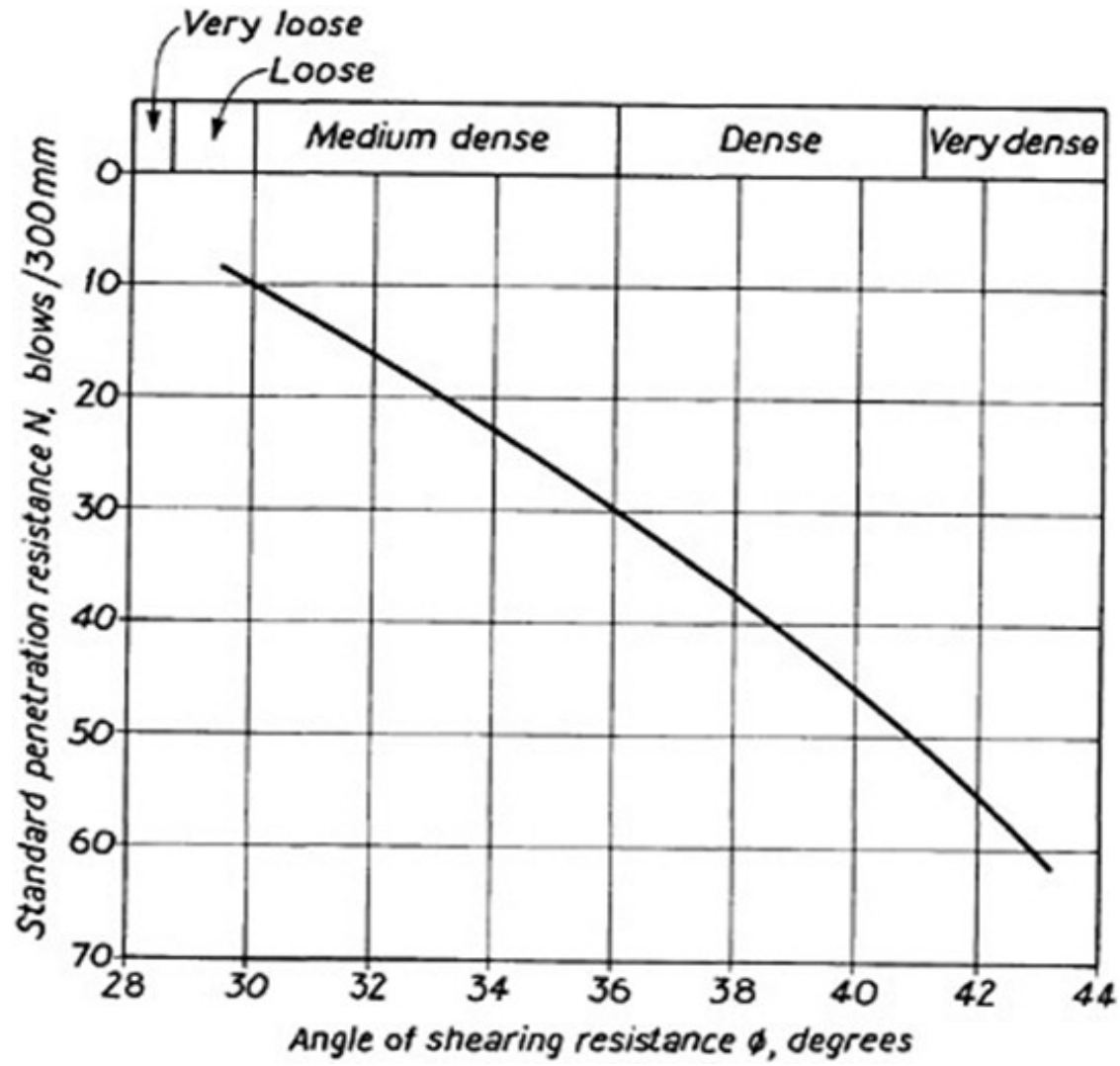

Fig. 2.5: Relationship between standard penetration test $\mathrm{N}$-values and friction angle (Peck et al. 1974) 
The most common pile type used within the rock strata is cast-in-place piles, as it is very difficult to drive steel and precast concrete piles into the rock. Many factors affect the shaft bearing capacity of cast-in-place pile in rock strata including the unconfined compression strength (quc), the elastic modulus of the rock surrounding the socket length and beneath the tip of the pile, and finally the pile surface roughness and concrete-rock interface strength. A derived bonding stress correlated to unconfined compressive strength was established by Horvath (1978), Rosenberg and Journeaux (1976) and Williams and Pells (1981) for cast-in-place piles in rocks. Hence the ultimate interface strength $\left(\mathrm{q}_{\mathrm{s}}\right)$ is related to the average unconfined compressive strength as follow:

$$
q_{s}=\alpha \beta q_{u c}
$$

where $\alpha$ is a reduction factor related to unconfined compressive strength of the rock, quc, as shown in Figure 2.4, and $\beta$ is a correction factor related to the discontinuity spacing in the rock mass (Fig. 2.7).

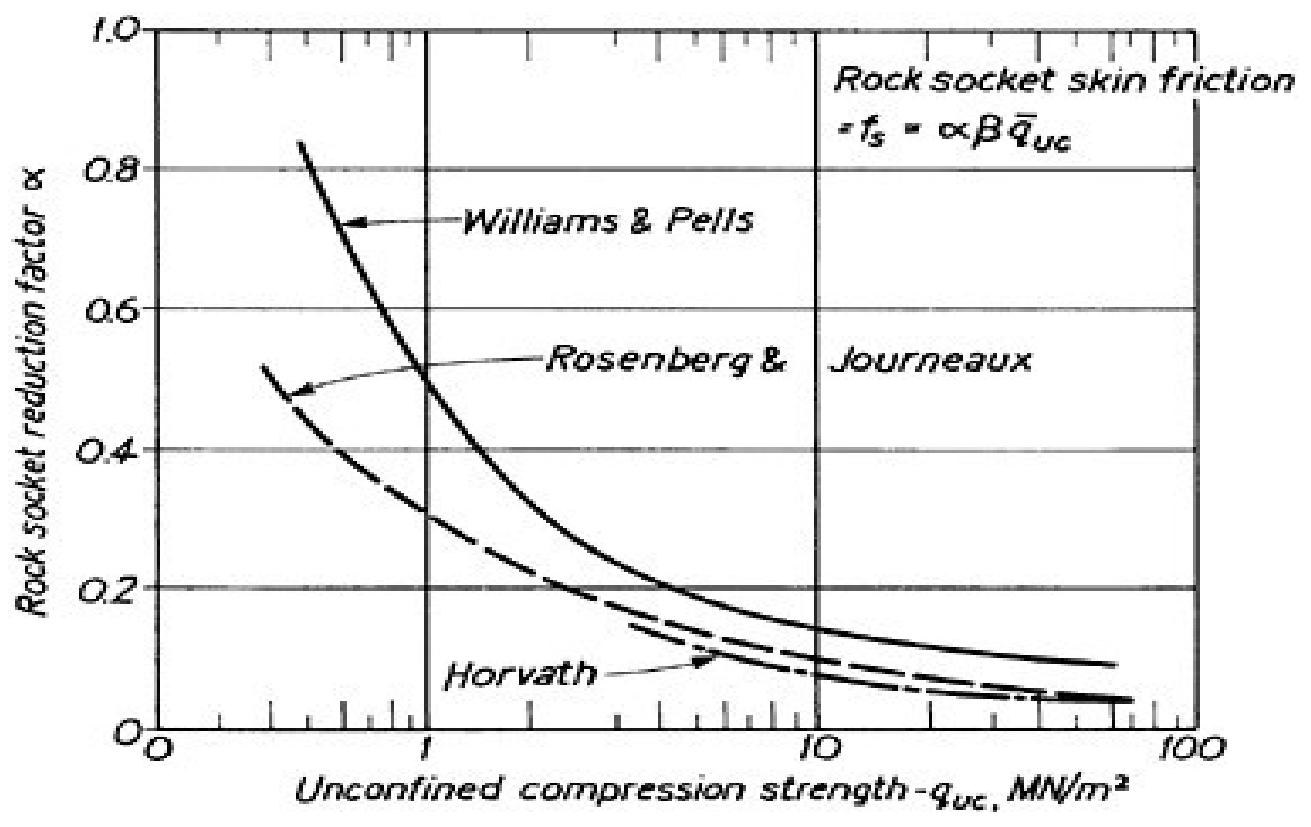

Fig. 2.6: Reduction factors for rock socket skin friction (afterTomlinson, 1994) 


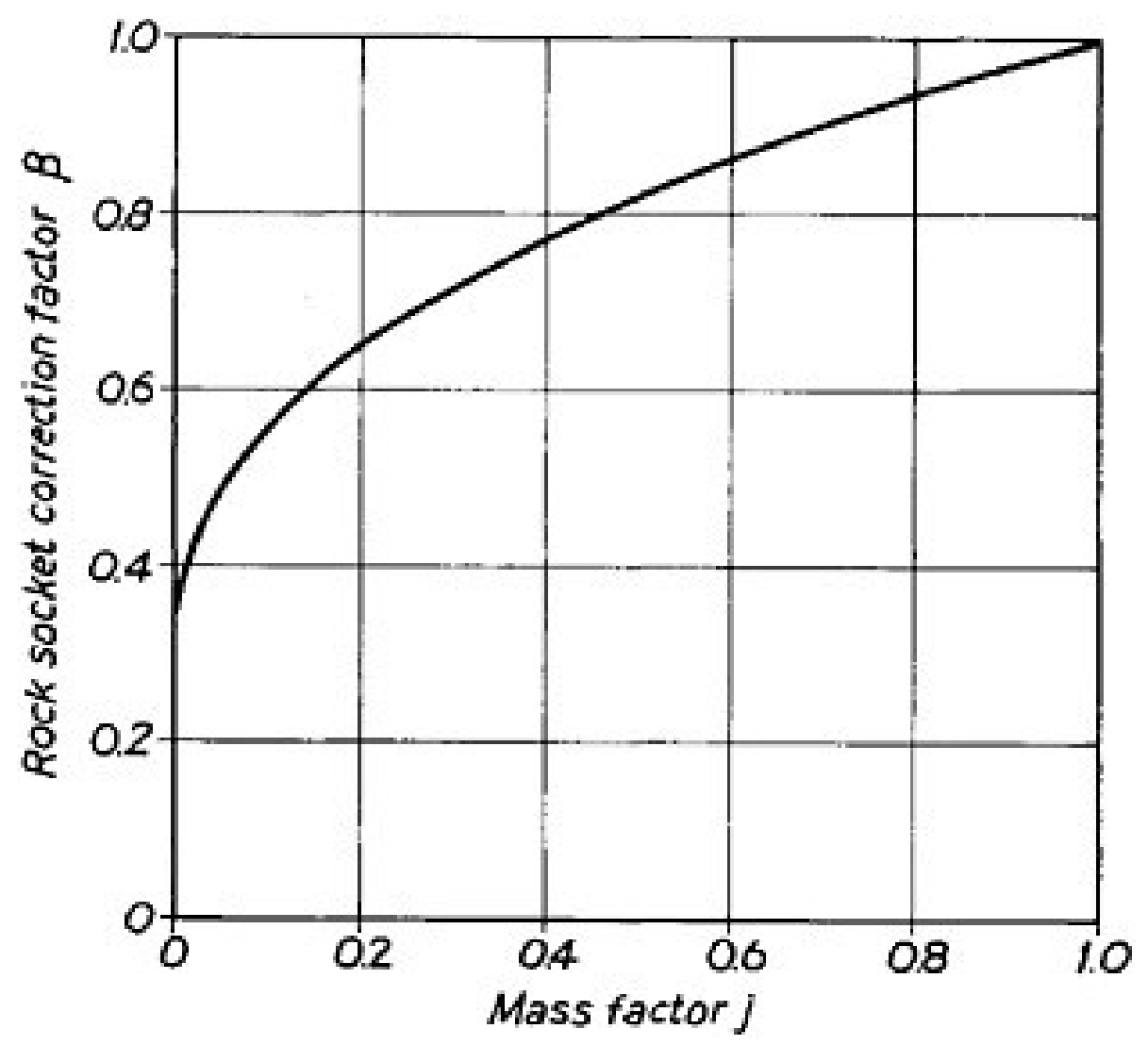

Fig. 2.7: Reduction factors for discontinuities in rock mass (Williams and Pells, 1981)

\subsubsection{Methods to Determine Toe Capacity in Soils and Rocks}

Various methods have been proposed to estimate the toe bearing capacity based on soil type, pile installation method and pile type among other parameters. Terzaghi's bearing capacity equation for footing is usually the base for calculating the toe bearing capacity of the pile:

$$
\mathrm{q}_{\mathrm{u}}=\mathrm{c} \mathrm{Nc}+\gamma \mathrm{D} \mathrm{Nq}+0.5 \gamma \mathrm{B} \mathrm{N} \gamma
$$

where $\mathrm{Nc}, \mathrm{Nq}$, and $\mathrm{N} \gamma$ are Terzaghi's bearing capacity factors which depend on soil friction angle, $\gamma$ is the soil unit weight, $\mathrm{D}$ is the pile length and $\mathrm{B}$ is the pile toe diameter. The factors governing the toe bearing capacity are mostly related to the various components like the consolidation of the 
soil along with the density, angle of internal friction, the shape and length of the pile, the coefficient of earth pressure and the undrained shear strength in cohesive soils.

The bearing capacity of the pile toe in cohesive soils is dependent on the undrained shear strength of the soil, $\mathrm{cu}$, and a bearing capacity factor, $\mathrm{Nc}$, as follow:

$$
q_{b}=N_{c} C_{u}
$$

The bearing capacity factor $\mathrm{N}_{\mathrm{c}}$ can be taken as equal to 9 provided that the pile length is more than five diameter of the pile in the bearing stratum. By referring to Canadian Foundation Engineering Manual (GCS, 2007) $\mathrm{N}_{\mathrm{c}}$ is a function of pile diameter varying from 6 to 9 , depending on the penetration of the bearing stratum, using 6 for the penetration less than 3 times pile tip and 9 for penetration of 3 diameters or more.

The bearing capacity of the pile in cohesionless soil can be estimated from equations (2.7) by neglecting the first part of the equation as follow:

$$
q_{b}=N q \sigma^{\prime}{ }_{v o}+0.5 \gamma B N_{\gamma}
$$

where $\sigma_{v o}^{\prime}$ is the effective overburden pressure at pile base level, $N_{q}$ and $N_{\gamma}$ are the bearing capacity factors proportional to the value of the soil angle of internal friction, $\gamma$ is the soil unit weight, and B is the pile toe diameter, Pile load test results reported by Meyerhof (1976) resulted in practical values for $\mathrm{N}_{\mathrm{q}}$ as a function of soil particle size of cohesionless soils. Many design manuals such as the CFEM (CGS, 2007) provide typical bearing capacity factor values depending on the soil type and pile installation method. The second part in equation 2.9 is approximately equal to the typical pile weight is usually neglected in the design which leads to cancelling the second term in this equation.

As for rock bearing capacity for cast-in-place piles, the unconfined compressive strength of the rock, the modulus of elasticity, and the level of fractures and cracks known as rock quality 
designation (RQD) affect the toe bearing capacity of the piles in rock. A modified bearing capacity factor was developed by Berezantsev (1961) and presented by Tomlinson (1995). The ultimate base resistance may be calculated from the following equation:

$$
\mathrm{q}_{\mathrm{b}}=2 \mathrm{~N}_{\mathrm{b}} \mathrm{quc}_{\mathrm{uc}}
$$

Where $\mathrm{N}_{\mathrm{b}}$ is the bearing capacity factor determined from $\mathrm{N}_{\mathrm{b}}=\tan ^{2}\left(45+\frac{\phi}{2}\right)$, quc is the unconfined compressive strength and $\phi$ is the angle of internal friction of the rock. quc can be obtained from laboratory core compression crushing test on undisturbed core sample. Figure 2.8 shows variation of the Terzaghi bearing capacity factors based on internal friction angle of rocks.

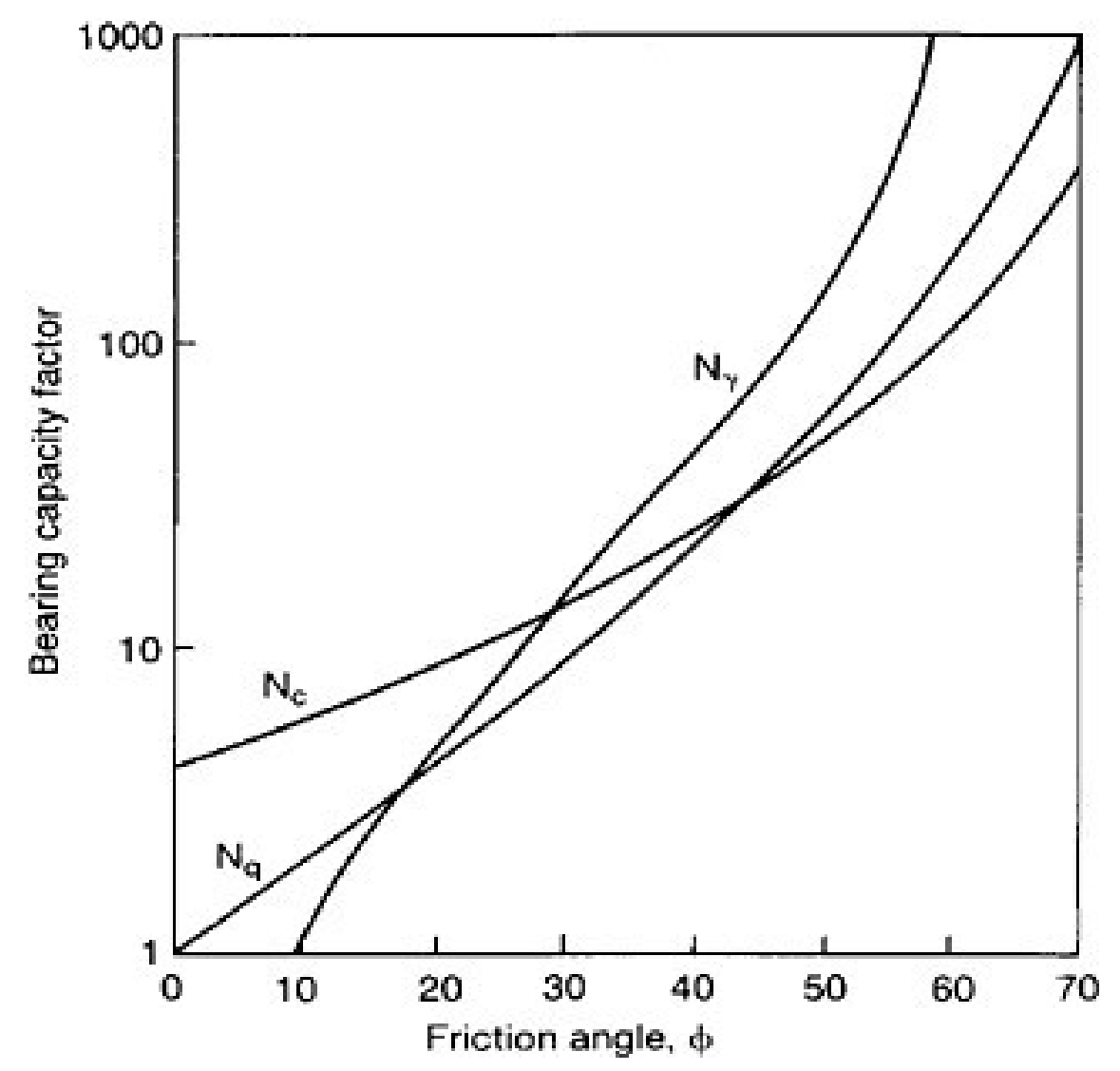

Fig. 2.8: Wedge bearing capacity factors for foundations on rock (from Pells and Turner, 1980) 


\subsubsection{Uplift Pile Capacity}

Uplift capacity of piles is normally dependent on the pile shaft frictional resistance and can be determined using the same procedure discussed above for the shaft capacity in different soil and rock materials. However, it is generally accepted that uplift capacity may slightly be lower than the pile shaft capacity under compressive loading (Poulos and Davis, 1980; Fleming et al., 1992). This is related to the fact that the download confinement mechanism differs from the upwards behavior of the shear failure envelope. St John et al. (1983) attributed under cyclic loading the loss in uplift capacity to changes in the packing of the soil grains and the attribution of the grains. Therefore the soil mineralogy may play a major factor in uplift skin friction. Rao and Venkatesh (1985) reported a significant reduction of unit shaft frictional resistance under pullout tests, up to $20 \%$ less than that of compressive tests. This variation in shaft capacity for uplift and compression test could be significant for different soils. Poulos (1989) observed that a skin friction in uplift loading will reduce the value of designed static friction to $50 \%$ for calcareous sand compared to $25 \%$ for silica sand. The reduction in skin friction is also related to the magnitude of pile movement relative to the soil. The ultimate or peak skin friction is usually achieved at a displacement about $1 \%$ of the pile diameter. Considering the significant uncertainties in estimation of pile shaft capacity for uplift conditions, Poulos and Davis (1980) and design manuals such as the CFEM (CGS, 2007) propose the reduction of uplift capacity from 60 to $80 \%$ of the frictional capacity of piles in compression.

\subsection{PILE LOAD TESTING}

Load testing is the most effective way to demonstrate whether the piles have been properly designed and constructed. Preliminary pile load test is normally implemented to compare the results and insure they comply with the design requirement and the building codes. Two types of 
standard methods are used on checking the pile capacity; static load testing methods ASTM D1143 / D1143M-07(2013) and dynamic methods ASTM D4945. Both methods are used to verify if the pile capacity complies with the analytical design calculations within the settlement tolerance. The British Standards (BS 8004:1986) specify at least one preliminary pile to be tested up to the destruction failure or 3 times the design load and $1 \%$ of the total number of the working piles to be tested to 1.5 times the design load.

\subsubsection{Compression Test}

Static pile load tests can be used to measure pile capacity for both axial loading in tension or compression, and for lateral loading. Two main types of tests are used for compressive loading on piles. The first is the constant rate of penetration (CRP) test developed by the Building Research Establishment in which the compressive force is progressively increased to cause the pile to penetrate the soil at a constant rate until failure occurs. The second type of test is the maintained load (ML) test in which the load is increased in certain stages, e.g., 1.5 times or twice the working load as per Table 2.2, and the time-settlement curve is recorded at each stage of loading and unloading. The ML test may also be taken to failure by progressively increasing the load in stages. Two general test setups are usually constructed, one is the Kentledge system static weights (Figure 2.9-a) and the other one is tension piles or cable anchors (Figure 2.9-b) for static pile load tests.

The ML test is the most convenient approach for proof loading tests on working piles. It is also suitable for use where empirical methods are employed to predict the ultimate load from measurement of residual deflections after returning the test load to zero at four or five stages up to the maximum load as shown in Figure 2.10. The load at each stage is held until the rate of settlement has decreased to less than $0.25 \mathrm{~mm} /$ hour and is still decreasing. 


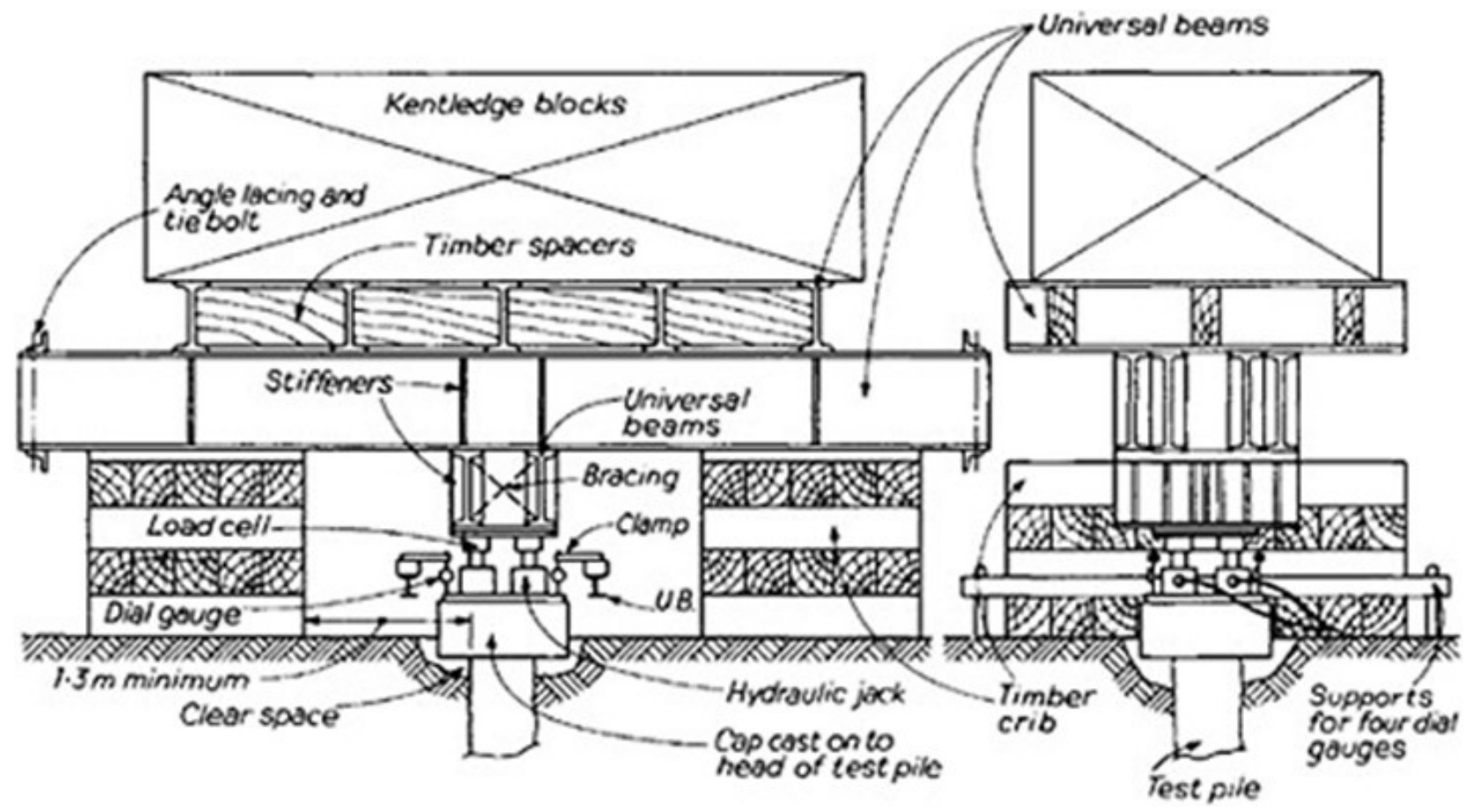

a)

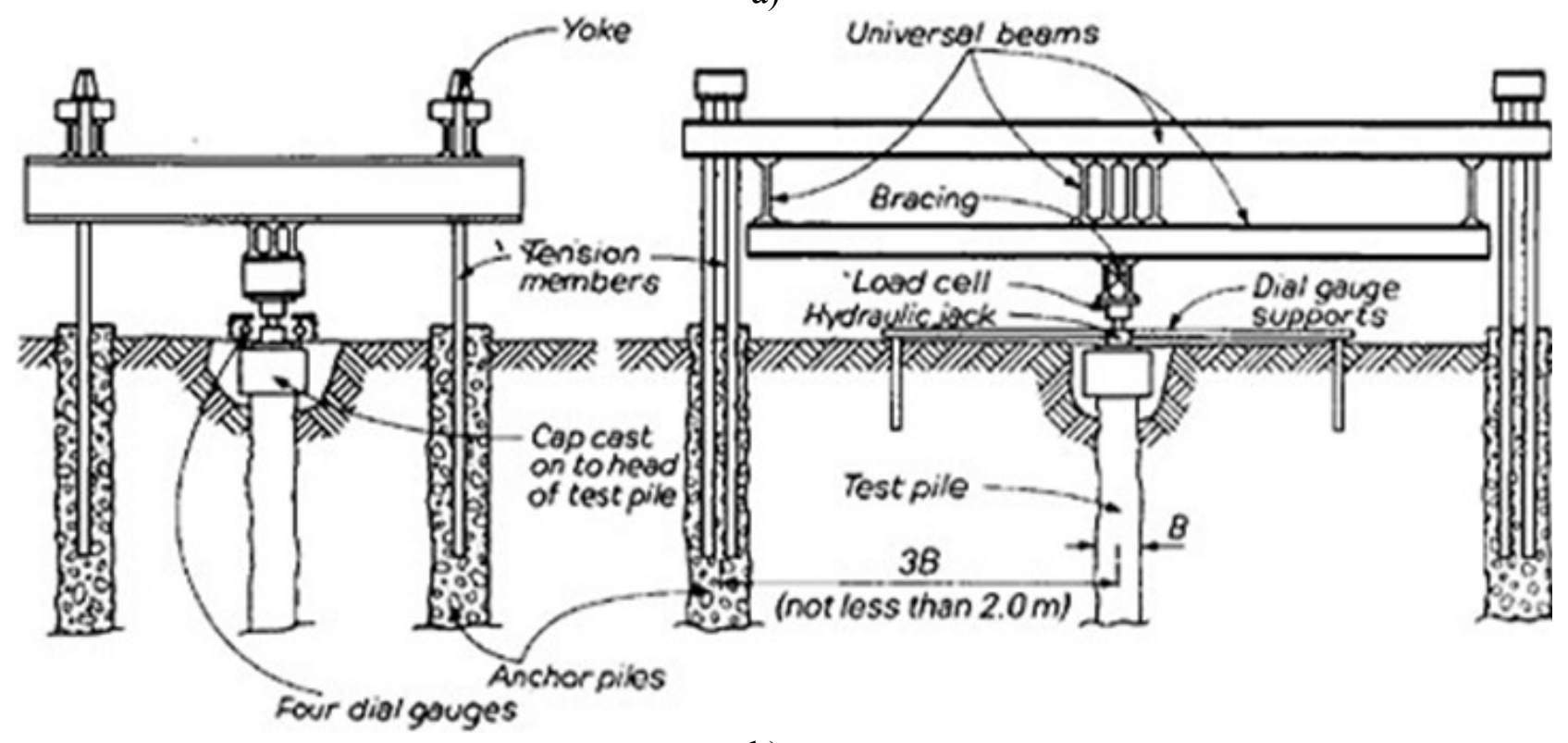

b)

Figure 2.9: a)Testing setup for compression test on pile using kentledge for reaction, and b) Tension reaction piles used for compression loads test ((Tomlinson, 1994) 
Table 2.2: Loading sequence for proof load test to $100 \%$ DVL (design vertical load) plus $50 \%$ SWL (serviceability working load)

\begin{tabular}{|c|c|}
\hline Load ( $\%$ of design load) & Load holding time \\
\hline $25 \% \mathrm{DVL}$ & 30 minutes \\
\hline $50 \% \mathrm{DVL}$ & 30 minutes \\
\hline $75 \% \mathrm{DVL}$ & 30 minutes \\
\hline $100 \% \mathrm{DVL}$ & 1 hour \\
\hline $75 \% \mathrm{DVL}$ & 10 minutes \\
\hline $50 \% \mathrm{DVL}$ & 10 minutes \\
\hline $25 \% \mathrm{DVL}$ & 10 minutes \\
\hline 0 & 1 hour \\
\hline $100 \% \mathrm{DVL}$ & 1 hour \\
\hline $100 \% \mathrm{DVL}+50 \% \mathrm{SWL}$ & 30 minutes \\
\hline $100 \% \mathrm{DVL}+75 \% \mathrm{SWL}$ & 30 minutes \\
\hline $100 \% \mathrm{DVL}+100 \% \mathrm{SWL}$ & 6 hours \\
\hline $100 \% \mathrm{DVL}+75 \% \mathrm{SWL}$ & 10 minutes \\
\hline $100 \% \mathrm{DVL}+50 \% \mathrm{SW} \mathrm{L}$ & 10 minutes \\
\hline $100 \%$ DVL & 10 minutes \\
\hline $75 \% \mathrm{DVL}$ & 10 minutes \\
\hline $50 \% \mathrm{DVL}$ & 10 minutes \\
\hline $25 \% \mathrm{DVL}$ & 10 minutes \\
\hline 0 & 1 hour \\
\hline
\end{tabular}



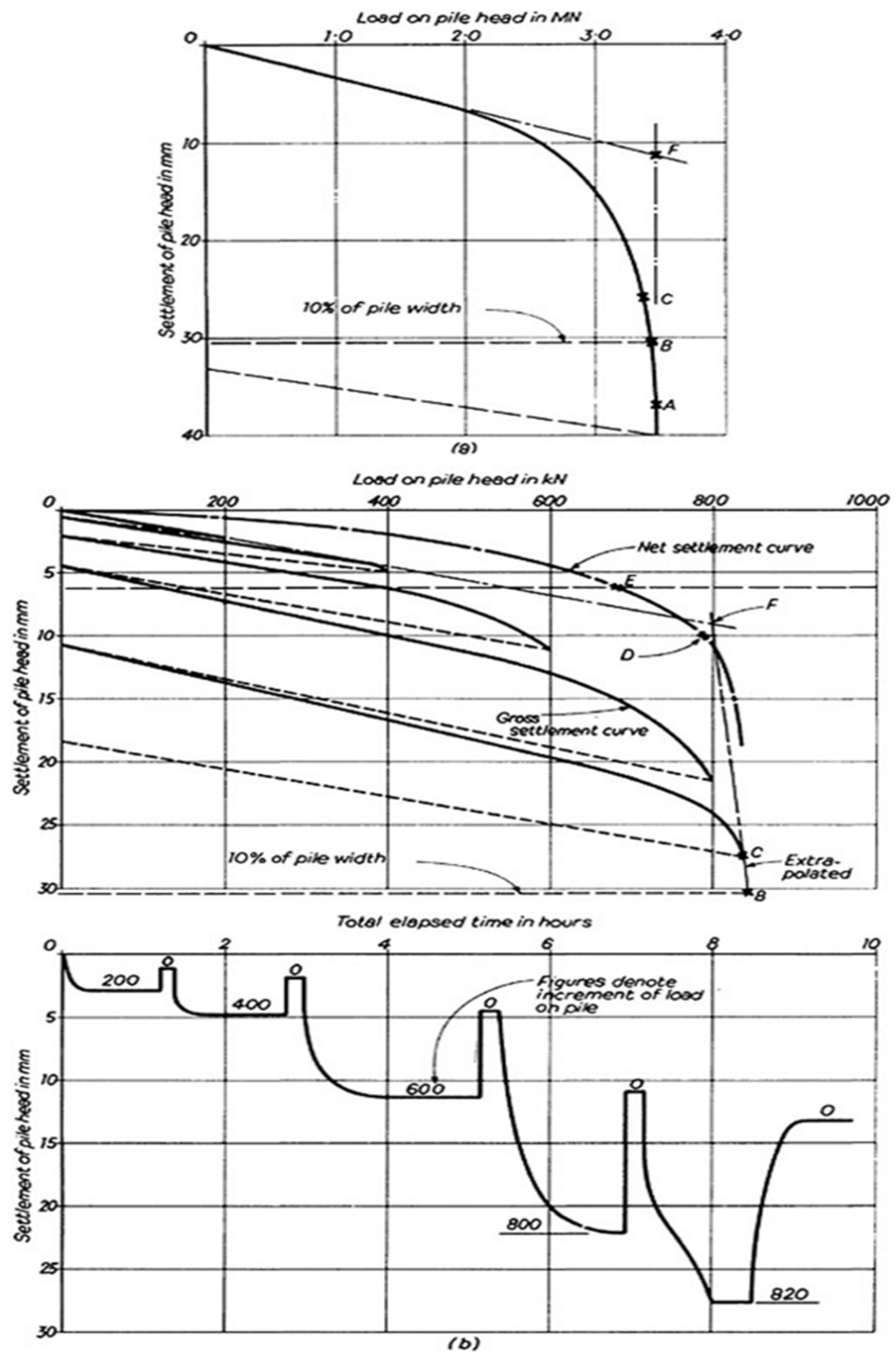

Figure 2.10: Typical load- settlement curves for CRP and ML (Tomlinson, 1994) 
The ultimate load would be interpreted in several different ways. The failure occurs in piles when the pile plunges down into the ground without any further increase in load. Most of the codes recognize the following criteria for defining the failure load. First the load at which settlement continues to increase without any further increase in load, second the load causing a gross settlement of $10 \%$ of the pile diameter, and third the load beyond which there is an increase in gross settlement disproportionate to the increase in load.

Dynamic load test is normally used to estimate pile resistance and integrity during pile installation. This method involves measuring the pile elastic response to the impact forces generated by the hammer during driving. The compressive wave caused by the impact load travels down the pile shaft and the pile-soil shaft and toe resistance reflect portions of this compressive wave in the opposite direction.

\subsubsection{Uplift Pile Load Test}

Similar to the compression load test, both the constant rate of penetration (CRP) test and the maintained load test (ML) can be implemented for pull out testing. For the ML test, the load is increased in stages up to 1.5 to twice the working load with the time and load-settlement curves are recorded at each stage of loading. This ML test may also be taken up to failure load. Figure 2.11 illustrates the test setup for uplift pile load test. A typical uplift test curves are then plotted showing the loads against time and settlements as shown in Figure 2.12. The criteria for evaluating the failure of the uplift pile is similar to the one stated previously for compression test. 


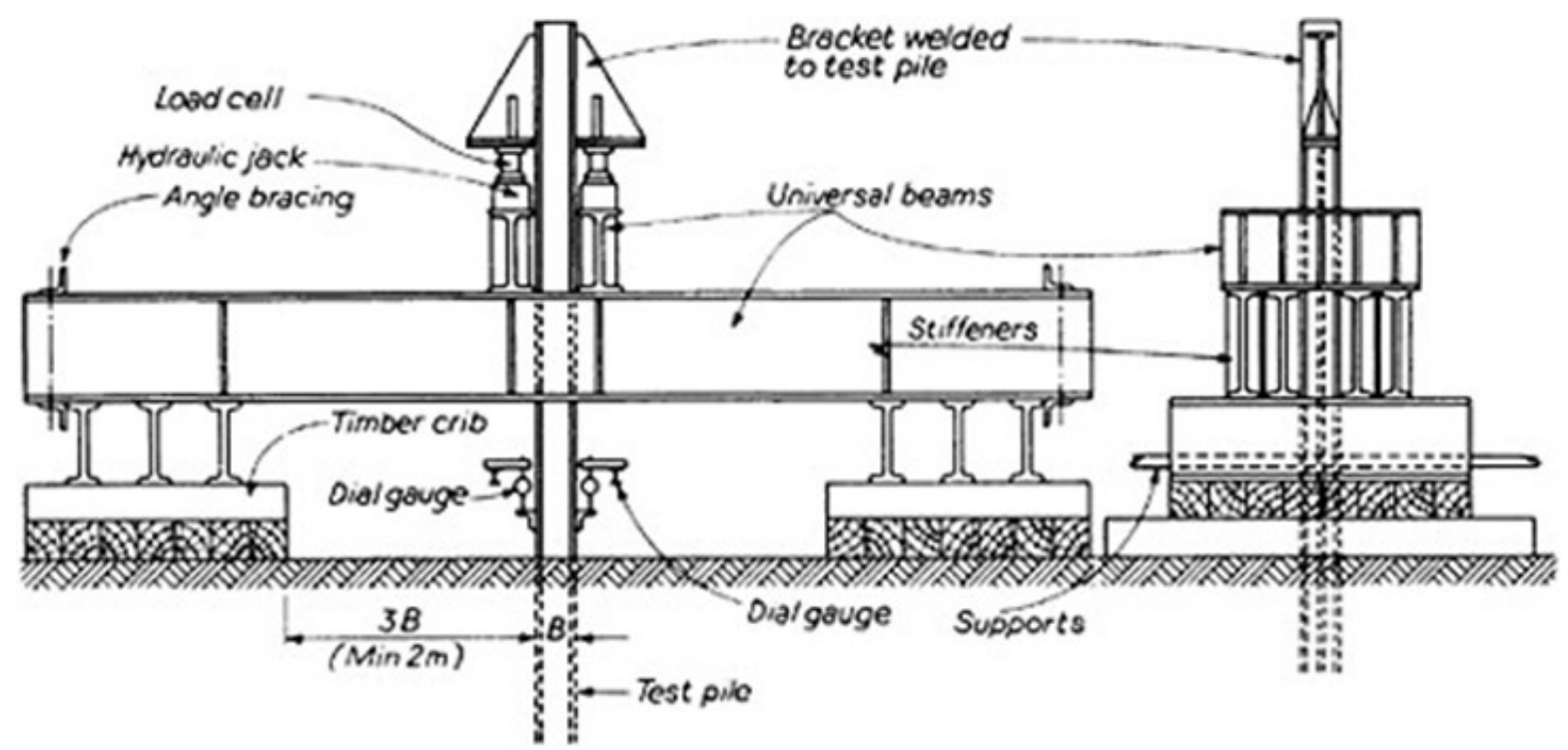

Figure 2.11: Test setup for uplift pile load test (Tomlinson, 1994)

\subsection{SHAFT CAPACITY OF CAST-IN-PLACE-PILE}

The process of construction can affect the engineering properties of the ground and pile-soil interface strength because the drilling operation and the type of drilling tools play a major role in increasing or reducing the shaft interface resistance. The pile-soil interface strength also depends on the time of keeping the hole open prior to pile installation as the change in moisture content and the degree of saturation of the soil may affect the interface shearing capacity. The existence of artesian water pressure may adversely affect the shaft capacity of cast-in-place pile too.

Many other circumstances may affect the selection of the method of installation which eventually affects the shaft resistance. For example, inadequate information representing the soil properties, the level of water table, the depth of founding stratum, the existence of cavities in ground stratum incumbent to follow the design of friction pile by neglecting the toe bearing reaction and the existence of aggressive or contaminated ground. 


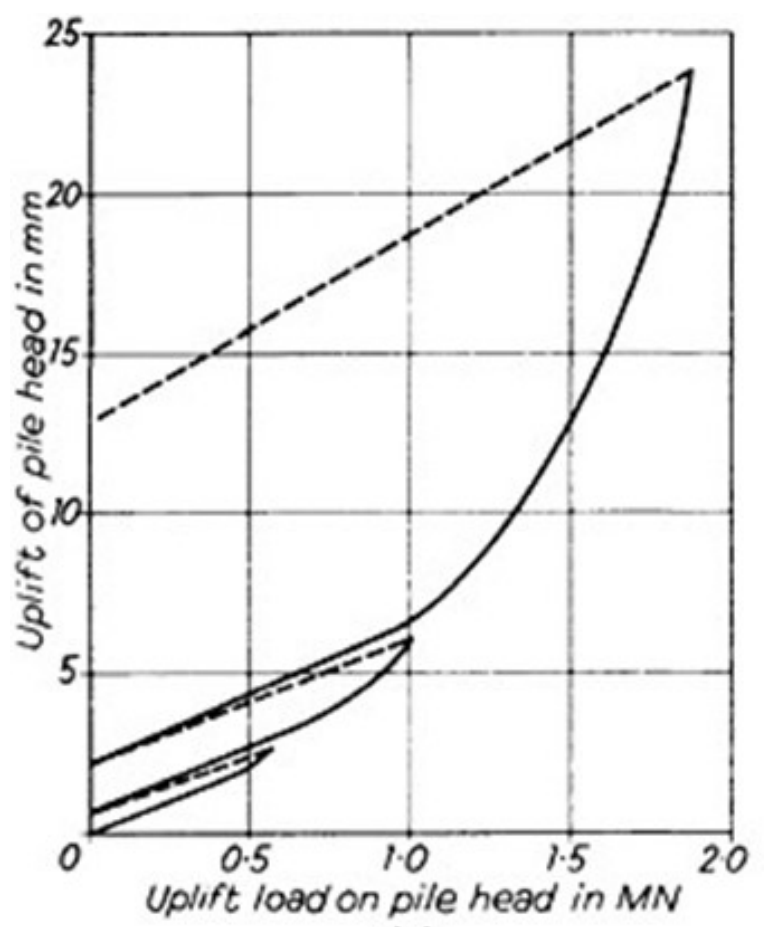

(a)

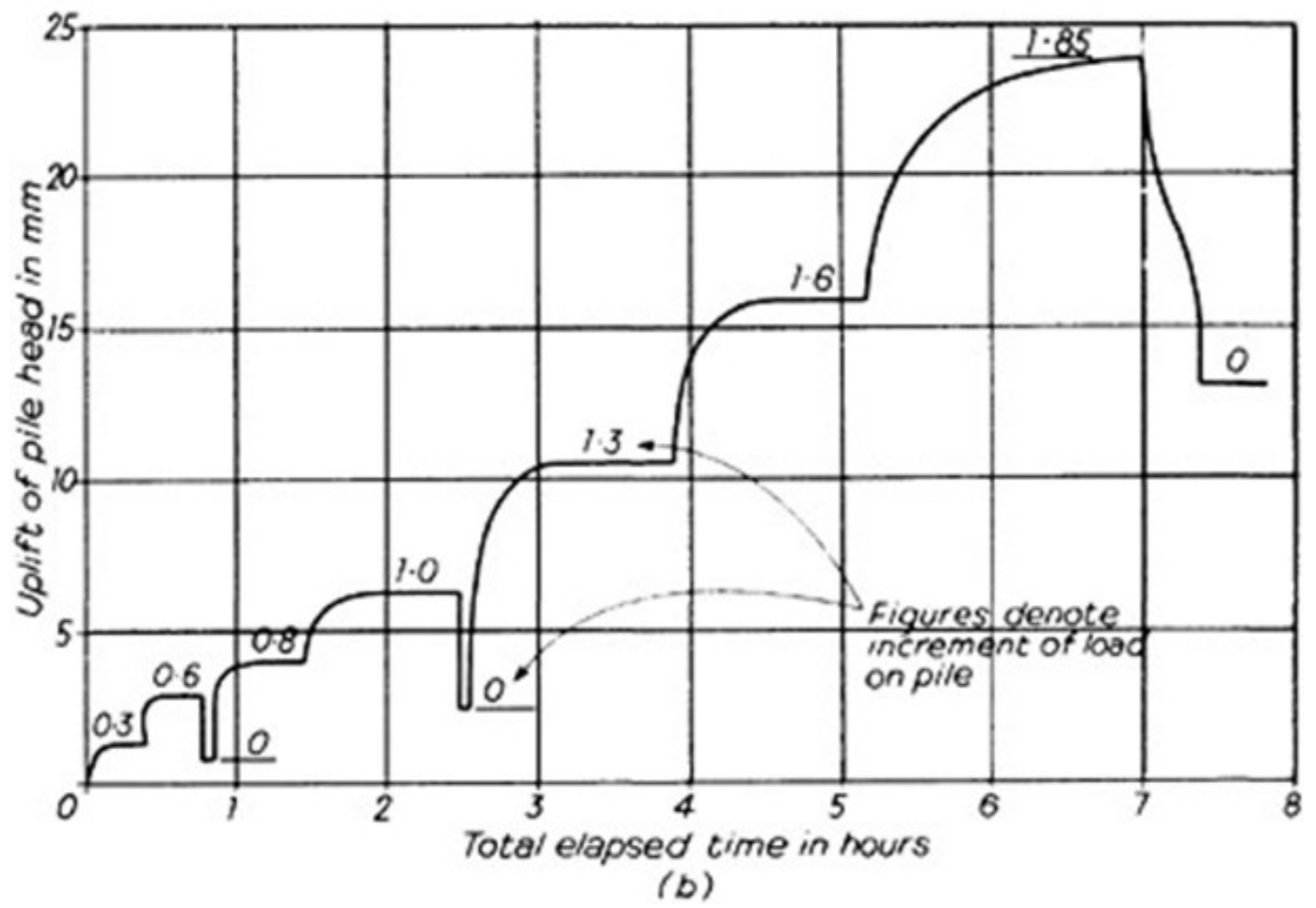

Fig. 2.12: Uplift load on test pile (ML test); (a) Load-uplift curve, (b) Time-uplift curve (Tomlinson, 1994) 
Large displacement or replacement pile will result in lateral displacement of the shaft surrounding the soil which may affect the frictional reaction of the pile. The design of replacement pile or cast -in-place pile is based on previous basic engineering rules and empirical formulas which have been experienced with time and found acceptable with a variable margin of safety factor from 1.5 to 3 depending on the importance of the structure. The concrete-pile interface behaviour plays the major role in the shaft resistance of cast-in-place piles. The controlling parameters in the pile shaft design in cohesive and sandy soils are summarized in Table 2.3 below. Most of these parameters are achieved from site investigations data such as standard penetration tests (SPT) and cone penetration tests (CPT) which form a frame for the actual parameters to be included in the design, i.e., c' and $\phi^{\prime}$

Interface shear strength behaviour between soil and concrete interfaces is an important design parameter for estimation of the shaft capacity of cast-in-place piles (also known as drilled shafts). The skin or shaft friction can be determined by a simple relationship between the coefficient of earth pressure at rest, the effective overburden pressure and the drained angle of the shearing resistance of cohesionless soils. In cohesive soils, the undrained shear strength between the concrete and soil (adhesion) would be an important parameter, while for rock strata, the interface strength between rock and concrete of the socketed length is considered. However, recently this design method has been modified by a factor which takes into consideration the effect of the method of installation on shear strength parameters too. 
Table 2.3: Drilled shaft capacity from different interpretation methods

\begin{tabular}{|c|c|c|c|c|}
\hline Methods & $\begin{array}{c}\text { Side } \\
\text { resistance }\end{array}$ & Tip resistance & $\begin{array}{c}\text { Parameters } \\
\text { required }\end{array}$ & Constraints \\
\hline $\begin{array}{l}\alpha \text {-Tomlinson } \\
\text { (Tomlinson, } \\
\text { 1980/1995) }\end{array}$ & \multirow[t]{2}{*}{$\mathrm{q}_{\mathrm{s}}=\alpha \mathrm{S}_{\mathrm{u}}$} & \multirow{4}{*}{$\mathrm{q}_{\mathrm{p}}=9 \mathrm{~S}_{\mathrm{u}}$} & $\begin{array}{c}\mathrm{S}_{\mathrm{u}} ; \\
\mathrm{D}_{\mathrm{b}} \text { (bearing } \\
\text { embedment) }\end{array}$ & $\begin{array}{c}\text { Bearing layer must } \\
\text { be stiff cohesive } \\
\text { Number of soil } \\
\text { layers } \leq 2\end{array}$ \\
\hline $\begin{array}{l}\alpha \text {-API } \\
\text { (Reese et al., 1998) }\end{array}$ & & & $\mathrm{S}_{\mathrm{u}}$ & \\
\hline $\begin{array}{l}\beta \text { in cohesive } \\
(\text { AASHTO, 1996/2000) }\end{array}$ & $\mathrm{q}_{\mathrm{s}}=\beta \sigma^{\prime}$ & & OCR & \\
\hline $\begin{array}{l}\lambda \text { (US Army Corps of } \\
\text { Engineers, 1992) }\end{array}$ & $\begin{array}{c}\mathrm{q}_{\mathrm{s}}= \\
\lambda\left(\sigma^{\prime}+2 \mathrm{~S}_{\mathrm{u}}\right)\end{array}$ & & $\mathrm{S}_{\mathrm{u}}$ & $\begin{array}{c}\text { Only for cohesive } \\
\text { soils }\end{array}$ \\
\hline $\begin{array}{l}\beta \text { in cohesionless } \\
\text { (Bowles, 1996) }\end{array}$ & $\beta \sigma^{\prime}$ & & $\mathrm{D}_{\mathrm{r}}$ & \\
\hline $\begin{array}{l}\text { Nordlund and Thurman } \\
\text { (Hannigan et al., 1995) }\end{array}$ & $q_{s}=K_{\delta} C_{F} \sigma^{\prime}$ & $\mathrm{q}_{\mathrm{p}}=\alpha_{\mathrm{t}} \mathrm{N}_{\mathrm{q}}^{\prime} \sigma^{\prime}$ & $\varphi$ & \\
\hline $\begin{array}{l}\text { Meyerhof SPT } \\
\text { (Meyerhof, 1976/1981) }\end{array}$ & $\mathrm{q}_{\mathrm{s}}=\mathrm{k} \mathrm{N}$ & $\mathrm{q}_{\mathrm{p}}=0.4 \mathrm{D} / \mathrm{BN}$ & $\mathrm{N}$ & $\begin{array}{l}\text { For cohesionless } \\
\text { soils } \\
\text { SPT data }\end{array}$ \\
\hline $\begin{array}{l}\text { Schmertmann SPT (Lai } \\
\text { and Graham, 1995) }\end{array}$ & $\mathrm{q}_{\mathrm{s}}=\mathrm{fn}(\mathrm{N})$ & $\mathrm{q}_{\mathrm{p}}=\mathrm{fn}(\mathrm{N})$ & $\mathrm{N}$ & SPT data \\
\hline $\begin{array}{l}\text { Schmertmann CPT } \\
\text { (McVay and } \\
\text { Townsend, 1989) }\end{array}$ & $\mathrm{q}_{\mathrm{s}}=\mathrm{fn}\left(f_{s}\right)$ & $\mathrm{q}_{\mathrm{p}}=\mathrm{fn}\left(\mathrm{q}_{\mathrm{c}}\right)$ & $\mathrm{q}_{\mathrm{c}}, \mathrm{f}_{\mathrm{s}}$ & CPT data \\
\hline
\end{tabular}

\subsection{PILE-SOIL INTERFACE}

Pile-soil interface behaviour is a critical component contributing towards the pile capacity. In castin-place piles, this interface behaviour is mainly governed by the concrete-soil interface interaction. Estimating pile resistance mobilized through ultimate shaft frictional capacity relies on characterizing the concrete-soil interface shear strength properties. These properties include interface apparent adhesion in cohesive soils and interface friction angle in cohesionless soils, and 
are used to estimate shaft resistance, $q_{s}$, based on the appropriate drained or undrained loading conditions.

Many researchers attempted to determine the interaction behaviour between the concrete pile and the surrounding soil and correlate and update the design parameters related to the development of new driving and drilling techniques used in pile construction.

Pile-soil interface behaviour has been investigated by various authors in order to characterize the soil and pile parameters affecting the interface shear strength. Peck (1958) reported that the roughness of the pile surface and the tapered shape of the pile have a direct influence on the magnitude of the skin friction. Potyondy (1961) used direct shear apparatus to characterize the interface shear behavior between piling materials and different types of soil where he found that surface roughness, soil moisture, soil composition and load magnitude are the controlling factors in analyzing the pile-soil interface shear resistance. Later on Lupini et al. (1981) proposed three different shearing failure modes under undrained conditions including turbulent, transitional, and sliding. Turbulent shear was related to increased disturbance of the clay microstructure, while sliding was linked to the lack of particles interlocking at the pile-soil surface. The transitional was suggested to be an intermediate state between the sliding and turbulent shearing failure. A similar failure mechanism was proposed by Stark and Eid (1994) stating that the interface shear strength could also be affected by clay fraction and clay mineralogy. More recently, Taha (2010) explored the influence of several parameters such as interface roughness, degree of saturation, over consolidation ratio, dry density and clay salt content on interface behaviour of pile-clay surfaces. Giraldo and Rayhani (2014) have investigated the pile-soil interface behaviour for traditional piling materials as well as fiber reinforced polymer piles. 
Interface behavior was also studied using pile load tests for bridge pier foundations resting on friction piles in soft clay (Blanchet et al., 1980). The results obtained for piles with identical lengths, indicated that the unit skin friction mobilized on a steel pile is only $70-80 \%$ of that developed on a precast concrete pile having a rougher surface. On the other hand, the interface shear strength values observed on shorter timber piles were about $60 \%$ higher than those measured on precast concrete piles. It is remarkable that all the above results are qualitatively and quantitatively identical to those reported by Peck (1958) or by Tavenas (1971) for piles in sand.

Practically the pile soil-surface interaction and reaction is related to the type of piles, the ratio between the length and the diameter of the pile and the method of construction, as well as soil characteristics, strength and boundary conditions of the pile-soils material. Therefore the design calculation of the pile carrying capacity is in accordance to soil mechanics principles and the empirical formulas which relate the known pile behavior to simple soil properties as the relative density and undisturbed shearing strength. These can be used as index properties to which empirical coefficients are applied to obtain a unit value for the skin friction and end bearing resistances. The most commonly used equations to evaluate the shaft friction capacity is $\alpha$ and $\beta$ methods where $\alpha$ is adhesion coefficient used for total stress analysis $\left(\mathrm{q}_{\mathrm{s}}=\alpha \mathrm{Cu}\right)$ and $\beta=\mathrm{Ks}$.tan $\delta$ is used for effective stress analysis as $\mathrm{q}_{\mathrm{s}}=\beta \sigma_{\mathrm{v}}^{\prime}$. These parameters are explained in section 2.3.

\subsubsection{Concrete-Clay Interface Behaviour}

Interface shear strength characterization in cohesive soils has not been studied as extensively as in sands. However, various studies have been conducted to examine different interfaces used in the construction and piling industry against various types of clays (e.g., Chu and Yin, 2006; Goh and Donald, 1984; Johnston et al., 1987; Ovando-Shelley, 1995; Taha, 2010). Lupini et al. (1981) 
investigated the drained residual strength of cohesive soils using a ring shear apparatus. He reported that the shearing behaviour was determined to be dependent on the shape and type of clay particles, specifically the ratio between rotund and platy particles. Soils with a high clay fraction showed sliding shear failure tend and found to be independent of surface roughness, while soils with lower clay content were shown to be dependent on the surface roughness as larger soil particles interact with the material interface. A similar study performed by Lemos and Vaughan (2000) showed that soils with high clay fractions undergo sliding shear failure where interface roughness does not play a significant effect on interface shear strength, whereas soils with low clay fractions experience turbulent shear failure due to additional particles interacting with the material interface. Another interface characterization study performed by Chu and Yin (2006) on soil-grout interface shear strength showed the importance of increased surface roughness which allows for the additional interlock between soil particles and pile surface leading to higher shear resistance.

The pile-soil interface strength for cast-in-place piles in cohesive soils is mainly governed by the concrete-soil interface strength. Tomlinson (1995), in his contribution to the understanding of the pile behavior in clay over the years, proposed that the characteristics of a thin soil layer surrounding the pile is the most important factor in controlling the pile-soil behaviour. The moisture content of the clay and its variation before construction, during drilling and after the installation of the pile has a tremendous effect on the pile frictional capacity with the time. The drilling causes a relief of lateral pressure on the shaft's hole causing swelling in clay and migration or seeping of the pore water towards the exposed clay surface. Meyerhof et al, 1992 measured an increase of $4 \%$ in the water content of London clay close to the interface with concrete during piling. 
Interfaces shear behavior of concrete pile presented by Blanchet et al. (1980) concluded that pore pressure induced by pile driving in clay is related to the pre-consolidation of the clay. However they are much larger for tapered piles due to the expansion of the cavity while driving such type of pile. The results of this observation may have consequences in the design of pile foundation especially when it is installed near slopes where the result of driving creates higher pore pressure causing instability.

\subsubsection{Concrete-Sand Interface Behaviour}

The interface shear resistance in cohesionless soils mainly depends on the soil particle size distribution, interface surface roughness, normal stresses at the interface and rate of shear displacement (Lemos and Vaughan, 2000). There has been significant research performed on interface characterization of typical pile materials with cohesionless soils compared to the cohesive soils. Most these interface research has been conducted through shearing different pile materials against soil.

The impact of normal stress on pile-soil interface behavior is considered through the coefficient of lateral earth pressure $\left(\mathrm{K}_{\mathrm{s}}\right)$ which relates the vertical overburden pressure to the horizontal stress acting normal to pile surface. In the case of driven concrete pile, the displacement of the soil increases the horizontal stress resulting from overburden pressure and hence increases the $\mathrm{K}_{\mathrm{s}}$. Drilling for cast-in-place concrete piles can loosen the surrounding soil, and thereby reduce the horizontal stress. Practically the concrete-sand interface strength is related to the depth of the pile, the circumference area of the socket length, the interface friction angle and finally the $\mathrm{K}_{\mathrm{s}}$ factor. This coefficient may vary from half the coefficient of lateral earth pressure at rest $\left(\mathrm{K}_{0}\right)$ up to twice $\mathrm{K}_{0}$ depending on the pile installation method. Kulhawy (1984) proposed the following values 
for $\mathrm{K}_{\mathrm{s}}$ for different pile foundations (Table 2.4). Moreover an extra reduction factor would be essential to be used for bored cast-in-place pile when bentonite is used for the purpose of holding the side of the hole. Fleming and Sliwinski (1977) suggested reducing the design capacity from $10 \%$ to $30 \%$ in this case due to the loss of the surface roughness of the pile shaft.

Table 2.4: Variation of coefficient of lateral earth pressure for different piles (Kulhawy, 1984)

\begin{tabular}{|l|c|}
\hline Pile Installation Method & $\mathbf{K}_{\mathbf{s}} / \mathbf{K}_{\mathbf{0}}$ \\
\hline Driven piles (large displacement) & $1.0-2.0$ \\
\hline Driven piles (small displacement) & $0.75-1.25$ \\
\hline Bored and cast-in-place piles & $0.7-1.0$ \\
\hline Jetted piles & $0.5-0.7$ \\
\hline
\end{tabular}

The mechanical properties of the interface between sand and concrete were investigated using direct shear tests (e.g., Potyondy et al, 1961; Clough et al. 1971), the concrete-sand interface strength was shown to be affected by the soil properties, moisture content, interface roughness, and normal stress. Zong-ze et al, (1994) have concluded that shear failure of the interface is actually a process that starts from the edge to the interior and then develops to distant apart. With the development of new techniques in quantifying the pile behaviour, special sensors nowadays are used along the surface of the pile to record the pile settlement and measure the horizontal stress acting on the side of the concrete shaft area. 


\subsubsection{Concrete-Rock Interface Behaviour}

Rocky foundation strata are mostly characterized by their unconfined compressive strength ( $\left.q_{u c}\right)$ and the rock quality. The quality of rock is defined by the total core recovery (TCR), i.e., total core recovered expressed as percentage of length drilled, the solid core recovery (SCR, length of core recovered as solid full diameter core pieces), rock quality designation (RQD, length of core recovered in length greater than $100 \mathrm{~mm}$ as $\%$ of the length drilled) and fracture index (FI, number of natural core breaks per meter of core length). These characteristics define the type of rock and its quality for pile foundation design and at the same time affect the behaviour of the interface shear strength with bored cast-in-place-pile. The type of tools used for drilling and cutting the rock will affect the surface roughness textures of the pile-rock boundaries in the drilled hole and proportionally affect the interface strength between the concrete and the rock materials. Osterberg and Gill (1973), Pells and Turner (1979) and Kulhawy and Goodman, (1987) have investigated the theoretical aspects of pile-rock interaction in the linear elastic field and proposed empirical procedures with respect to the unconfined compression strength of the rock using the results of loading tests on field pile models.

Practically the interface behavior of pile-rock is governed by the basic Mohr-Coulomb failure criterion. The pile-rock slip will occur when the load reaches the ultimate capacity of the pile or when the mobilized shear stress $\tau$ reaches the strength of the rock materials. In this criterion $\left(\tau=\mathrm{c}_{\text {peak }}+\sigma_{\mathrm{n}} \tan \delta\right), \mathrm{c}$ is the peak interface adhesion, $\sigma_{\mathrm{n}}$ is the average normal stress at the pile interface and $\delta$ is the pile-rock interface friction angle.

One of the most used empirical design approaches for the concrete pile-rock equations was discussed in section 2.3.1. 
The concrete-rock interface strength has not been widely explored as the toe bearing capacity was considered to be the major element in bearing capacity of cast-in-place piles in rocks. Johnston et al. (1987) utilized a direct shear apparatus to characterize pile sockets in weak rocks. The pile-rock surface roughness was found to be the controlling parameter in pile-rock interface behaviour. However, due to the scale of the testing, the effect of rock quality (RQD) was not properly investigated.

\subsection{METHODS TO IMPROVE PILE SHAFT CAPACITY FOR CAST-IN-PLACE PILE}

This section is intended to shed some light on other researchers whom studied different methods for improving the pile shaft capacity by introducing different mechanism to improve the concretesoil interface behavior. This type of pile is constructed in different types of soils using different types of drilling tools to match the soil density and strength for easier drilling. Four types of improvement techniques were generally used to enhance the pile shaft performance including use of expansive concrete, base enlargement, fiber reinforced polymer (FRP) concrete pile, and cutting groves inside concrete whole shaft.

\subsubsection{Use of Expansive Concrete in Drilled Shaft Cast-In-Place Piles}

The expansive cement is a mixture of normal Portland cement and an expansive component. The use of expansive cement materials in bored hole can fill the possible gaps and holes at the pile-soil interface area and improve the bonding between the pile and soil and consequently increase the pile shaft resistance (Figure 2.13). Various application of expansive concrete have been suggested (e.g., Bertero and Choi,1962; Bertero and Iragorry-Montero, 1964), but the present commercially 
available expansive cements are, in general, of a shrinkage-compensating nature and would not produce additional lateral pressure against the soil, which is the desired effect in drilled shafts. Expansive cement concrete can increase the frictional capacity of drilled shafts in stiff clay by as much as 50\% and reduce the settlement by about 50\% (Shiekh, 1974; Timusk and Sheikh, 1977). The results, however, are valid for short-term behaviour of drilled shafts made of expansive cement. The long-term behaviour of such shafts remains to be under investigation (Sheikh et al. 1984).

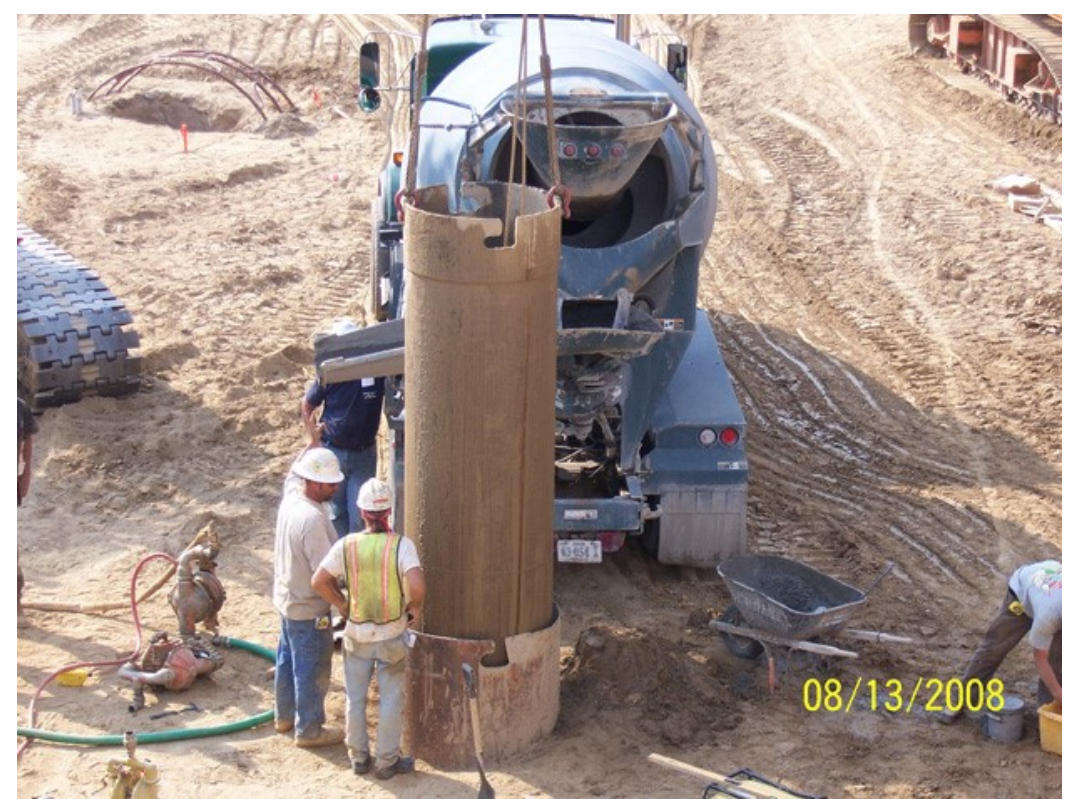

Figure 2.13: Use of expansive cement in the concrete mix for cats-in-place piles

\subsubsection{Enlargement of Drilled Shaft Base}

This type of shape enlargement in pile is mainly used to improve both the end bearing and the uplift resistance of the piles. Using a special expanding bucket driven to the bottom of the drilled hole, to the pile cross section at the toe is enlarged to provide either higher uplift capacity or base 
bearing capacity (Figure 2.14).This method creates an advantage for piles subjected to uplift pressure or expansive soils. The base enlargement can also reduce the differential settlement of the foundation. The main disadvantage of this method is the difficulty in maintaining the same form of the bell shape due to inhomogeneity of the soil and collapse that may happens in drilled enlarged holes.

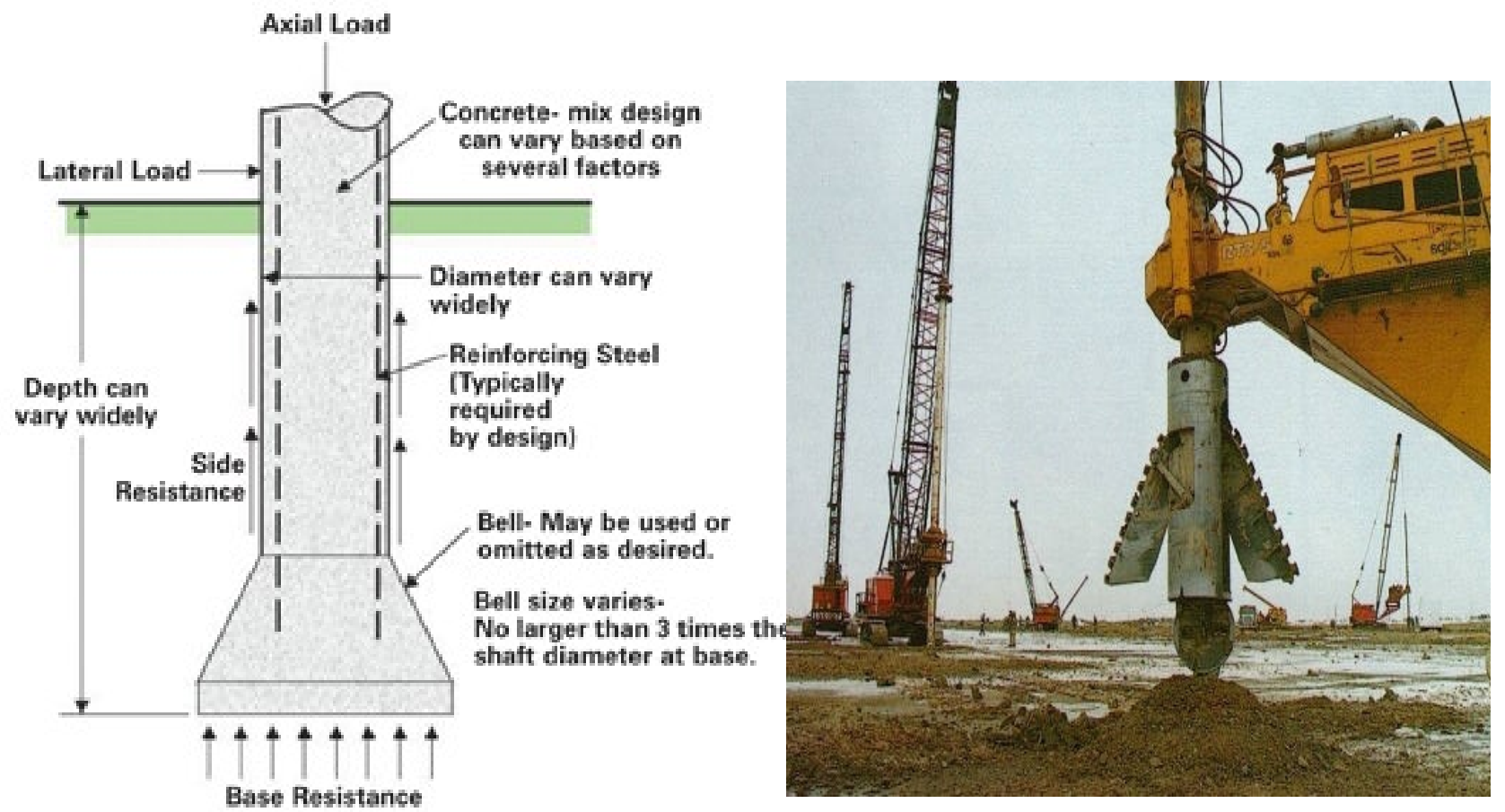

Figure 2.14: The base enlargement of the toe (P. Manickam \& Company)

\subsubsection{FRP Concrete Piles}

Composite piles or FRP piles have been used in particular projects where harsh marine environment may lead to corrosion of the pile materials. The role of the composite material is to create confinement around the concrete pile while producing extra friction on the external shaft of the pile due to higher degree of surface roughness and protecting the pile materials from possible 
corrosion (Figure 2.15). Polymer surface texture and fiber orientation were shown to significantly affect the FRP-soil interface resistance (Giraldo and Rayhani, 2014). The type of FRP materials have also shown to affect the pile performance. Glass FRP piles present a highly textured surface due to the raw fiber weaving pattern and significant protrusions while the Carbone FRP piles present less a pronounced surface texture with the $90^{\circ}$ orientation. FRP piles were reported to produce an increase in shaft resistance up to $40 \%$ over steel piles, however the cost of FRP pile is 2 to 3 times the price of normal concrete pile, the long track record of its performance or durability has not been yet experienced.

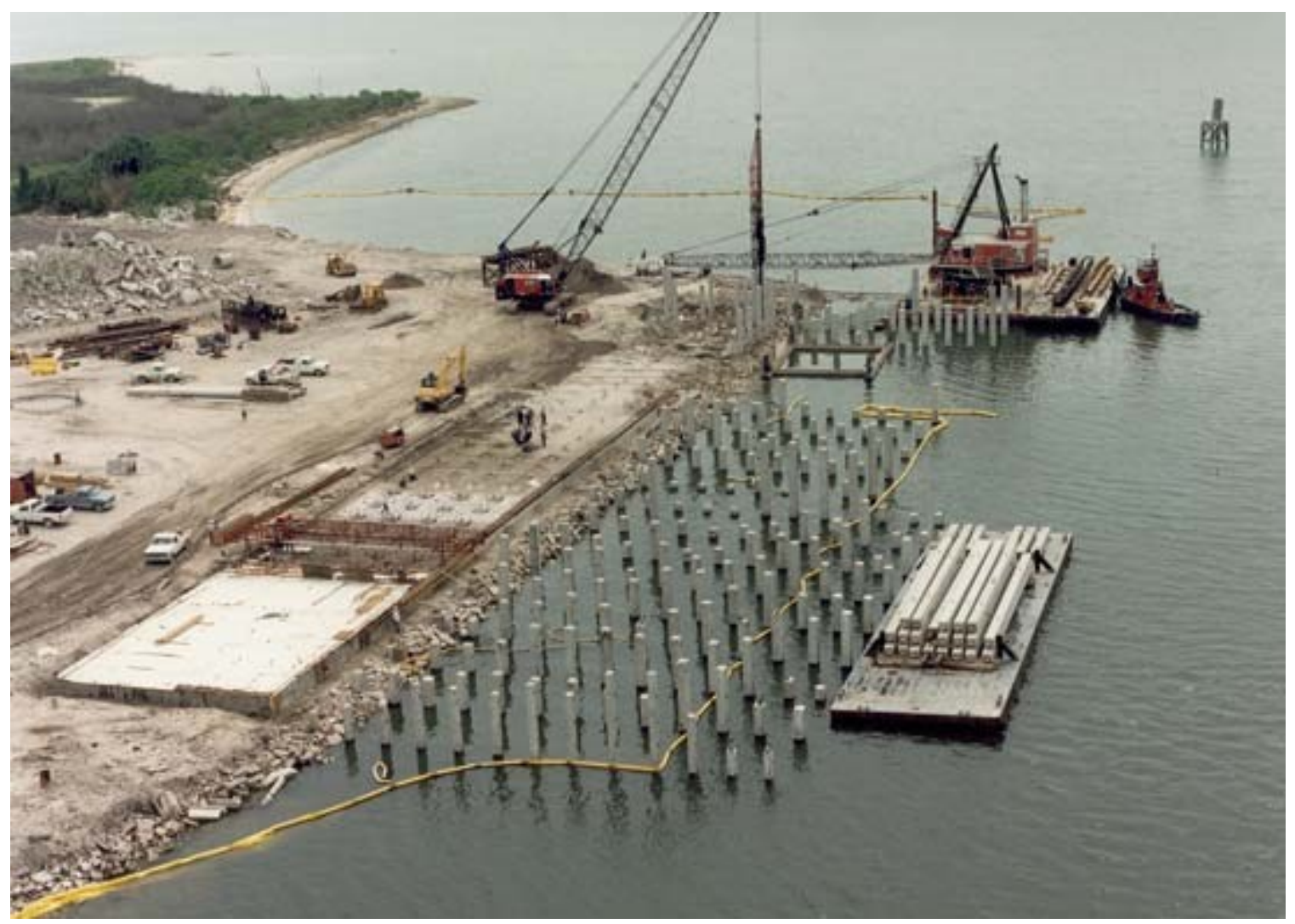

Figure 2.15: FRP piles used in harsh marine environments 


\subsubsection{Cutting Grooves into the Socket Wall}

The primary factors controlling the behavior of socketed pile with big diameter in weak rocks are the strength and deformation characteristics of the concrete pier, the rock mass, the interface friction between the concrete pier and the rock. The pile surface roughness provides a quantitative evaluation of relative roughness. Shaft capacity at failure is increased while implementing a extra surface roughness through cut and groove system during pile construction (Figure 2.16). The benefits gained by increasing the roughness of socket walls were shown to be about $30-40 \%$ in pile capacity (Horvath et al. 1983). Development of construction equipment and methods to economically accomplish these ends should be pursued. The disadvantages of this method are mainly related to the lack of a design capacity formula, difficulty in constructing groove when diameter is relatively small and inhomogeneity of the groove along the pile shaft.

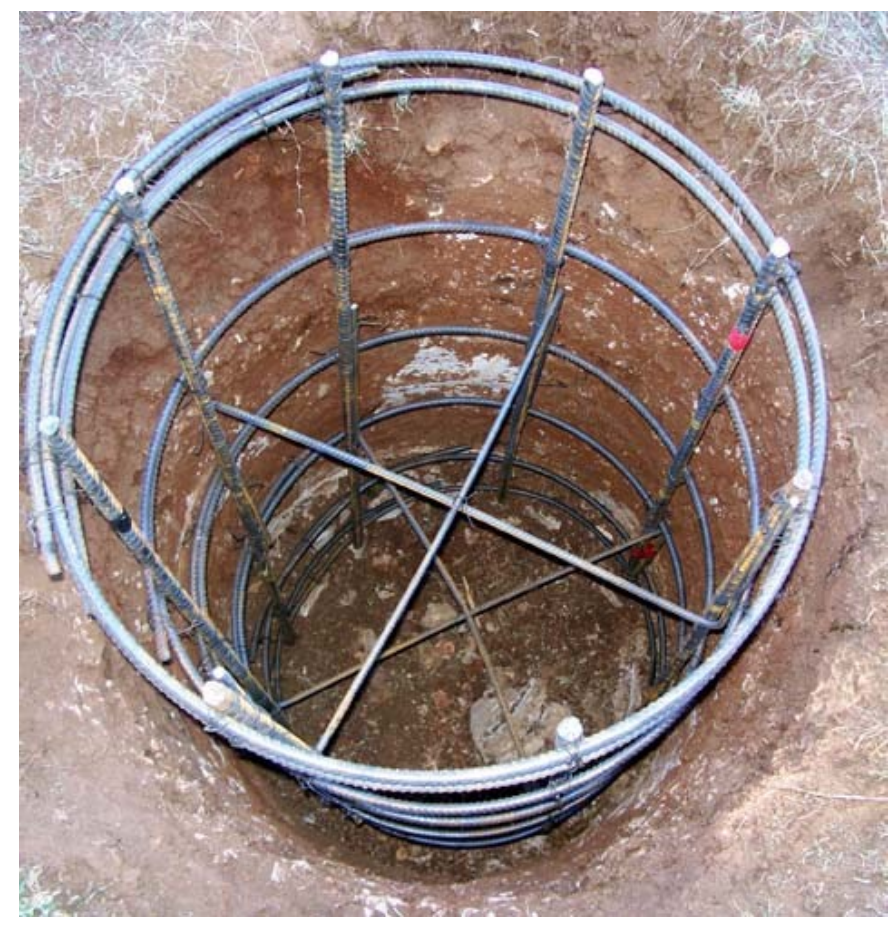

Figure 2.16: Cutting grooves used to improve the shaft capacity of cast-in-place piles 


\subsubsection{The New Hooked Pile Method for Drilled Cast-In-Place Piles}

Drilled shafts can be executed using a continuous flight auger system and temporary or permanent Caissons system. The main advantages of cast-in-place piles are the flexibility in constructing the length and diameter of the pile required to safely resist the design load. However, the uncertainty of knowing the exact shape of the pile during construction, possible poor bonding between the pile and the surrounding materials, and the lack of possibility for pile inspection after concrete pouring are main disadvantages of this pilling method. Although the earlier discussed methods could improve the shaft capacity of these piles to certain extent, but there is still a need to overcome the disadvantages of this pilling technique through improvement of the previous methods or developing a new enhancement method.

Implementing a hook system on the surface of the pile could be an option to improve the bonding between the pile and the surrounding material. This hypothesis is explored in this study. The role of the Hook is to distribute the load reactions after transferring them from the pile shaft to the surrounding soil/rock by providing a passive force to the surrounding surfaces. Comparing the other types of enhancement approaches previously used in pile industry, the hook system is expected to play a central and direct role in terms of surface roughness. The hook accessories and its role are properly controlled by a definitive distribution all around the shaft area. Failure of even a single link may result in no danger to the whole system. The size and weight of the hooks will be proportional to the pile load and pile size. Fixing hooks with the steel cage as staggered distribution at a certain distance could enhance the pile shaft capacity. Each hook will resist a load equal to the total friction load of the shaft per meter of height divided by the number of hooks. Practically it is difficult to estimate the actual shaft capacity that governs the use of 
factor of safety when calculating the number of the hooks. The type of the hook and its strength will be dependent on the type of soil and the pile dimension.

\subsection{SUMMARY}

Drilled cast-in-place piles are the most used pilling method in pile industry to resist heavy loads from high rise buildings or bridges due to their flexibility in the pile dimensions and the ease of installation technique. Most studies conducted on the behavior of different piles in different soil strata found to be insufficient to cover all site conditions, economical cost and the method of installation which sometime creates an obstacle for executing deep piles. The cast-in-place piles are mainly based on their toe bearing capacity as the pile shaft capacity was found to be less contributing due to weaker bonding between the pile and the surrounding materials. Although a series of improvement techniques were proposed to enhance the pile shaft capacity for different application, however, there is a need for improvement of the pile-soil interface performance in different site conditions. This research focuses on development of a new improvement method to increase the shaft capacity of cast-in-place piles using the hooked pile system. 


\section{CHAPTER 3}

\section{HOOKED PILE-SOIL INTERFACE STRENGTH}

\subsection{INTRODUCTION}

Determination of pile-soil interface behaviour is important for proper estimation of load carrying capacity of pile foundations. Pile capacity is normally developed through the frictional resistance of pile shaft as well as the bearing capacity underneath the toe of the pile. The pile shaft capacity may not play a significant role in cast-in-place piles due to the soil softening during pile installation and possible caving of the surrounding soil. This uncertainty in estimating the pile load capacity may lead to uncertainties in estimation of the pile length as well as number of piles required for foundation design. It might also increase the cost of foundation construction.

This chapter describes and experimental program to examine the effect of implementing hooks in the pile-soil interface on pile-soil interface strength of cast-in-place piles in different types of soils. The shearing resistance between soil and the interface surface for cast-in-situ concrete piles is fundamentally related to the pile surface roughness as well as the soil properties. Therefore, these properties are massively required in order to study the pile-soil interface strength behavior and for the design and performance of piles, secant wall, sheet pile and anchor rods.

The pile interface shear resistance depends on the soil type, grain size distribution, and interface material, surface roughness, normal stresses at the interface and rate of shear displacement (Lemos and Vaughan, 2000). There has been significant work completed on 
interface characterization of typical pile materials with sandy soils compared to work performed on clayey soils and, in particular sensitive marine clays (Rouaiguia, 2010). Laboratory testing of soils sheared against plain concrete and hooked concrete surfaces was used to develop insights into improvement of pile-soil interface strength and, hence, pile shaft capacity of cast-in-place piles. The interface strength of the hooked concrete surfaces was compared with those achieved for plain concrete surfaces sheared against sand and clay soils.

\subsection{SOIL PROPERTIES}

Two types of soils, i.e., sand and clay, were used in this study to examine the pile-soil interface strength of cast-in-situ piles. The clay soil, known as Leda Clay, was obtained from a site in Navan, Ontario, using undisturbed block sampling. Leda clay, also known as Champlain Sea clay, was formed about 10,000 years ago at the pre-historic Champlain Sea. Fine grain sediments originated from glacial abrasion of the Canadian Shield were deposited in the Champlain Sea and formed this clay. Nowadays this clay is found the Ottawa Valley and the St. Lawrence drainage basin. The sandy soil employed in this study was fine grained sand used in construction industry. A series of particle size analysis (ASTM D422, 2007) and Atterberg limit tests (ASTM D4318, 2010) were carried out to determine the index properties of the soils. Figure 3.1 shows the particle size distribution of the soils and Table 3.1 summarizes the index properties of the two soils. The clayey soils showed a $40 \%$ clay fraction, a plasticity index of $23 \%$ and an activity of 0.55. The soils can be classified as $\mathrm{CH}$ and SP, respectively, according to the USCS (ASTM D2487, 2011).

A vane shear test in accordance with the field vane shear test procedure outlined in ASTM D2573 (2008) was performed to determine the undrained shear strength of the clay $(\mathrm{Su}=$ 
$50 \mathrm{kPa}$ ). The coefficient of 1-D consolidation of the clay achieved from an oedometer test (ASTM D2435/2435M, 2011) showed a value of $1.4 \times 10^{-4} \mathrm{~cm}^{2} / \mathrm{s}$. The standard Proctor compaction test (ASTM D 698) showed a maximum dry density of $1.41 \mathrm{Mg} / \mathrm{m}^{3}$ and $1.9 \mathrm{Mg} / \mathrm{m}^{3}$ at optimum gravimetric water content of $30 \%$ and $10 \%$ for clay and sand respectively.

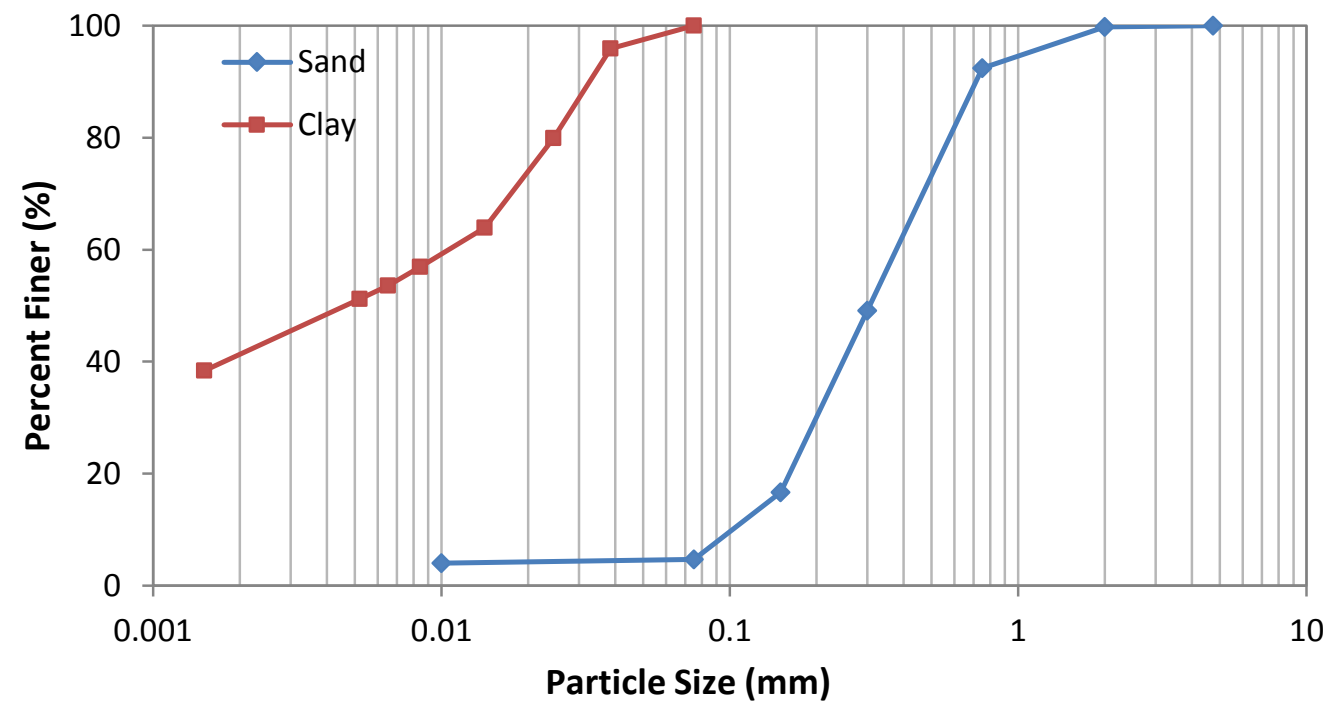

Figure 3.1: Leda Clay and Sand grain size distribution

Table 3.1: Index properties of soil samples (Giraldo and Rayhani, 2014)

\begin{tabular}{|c|c|c|c|c|c|c|c|c|c|c|c|}
\hline $\begin{array}{c}\text { Soil } \\
\text { Type }\end{array}$ & $\begin{array}{c}\rho \\
\left(\mathrm{Mg} / \mathrm{m}^{3}\right)\end{array}$ & $\begin{array}{c}w \\
(\%)\end{array}$ & $\begin{array}{l}\mathbf{L L} \\
(\%)\end{array}$ & $\begin{array}{c}\text { PI } \\
(\%)\end{array}$ & $\begin{array}{l}w_{\text {opt }} \\
(\%)\end{array}$ & $\begin{array}{c}\rho_{d(\max )} \\
\left(\mathbf{M g} / \mathbf{m}^{3}\right)\end{array}$ & $\begin{array}{c}S_{u} \\
(\mathrm{kPa})\end{array}$ & $\begin{array}{c}c \\
(\mathrm{kPa})\end{array}$ & $\begin{array}{l}\phi \\
\left({ }^{\circ}\right)\end{array}$ & $\begin{array}{c}c^{\prime} \\
(\mathrm{kPa})\end{array}$ & $\begin{array}{l}\phi^{\prime} \\
\left({ }^{\circ}\right)\end{array}$ \\
\hline Clay & 1.53 & 67 & $\overline{51}$ & $\overline{23}$ & 30 & 1.41 & $\overline{50}$ & 42.2 & 23.3 & 8.6 & 26.0 \\
\hline Sand & 2.08 & 8.0 & - & - & 10 & 1.90 & - & - & - & 0 & 33.0 \\
\hline
\end{tabular}

$\rho=$ bulk density; $w=$ moisture content; $w_{\text {opt }}$ optimum moisture content; $\rho_{d(\text { max })}$ maximum dry density; $c_{v}=$ coefficient of consolidation; $S_{u}=$ undrained shear strength; $c=$ cohesion when sheared at $2 \mathrm{~mm} / \mathrm{min}$.); $\phi=$ friction angle when sheared at $2 \mathrm{~mm} / \mathrm{min}$.); $c^{\prime}=$ cohesion (drained); $\phi^{\prime}=$ friction angle (drained)

A direct shear box testing program according to ASTM D3080/D3080M (2012) was performed on both sand and clay specimens in order to determine their shear strength parameters 
under drained and undrained shearing conditions. The shearing rates used were $0.05 \mathrm{~mm} / \mathrm{min}$ for drained conditions and $2.5 \mathrm{~mm} / \mathrm{min}$ for undrained conditions. Table 3.1 summarizes the properties of both clay and sand materials used in this study.

\subsection{EXPERIMENTAL PROGRAM}

For most of the geotechnical designs concerning foundations, earthworks and slope stability issues, the soils are required to withstand shearing stresses along with compressive stresses. The shaft bearing capacity of cast-in-situ piles is related to the ultimate shearing resistance at the interface between the soil and pile. This interface shearing resistance depends on the interface material and its roughness as well as on the properties of the soil, the magnitude of the normal stress and the rate of shear displacement (Lemos and Vaughan, 2000).

A direct shear box device was employed to simulate the shear behaviour between the cast-in-place-pile surface versus surrounding clay and sandy soils. Similar approach has previously been used to investigate the pile-soil interface strength for different materials (e.g., Giraldo and Rayhani, 2014). Although the box size of $60 \mathrm{~mm}$ square seems to be a little small for interface investigation, but the data generated from these tests were shown to be reliable as per previous findings in the literature (e.g., O'Rouke et al., 1990). A schematic of the direct shear box used for this study is illustrated in Figure 3.3. 


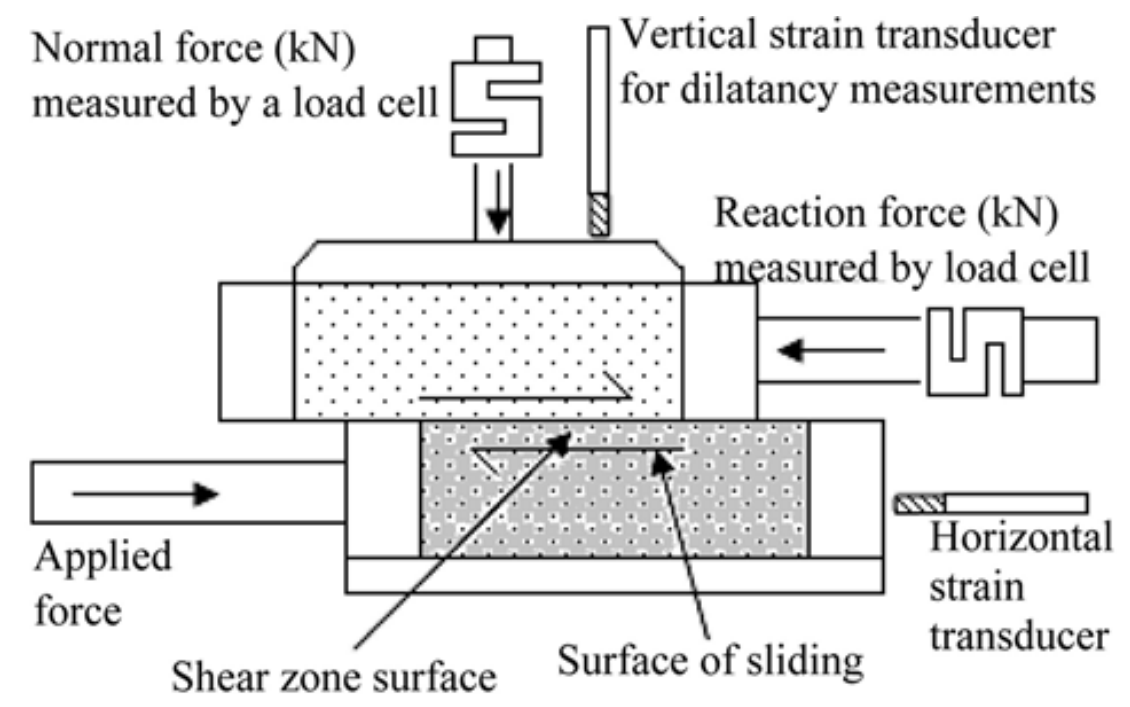

Figure 3.2: Modified shear box used for pile-soil interface testing

\subsubsection{Pile Interfaces}

The pile surface roughness plays a critical role in determining the interface strength and hence the frictional capacity along the shaft of the pile (e.g., Lemos, 1986; Lemos and Vaughan, 2000). Interface roughness is caused by the undulations along the surface of the pile as well as the particles of the soil sheared against the surface. This phenomenon will generate extra internal resistance against shear at the interface level.

The pile surface roughness coefficient in cast-in-situ piles would be significantly affected by the method of the pile construction and installation as well as the soil internal friction angle. Most previous research correlated the interface shear strength parameters between the pile and soil $\left(\mathrm{c}_{\mathrm{a}}, \delta\right)$ to the shear strength properties of the soil. These studies provided interface apparent adhesion and apparent frictional values proportional to the cohesion and friction angle of the soil for each method of construction for sand and clay (e.g., Tomlinson, 1994), which may vary from 0.5 to more than 1 . 
In order to investigate the interface strength of cast-in-situ concrete piles in different soils, both the clay and sand soil specimens were sheared against concrete planes confined by the bottom half of the box in the direct shear apparatus, whilst the upper half of the box confined the soil (Figure 3.2). Two types of concrete surfaces including a plain concrete without hook and concrete specimens with steel hooks (fabricated steel wires) were examined. The concrete contained sand and gravel aggregates (maximum size $=6.5 \mathrm{~mm}$ ), which are commonly used in the pile industry for making piles.

\subsubsection{Sample Preparation}

The concrete-soil interfaces were prepared by filling the lower half of the shear box with a precast concrete mold similar to the concrete surface used for cast-in-situ piles in industry. The tests were performed on two types of soils (clay and sand) against modified concrete surface with hooks and plain concrete surface without hooks.

In order to prepare the concrete interfaces, a sand/cement mixture at a ratio of 1:3 was mixed with a of $35 \%$ water content by weight. Two concrete interface samples were cast in the lower portion of the shear box device, and allowed to cure for 14 days prior to initial testing. The first sample was left without hooks while the second sample was cast with the provision of two hooks (hard steel bending wire $1.2 \mathrm{~mm}$ diameter cut \& hooked as V shape and projected $2.5 \mathrm{~mm}$ outside the concrete surface) at the concrete surface (Figure 3.3). The hooks were installed at the concrete-soil interface assuming that each hook fixed in place would contribute in improving the frictional resistance provided by the concrete surface. 


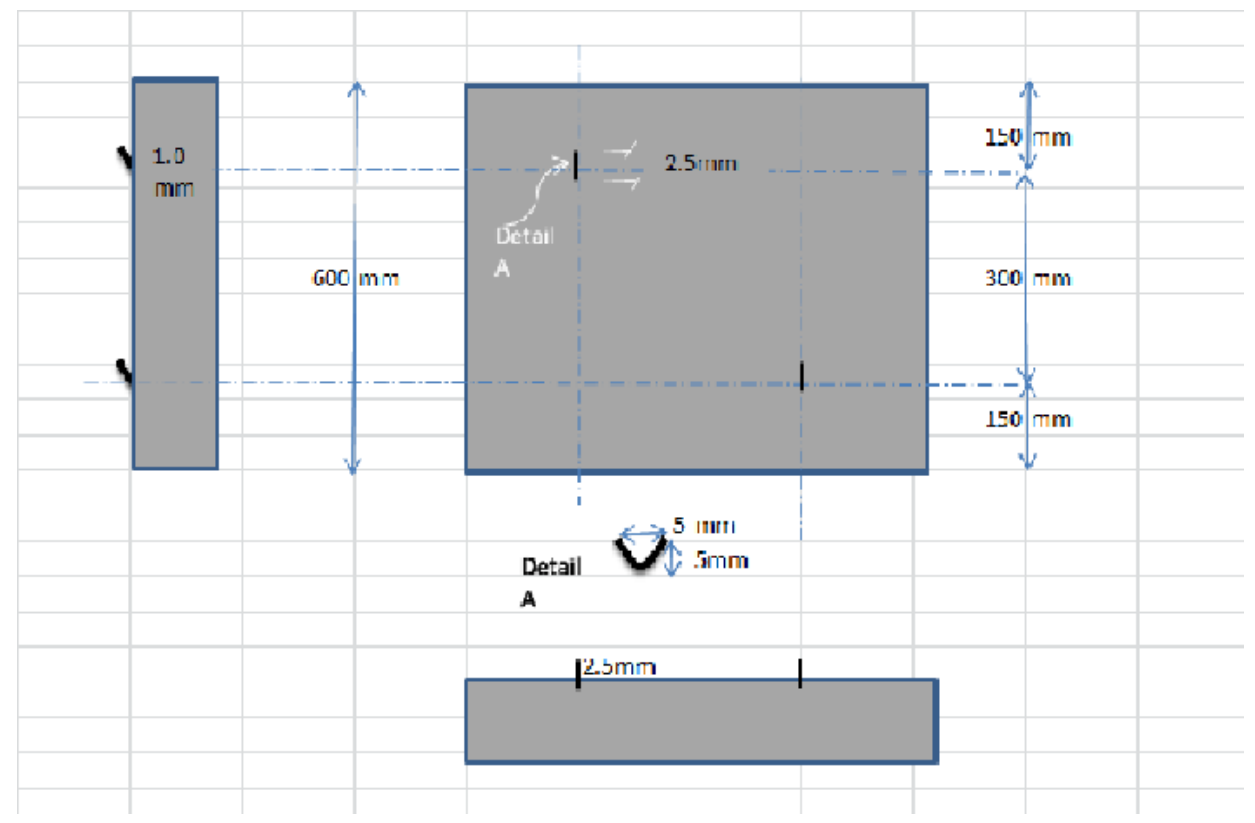

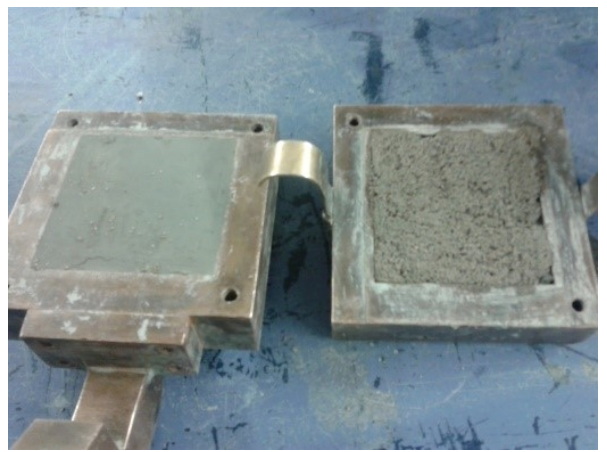

a) No hook

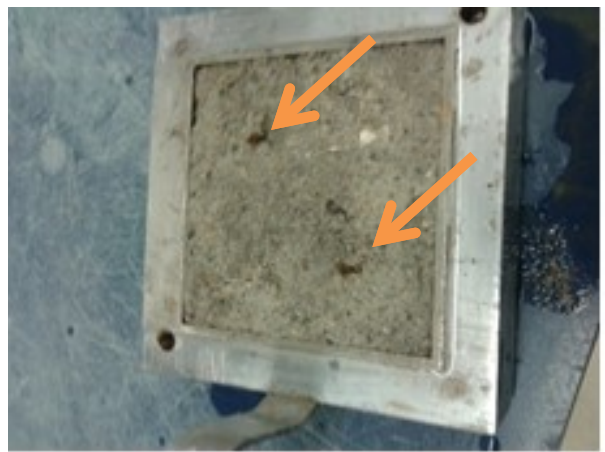

b) Concrete interface with hooks

Figure 3.3: Surface interface and profile for concrete with hooks and without hooks

To prepare the clay specimens, an undisturbed specimen of Leda clay was carefully cut to match the upper-half opening of the box and fitted to ensure complete concrete-clay contact at the interface. The specimens were slowly pushed into the box and the extra parts were trimmed to match the shape of the box, ensuring complete interface contact. The sand specimens were prepared by molding the sand in the upper box of the direct shear apparatus at a moisture content of $21 \%$. The sand was compacted to achieve a dry density of $1.8 \mathrm{~g} / \mathrm{cm}^{3}$ or $(0.95 \times \rho d \max )$ by tamping. 


\subsubsection{Testing Procedure}

The pile-soil interface testing was conducted using a displacement-controlled direct shear apparatus according to ASTM D3080 and ASTM D3521. The shear box has inside specimen dimensions of $60 \mathrm{~mm}$ by $60 \mathrm{~mm}$ and a specimen height of $25.4 \mathrm{~mm}$. Lateral loads were applied using mechanical actuators, while the normal loads were applied by a steel bearing arm using weights to apply vertical stresses to the specimen. The shearing stresses were measured through a digital load cell connected horizontally to the top section of the shear box. Horizontal and vertical displacements were measured through linear variable differential transducers (LVDT) connected to a digital logging station using LabView software.

The assemble shear box was placed within a metal container which was laid upon a set of linear ball bearings allowing unrestricted horizontal displacements. The containing metal box was filled with water to ensure saturated conditions and to simulate the real pile-soil condition in the field. The confining pressure was applied through a steel bearing arm connected to the top section of the shear box. Three different confining pressures of 95, 170 and $270 \mathrm{kPa}$ were applied to simulate typical lateral earth pressures along the pile shaft at a deep cast-in-situ pile. The application of confining pressure was continued until a constant vertical settlement was achieved. Then horizontal shearing applied on the sample.

Two shearing rates were used to simulate drained loading condition for concrete-sand interfaces and undrained conditions for concrete-clay tests. A loading rate of $0.05 \mathrm{~mm} / \mathrm{min}(5 \%$ strain per hour) was used to simulate the drained conditions, while undrained condition was achieved at a shearing rate of $2.5 \mathrm{~mm} / \mathrm{min}$. It should be noted that the shearing rate used for the drained condition might not simulate the real drained conditions for shear tests. However, this was the lowest possible rate that could be achieved by the apparatus used. 
Two groups of tests were implemented; one for concrete surface without any modification and the second series for a concrete surface with 2 Hooks implemented against the shearing direction (Figure 3.3). The shearing rates were achieved through the use of a precise screw type actuators calibrated to $0.05 \mathrm{~mm} / \mathrm{min}$ and $2.5 \mathrm{~mm} / \mathrm{min}$ in order to simulate drained and undrained conditions, respectively. The shearing was carried out up to a strain of $8.5 \%$ or until residual shear strength conditions had stabilized. Following failure of the specimen, the assembly was dismantled and a visual inspection of the shearing surface was carried out in order to identify the possible failure mechanism acting along the interface.

\subsection{RESULTS AND ANALYSES}

\subsubsection{Concrete-Clay Interface Shear Strength}

Two sets of interface tests were conducted shearing concrete interfaces with hooks and without hooks against undisturbed clay specimens under three different normal pressures of 95, 170 and $270 \mathrm{kPa}$. In order to analyze the performance of the hook contribution and its effect on the shear strength behaviour of the interface, the results from both the plain concrete-soil interface tests were comparted to those conducted on hooked concrete interfaces. The comparison were done in terms of the relation between the shear stress vs. horizontal strain for the different stages of loading for plain concrete surface and modified hooked concrete surface as well as the estimated shear strength parameters.

Undrained conditions were applied to determine the cohesion of the soil and the apparent adhesion between the concrete interface surfaces and clay. The shear stress-displacement curves for both the plain concrete-clay and hooked concrete-clay interfaces are shown in Figures 3.4 and 3.5, respectively. For the range of normal stresses tested, the shear stress-displacement 
curves exhibited a maximum stress followed by a nearly constant residual shear stress. For plain concrete interface, the shear strength was stabilized at a horizontal displacement of about $3.0 \mathrm{~mm}$ equivalent to $5 \%$ of the total strain. The residual (nearly constant volume state) shear strength for the plain concrete interface ranged from $19 \mathrm{kPa}$ to $22 \mathrm{kPa}$ for normal stresses ranging from 95 to $270 \mathrm{kPa}$.

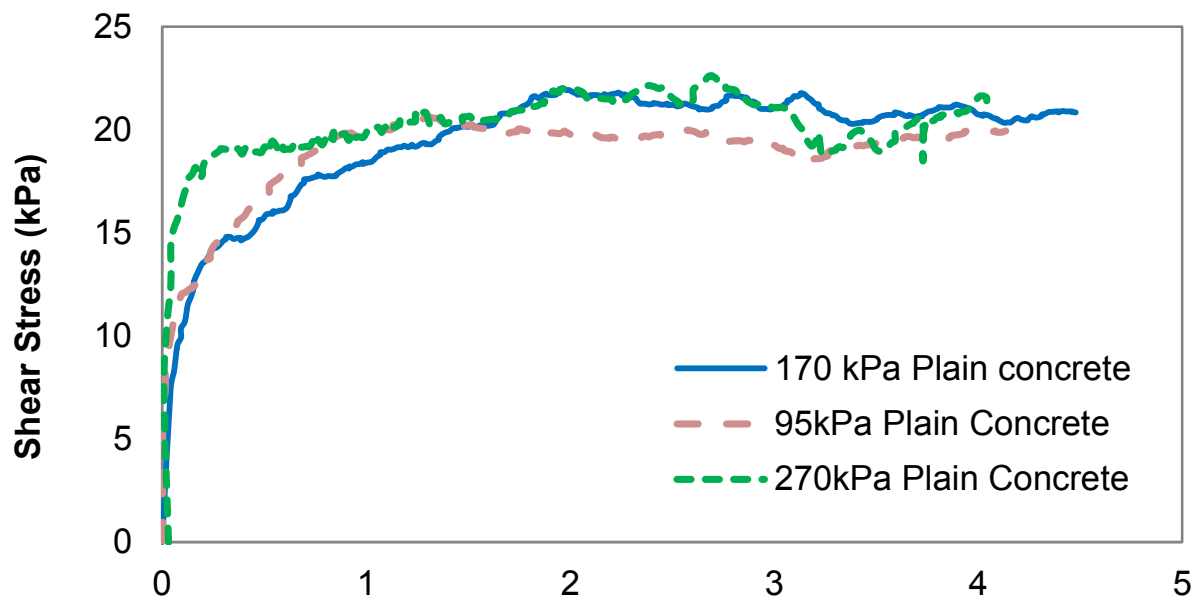

Horizontal Displacement (mm)

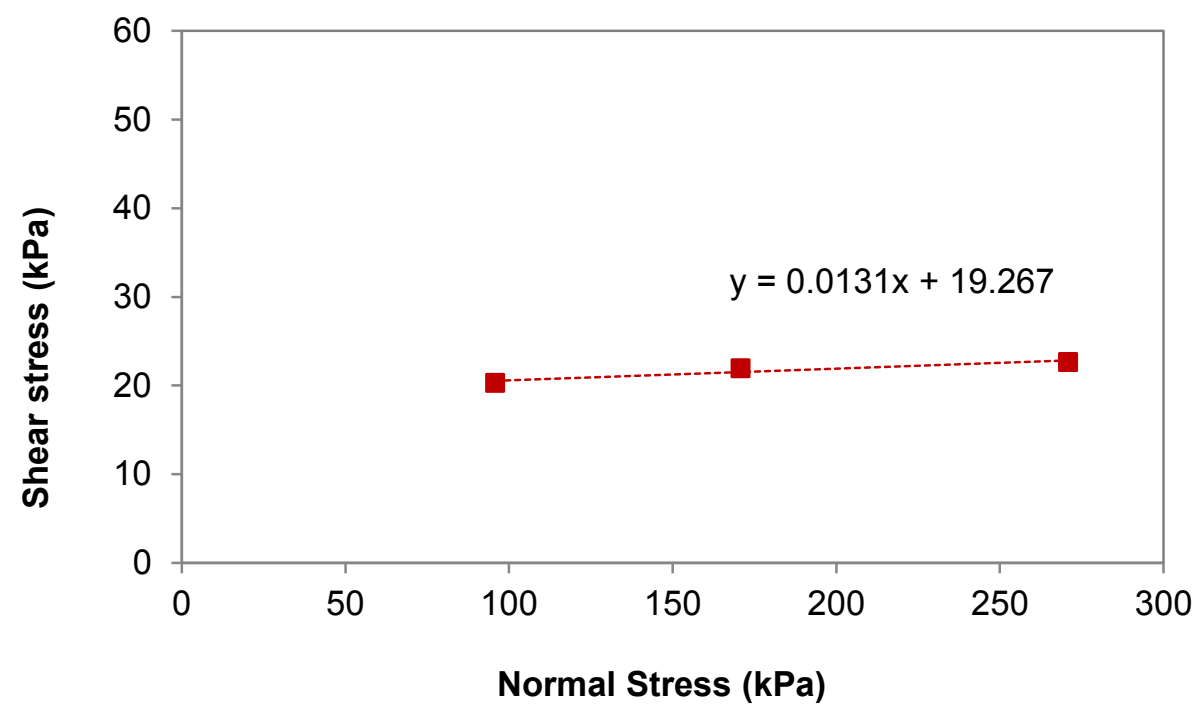

Figure 3.4: a) Shear Stress-strain readings from shear box tests for plain concrete-clay interface b) Failure envelopes under undrained conditions for plain concrete-clay interface 
The stress-displacement curves for hooked concrete-clay interface tests (Figure 3.5) are similar to those of the clay sheared against plain concrete, although the interface strength is not the same. The residual shear strength for hooked concrete interface were significantly higher compared to those for the plain concrete, ranging from 55 to $115 \mathrm{kPa}$ under similar normal stresses. This relatively high strength with the hooked concrete interface could be related to higher roughness of the hooked concrete surface, as the rough surface will lead to development of higher shear strength at smaller shear displacement.

On the other hand, the peak shear strength for the hooked concrete interface was achieved at much smaller displacement of less than $2 \mathrm{~mm}$ (3\% shear strain) compared to those for plain concrete surface. The plain concrete-clay specimen experienced a strain hardening behaviour until reaching peak strength at over $4 \%$ of horizontal strain, while the hooked interface demonstrated peak strength at a strain range of about $2-3 \%$ following a strain softening region until stabilizing at about $5 \%$ strain to reach a residual strength state.

Interface strength envelopes for both the concrete surfaces are shown in Figures 3.4 to 3.5. The interface apparent adhesion, $c_{a}$, obtained from linear fits to the test data for both plain concrete- and hooked concrete-clay were estimated at 19 and $34 \mathrm{kPa}$, respectively. The interface friction angle, $\delta$, was also estimated at about $1^{\circ}$ and $16^{\circ}$ for the plain and hooked concrete interfaces respectively. As it is noted, the soil sheared against the hooked concrete showed significantly higher interface apparent adhesion and friction angle. This difference in shear strength behaviour could be explained by higher surface roughness and, hence, improved interlocking between the pile and soil. This higher surface roughness leads to higher interface shear resistance in the hooked piles. 

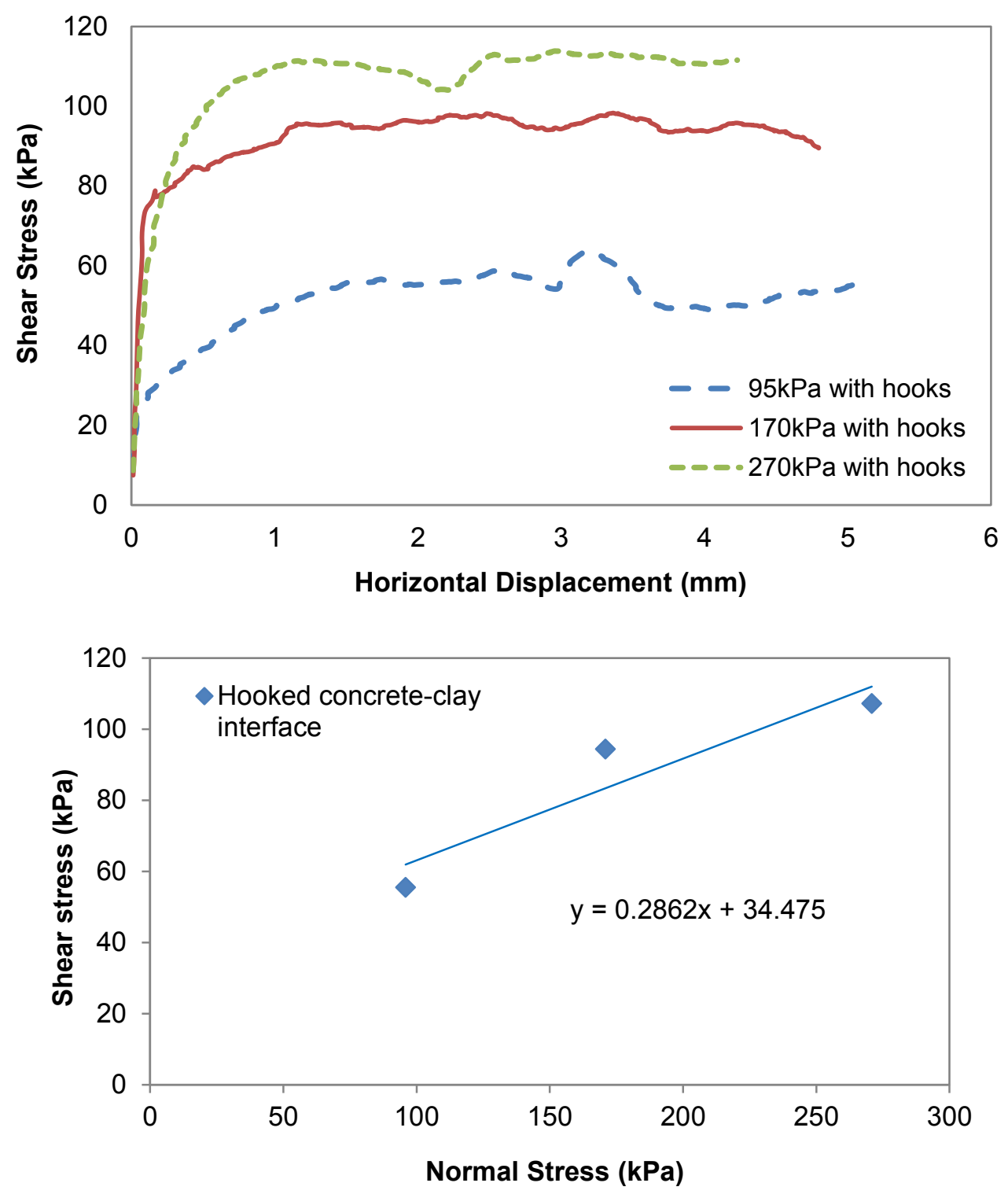

Figure 3.5: a) Shear Stress-strain readings from shear box tests for hooked concrete-clay interface b) Failure envelopes under undrained conditions in hooked concrete-clay interface

The interface test results may also be analyzed by comparing the interface apparent adhesion, $c_{a}$, and internal friction angle with respect to the undrained shear strength parameters of the soil. The ratio between the interface apparent adhesion and the undrained cohesion, $c_{a} / c$, increased from a value of 0.45 for plain concrete-clay interface to 0.80 for the modified interface with two hooks. Values of the interface adhesion for cast-in-situ piles in soft clays are generally 
taken to be 0.5 to $0.6 \times c_{u}$, which is slightly higher than the values obtained for plain concrete, but, significantly lower than those obtained for hooked interface presented here. This demonstrates that, hooked concrete piles could significantly improve the load carrying capacity of cast-in-place piles.

Figures 3.4(b) and 3.5(b) also show the ratio of the interface friction angle of both plain and hooked concrete surfaces to the soil's internal friction angle $\delta / \phi$. The interface friction angle for the plain concrete corresponds to a value between $0.04 \phi$ for plain concrete-clay to $0.68 \phi$ for the hooked concrete interface. Comparing these results, hooked interface demonstrates significantly improved frictional resistance compared to plain concrete. These results support the idea of the development of turbulent shearing mechanisms along the hooked concrete interface due to disturbance of the clay particles at the interface microstructure and the development of sliding or transitional shearing mechanisms along the plain concrete interface (Kishida and Uesegui, 1987).

\subsubsection{Concrete-Sand Interface Shear Strength}

As discussed earlier, the interface tests in sand was conducted under semi-drained condition at a shearing rate of $0.05 \mathrm{~mm} / \mathrm{min}$ for both the plain and hooked concrete surfaces. The shear stress displacement curves for sand vs concrete and modified concrete with hooks interfaces are shown in Figures 3.6 and 3.7, respectively. For the entire range of normal pressures tested, the stressstrain curves exhibited a peak shear stress followed by a nearly constant volume state in plain concrete interface tests. For the hooked concrete tests, the tests showed a peak shear stress followed by a stress reduction toward a residual shear stress (strain softening). This significant difference in shear stress-strain behaviour was due to the implementation of hooks at the pile interface, as all other testing conditions were similar. 

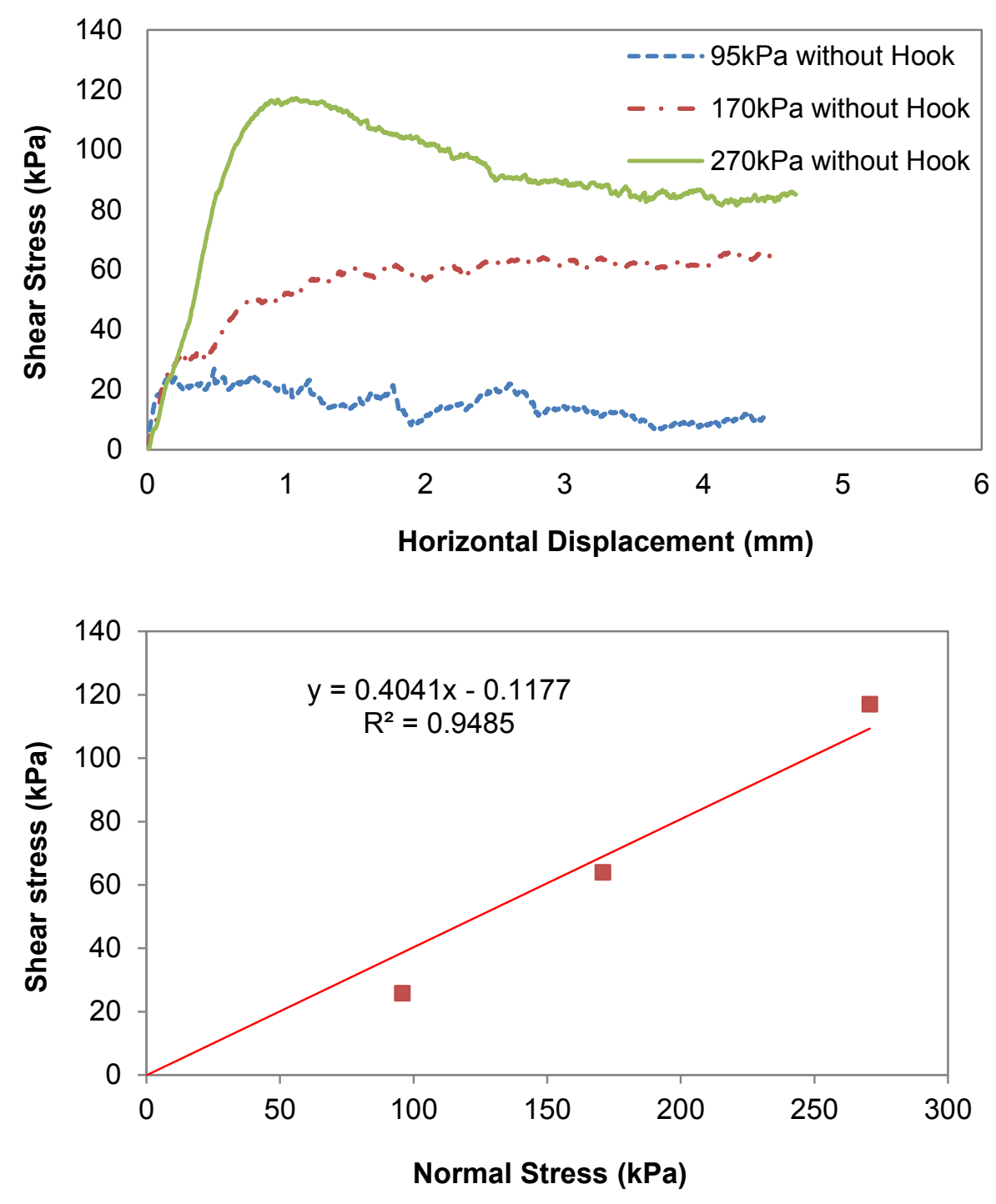

Figure 3.6: a) Shear Stress-strain readings from shear box tests for plain concrete-sand interface b) Failure envelopes under drained conditions in plain concrete-sand interface

The peak shear stress achieved for plain concrete interface varied between $25-117 \mathrm{kPa}$ under the normal stresses of 95-270 kPa. These values were significantly higher for the hooked concrete interface ranging from 50-140 $\mathrm{kPa}$ under similar normal pressures. The peak shear stresses for the hooked interface was achieved at much smaller strains of less than $2 \%$ compared to 
those for plain concrete (2-6\%). As it is obvious, the hook implementation increases the shear resistance of the pile-sand interface while reducing the strain at the peak shear stress. This improvement in interface shear strength is related to higher surface roughness at the interface as well as better interlocking between the sand and the pile.
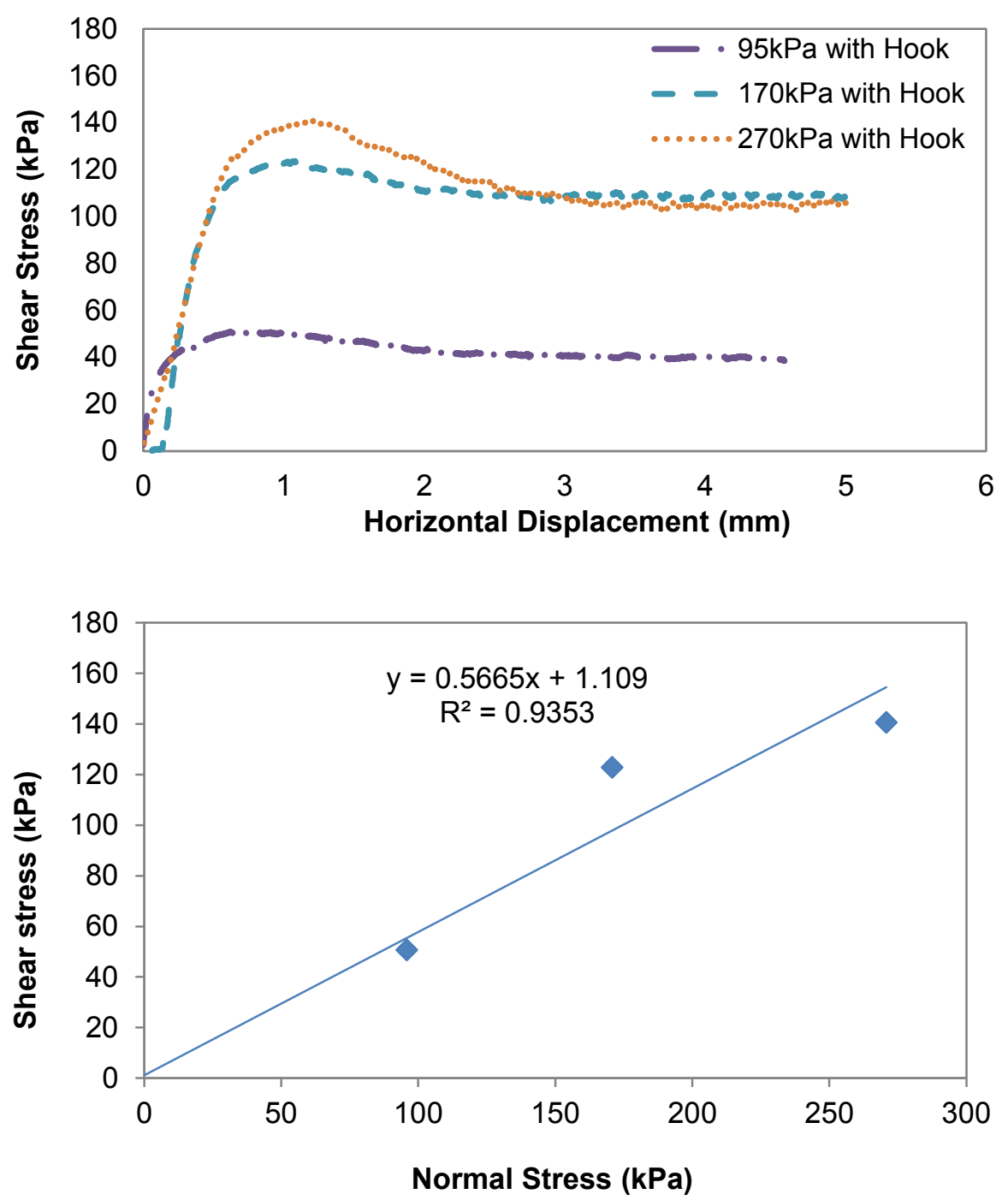

Figure 3.7: a) Shear Stress-strain readings from shear box tests for hooked concrete-sand interface b) Failure envelopes under drained conditions in hooked concrete-sand interface 
The interface friction angles were estimated for each test based on the stress envelope for three different normal stresses (Figures 3.6, 3.7). As it can be seen, the interface friction angle for the concrete-sand system increased from a value of $22^{\circ}$ for the plain concrete-sand interface to about $29.5^{\circ}$ for the hooked concrete-sand tests. These results show that implementing two kooks with a surface area of about $3 \mathrm{~mm}^{2}$ on a concrete interface of $3600 \mathrm{~mm}^{2}$ increased the interface friction coefficient by about $60 \%$.

As discussed earlier, the interface friction angle $(\delta)$ is analogous to the interface friction angle used in evaluating the shaft capacity of piles. The ratio between the interface friction angle, $\delta$, and the friction angle of the soil, $\phi$ ', will be about 0.66 and 0.89 for the plain concrete-sand and hooked concrete-sand, respectively. Values of the interface friction angle for cast-in-situ piles drilled into sand are generally taken to be 0.5 to $0.7 \times \phi_{\text {soil }}$, which agrees with the experimental data presented here for the plain concrete surface. Modifying the concrete interface with hook system will significantly improve the interface resistance of the cast-in-situ piles and, hence, the cost of piling through reduction in pile dimensions and/or numbers.

\subsubsection{Influence of Hook on Pile-Soil Interface Shear Strength}

Results presented in Figures 3.5 - 3.7 show that implementing hook system at the interface of concrete can improve the shear resistance of interface surfaces in different soils. For example, using two diagonal hooks at concrete-sand interface increased the residual shear strength of castin-situ concrete sheared against sand from about $63 \mathrm{kPa}$ to $107 \mathrm{kPa}$ under a normal stress of 170 $\mathrm{kPa}$ (Fig. 3.8). This significant increase in residual shear strength was only achieved by employing two tiny hooks with an area of $3 \mathrm{~mm}^{2}$ at the concrete surface of $3600 \mathrm{~mm}^{2}$. From interface shear strength perspective, the hooked concrete interface increased the interface friction 
angle of plain concrete from about $22^{\circ}$ to $29.5^{\circ}$. This $34 \%$ increase in interface friction angle could potentially lead to more than $30 \%$ saving in the cost of construction of cast-in-situ piles as well as reduction in the construction time.
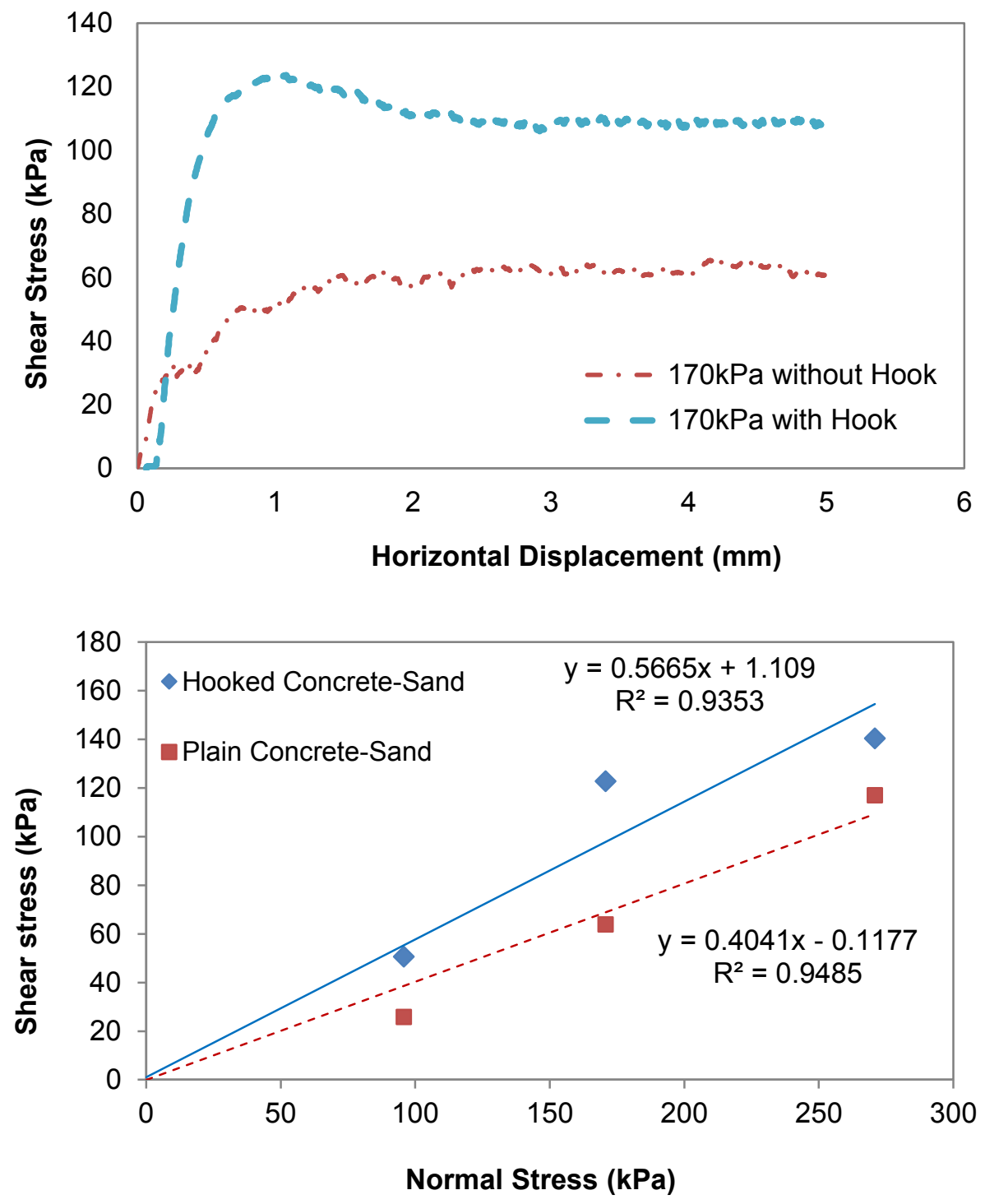


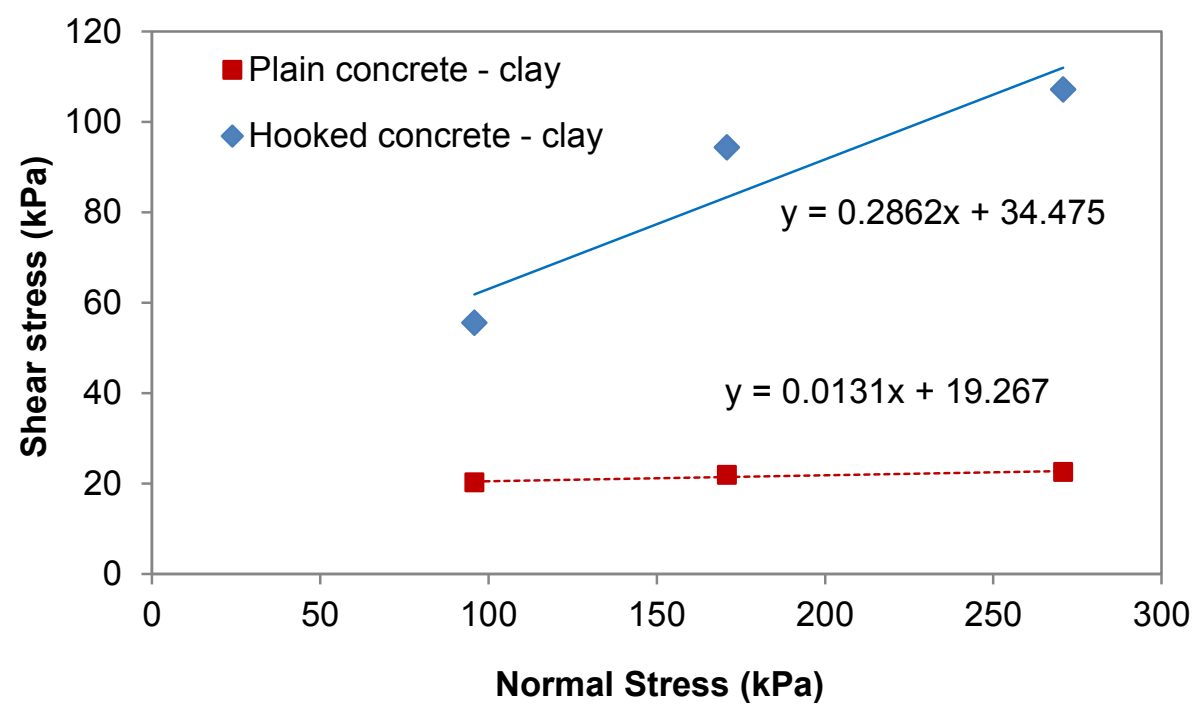

Figure 3.8: a) Comparison of shear stress-strain curves for plain concrete- and hooked concretesand interface under $170 \mathrm{kPa}$ normal stresses; b) Failure envelopes under drained conditions for both plain concrete-and hooked concrete-sand interfaces; c) Failure envelopes under undrained conditions for both plain concrete-and hooked concrete-clay interfaces

The peak shear strength for the hooked concrete surface was also reached at much smaller shear strain. While the peak shear stress for the plain concrete sheared against sand under a normal stress of $170 \mathrm{kPa}$ was achieved at a shear strain of about $7 \%$, this strain was less than $2 \%$ for the hooked concrete tested under similar conditions. Therefore, the hooks enriched the capacity of the concrete interface and maintained this higher load carrying capacity at a very low rate of strain. This improves the construction of a structural foundation where the settlement needs to be minimized. The proportion of the hook component may be adjusted to achieve the desired friction potential. 


\subsubsection{Performance of Hooked Pile Interface in Different Soils}

In order to evaluate the performance of hooked concrete interface in different soils, the shear strength parameters achieved from direct shear tests are summarized in Table 3.2 for both sand and clay soils. The increase in interface apparent adhesion for the hooked piles estimated through comparison of the adhesion relative to the plain concrete in clay would be about $78 \%$. This improvement for the interface friction angle in clay was significantly higher, changing from $1^{\circ}$ to $16^{\circ}$. The interface friction angle for concrete specimens sheared against sand under drained condition changed from $22^{\circ}$ for plain concrete surface to about $29.5^{\circ}$ when 2 hooks were installed at the surface of the concrete. These observations demonstrate that hooked piles would improve the shaft capacity in both sands and clayey soils. However, the rate of increase in both apparent adhesion and interface friction angle for clayey soil under total stress analysis would be much higher than those for sand. More investigation is required to draw a better conclusion with respect to performance of hooked piles in different materials.

Table 3.2: Interface shear strength parameters for sand and clay

\begin{tabular}{|c|c|c|c|c|c|}
\hline Soil & Interface & $c_{a}(k P a)$ & $\mathbf{c}_{\mathbf{a}} / \mathbf{c}_{\mathrm{u}}$ & $\delta\left(^{\circ}\right)$ & $\delta / \phi$ \\
\hline \multirow{2}{*}{ Clay } & Plain concrete & 19 & 0.45 & 1 & 0.04 \\
\hline & Hooked concrete & $34^{*}$ & 0.80 & $16^{*}$ & 0.68 \\
\hline \multirow{2}{*}{ Sand } & Plain concrete & - & - & 22 & 0.66 \\
\hline & Hooked concrete & - & - & $29.5^{* *}$ & 0.89 \\
\hline
\end{tabular}




\section{CHAPTER 4}

\section{LOAD TRANSFER OF HOOKED CAST-IN-PLACE CONCRETE PILES IN CLAY Patent Pending}

\subsection{INTRODUCTION}

Cast-in-place piles are commonly used in construction industry to transfer the load of superstructures to competent ground strata in wide range of geological settings. They are known as the most flexible and practical method in piling construction as they can be used in any diameters and up to any practical depth. Several studies have been elaborated and developed on the shaft capacity of the cast-in-place concrete pile in different soils (sand, clay and rock). The shaft capacity of cast-in-place piles may not be fully developed in caving soils and fractured rocks due to possible gap between the pile and the surrounding soil. Concrete water has also shown to affect the shaft capacity of cast-in-place piles in clay soils. This study aims to investigate possible enhancement of pile shaft capacity in cast-in-place piles by implementing shaft engagement elements known as hook system. A series of field static load tests on cast-inplace pile were conducted to demonstrated the degree of improvement of pile capacity.

A cast-in-place pile with hook system is a concrete pile drilled and filled with concrete after installing the reinforcing steel cage in the drilled shaft. The hook system consists of a prefabricated hard steel bar having the shape of a hook downward for compression passive inclusion reaction and upwards for uplift passive inclusion reaction. This hook has a mechanism enabling to push itself into the pile surrounding soil to create a full pie-soil bonding and clutching 
with it. The hooks are placed in a staggered shape at equal distances along with the steel bars of the pile reinforcing cage as shown in Figure 4.1. This system has not been yet recognized in the industrial field but it is expected to provide economic saving in pilling industry. The hooked piles are not expected to affect the pile installation time since they are fixed on the rebar while preparing the steel cage but it would require an excellent control system to achieve the best economical and scientific outputs of the system.
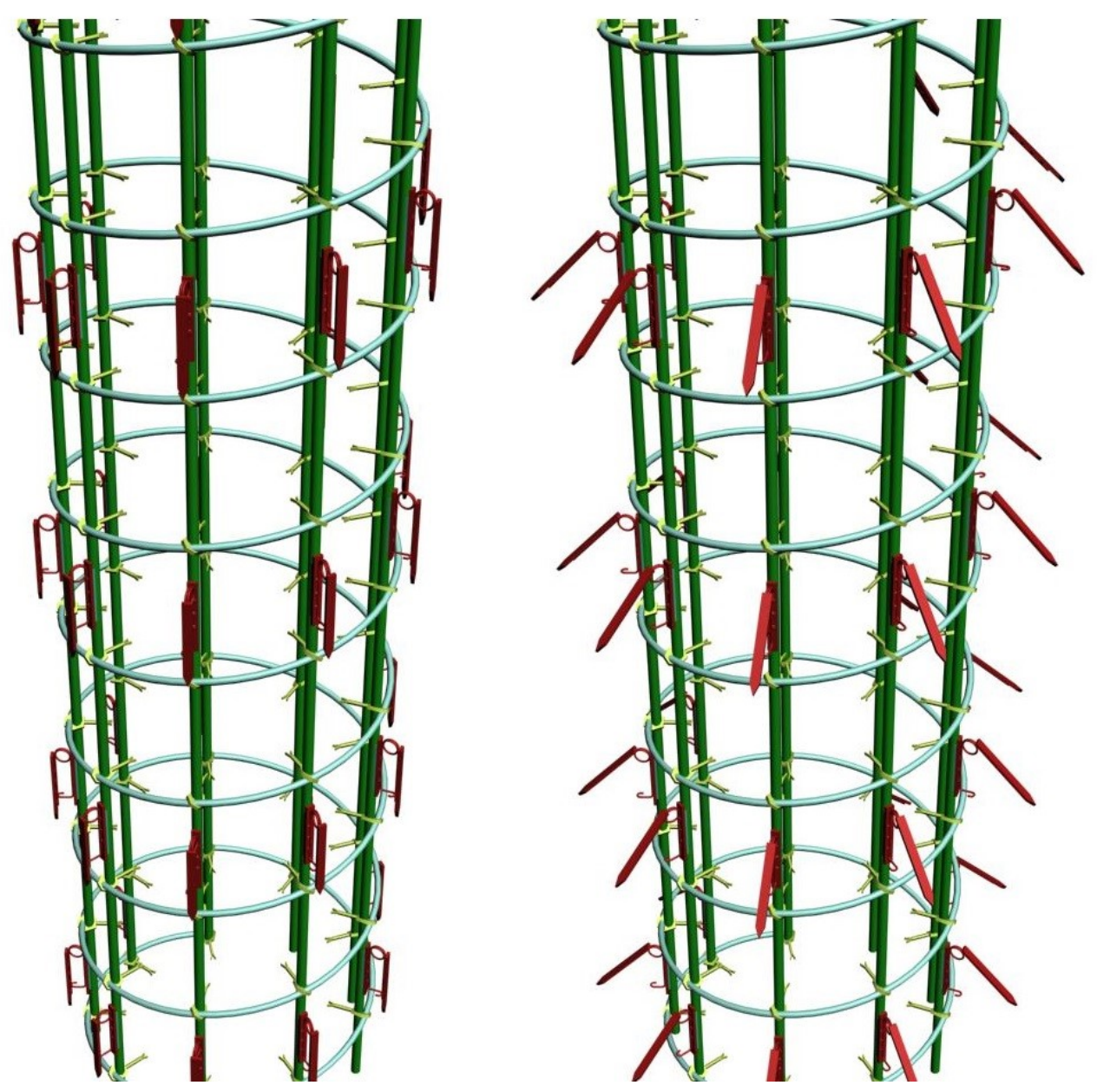

Figure 4.1 Modified cast-in-place concrete pile shaft with Hook system 


\subsection{PILE BEARING CAPACITY}

The load carrying capacity of cast-in-place piles is a function of the pile shaft resistance which is represented by the soil shear strength parameters, and the toe bearing resistance represented by bearing capacity factors derived from Terzaghi's bearing capacity equation. This study focuses on increasing the pile-soil interface resistance around the pile shaft and not the bearing of the pile tip. There is no empirical or analytical method for calculation its resistance, but as a preliminary assumption we consider the shaft capacity of the hooked pile as the summation of two pile-soil resistance components. The first component, $q_{s l}$, is the pile shaft resistance provided by the concrete-soil interface strength which is represented by a function of the soil shear parameters and cohesion properties (conventional unit shaft resistance equation). The second capacity component, $q_{s 2}$, would be the passive resistance created by the hooks in order to prevent the movement of the pile and consequently increase the pile capacity. In conventional cast-in-place piles, the shaft resistance is totally based on the ultimate capacity of the plain concrete shaft, i.e., $q_{s l}$, which can be calculated using normal procedures for piles in clay soil. The shaft resistance $\left(Q_{s}\right)$ in clay soils is typically estimated from the following equation:

$$
Q_{s}=\pi D L q S
$$

where $D L$ is pile circumference area, $L$ is pile embedment and $q_{s l}$ is the average shear strength, also known as unit shaft resistance, along the soil-pile contact area. Furthermore the average shear strength $q_{s}$ can be expressed in terms of the soil undrained shear strength $\left(\mathrm{C}_{\mathrm{u}}\right)$ and an empirical adhesion factor, $\alpha$, accounting for pile-soil adhesion which is typically correlated to $S_{u}$ $\left(q s=\alpha C_{u}\right)$.

For drained condition, the unit shaft resistance is a function of the interface friction angle between the pile surface and the soil, $\delta$, the lateral earth pressure perpendicular to the surface of 
the pile, and the effective stresses dependant on pore pressure along the pile shaft. The lateral earth pressure along the pile shaft is in turn a function of the stress level along the length (vertical earth pressure) of the pile and the coefficient of lateral earth pressure $K_{s}$. The frictional resistance $q_{s}$ can be represented by the following relationship:

$$
q_{s}=\sigma_{v}^{\prime} K_{s} \tan \delta
$$

where, $\sigma_{v}^{\prime}$ is the vertical effective stress at a particular depth along the length of the pile, $K_{s}$ is the coefficient of lateral earth pressure and $\delta$ is the soil-pile interface friction angle. In practice, lateral earth pressure coefficient is influenced by various factors including method of installation, soil compressibility, overconsolidation ratio and initial stress levels. In addition, the soil-pile interface friction angle is influenced by the pile material, pile surface roughness, soil grain size, normal stresses at the soil-pile interface and installation methods. Toe bearing capacity $\left(\mathrm{Q}_{\mathrm{b}}\right)$ of cast-in-place piles in clay soils can be calculated according to the following expression:

$$
Q_{b}=N_{c} C_{u} A_{b}
$$

where $N_{c}$ is a bearing capacity factor, typically 9 for pile diameter under $0.5 \mathrm{~m}$ as suggested by CFEM (CGS, 2007). $C_{u}$ is the soil undrained shear strength, and $\mathrm{A}_{\mathrm{b}}$ is the pile toe contact area. Implementing the hook system in pile-soil interface is expected to increase the unit shaft resistance of cast-in-place piles under both drained and undrained loading conditions. This possible change in the pile shaft capacity is the focus of this study and will be discussed below. 


\subsection{EXPERIMENTAL PROGRAM}

An extensive pile load testing program was conducted on both normal cast-in-place piles and modified piles with hook system in a marine clay soil to study the impact of hook system on load transfer of bored cast-in-place piles.

\subsubsection{Properties of the Hooked Model Piles}

To investigate the effect of hook implementation on pile-soil interface shear strength, four castin-place piles (P1, P2, P3, and P4) were considered. The first pile was a conventional cast-inplace concrete pile (with no hook), while the second was modified with installation of seven hooks on the pile cage. The third and fourth piles were fitted with five hooks to evaluate the impact of number of hooks as well as the test repeatability.

All model piles were fabricated in place at the field site using three main constituents: concrete, steel reinforcement and the hook enhancement. The pile cages were manufactured at a length of $1200 \mathrm{~mm}$ and diameter of $200 \mathrm{~mm}$ using $10 \mathrm{M}$ steel rebar, and the pile cages were reinforced with 2 steel rings one at the top and one at the bottom. The $10 \mathrm{M}$ rebar was fixed in the center of the pile to allow a space for the hooks and this pivot rebar was welded to the two top and bottom stirrups to create the shaft reinforcing cage. For the modified hooked cages, 5 and 7 hooks were installed on each pile. The hooks were prefabricated using hard steel bars with a shape similar to the hooks presented in Figure 4.1 with a cross section of $25 \times 2 \mathrm{~mm}$ thickness and interface area of about $25 \times 25 \mathrm{~mm}$. The hook materials used in the test are in accordance to ASTM A1018/A1018M-10 Standard Specification for Steel, High-Strength Low-Alloy with Improved Formability. Figure 4.2 shows a schematic configuration of the hooks on the steel 
cage, and Figure 4.1 shows the modified cast-in-place piles as well as the convenient piles used for pile load tests in this study.

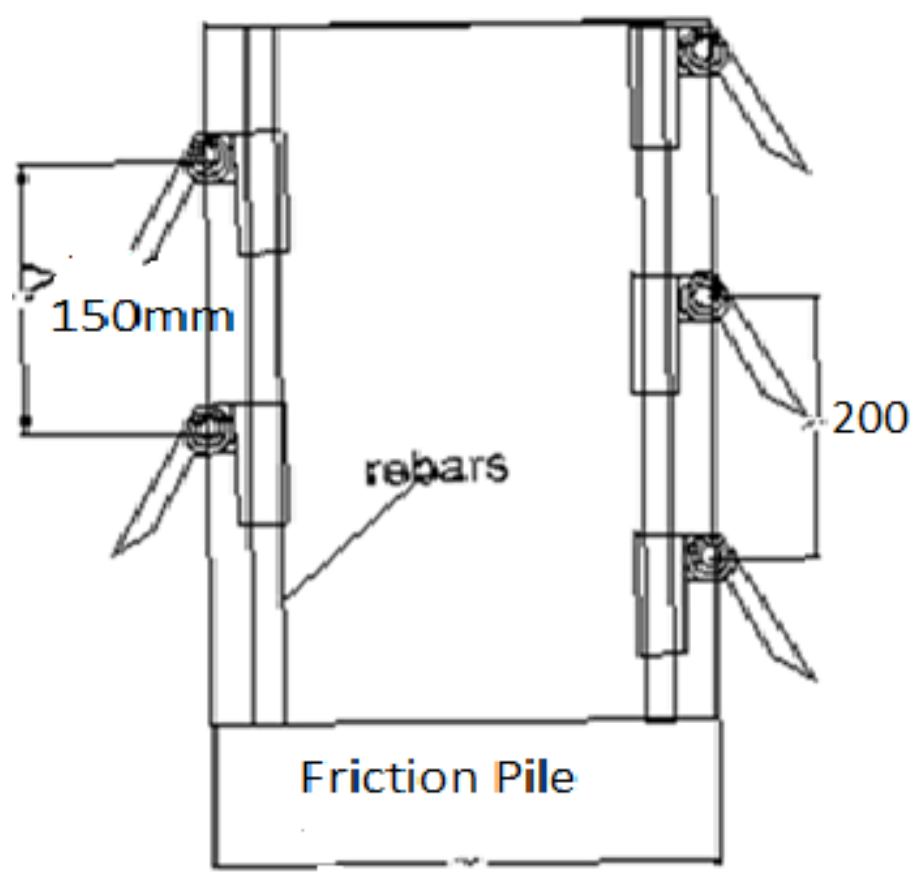

$200 \mathrm{~mm}$

Figure 4.2: Modified cast-in-place concrete pile shaft with Hook system

\subsubsection{Subsurface Conditions}

Pile-load tests were conducted in Gloucester test site known as the "Canadian Geotechnical Research Site No. 1 located in south of Ottawa, Ontario. The soil in the site is marine clay known as Leda Clay or Champlain Sea Clay which covers the Ottawa valley and Southern Quebec. The clay material formed near the end of the most recent glaciation period in the prehistoric Champlain Sea, where fine sediments and rock flour generated from glacial abrasion of the Canadian Shield settled to form thick deposits of Leda Clay along the St. Lawrence drainage 
basin. This area was excavated and a top soil of approximately $1 \mathrm{~m}$ was removed to reach the clay soil. Field vane shear tests were performed in accordance with the field vane shear test procedure described in ASTM D2573 (2008) at different depths. The undrained shear strength was found to be $48-50 \mathrm{kPa}$ for a depth of $500 \mathrm{~mm}$ to $1 \mathrm{~m}$. Atterberg limit tests were carried out in accordance with ASTM D4318 (2010), showing a plastic index of 23\%. In order to establish the particle size distribution, a hydrometer test was carried out in accordance with ASTM D422 (2007) which showed a $40 \%$ clay fraction and an activity of 0.55 . The soil is classified as $\mathrm{CH}$ according to the USCS (ASTM D2487, 2011). The coefficient of 1-D consolidation was measured according to ASTM D2435/D2435M (2011) and presented a value of $1.4 \times 10^{-4} \mathrm{~cm}^{2} / \mathrm{s}$. A direct shear box testing program according to ASTM D3080/D3080M (2012) was also performed on intact clay specimens in order to determine its drained and undrained shear strength parameters. The shearing rates used were $0.05 \mathrm{~mm} / \mathrm{min}$ for drained conditions and 2.5 $\mathrm{mm} / \mathrm{min}$ for undrained conditions. The index properties of the soil are given in Table 4.1.

Table 4.1: Index properties of Leda clay at Canadian Geotechnical Research Site No. 1 in Gloucester, Ontario

\begin{tabular}{|c|c|c|c|c|c|c|c|c|c|}
\hline $\begin{array}{c}\boldsymbol{\rho}, \\
\left(\mathbf{M g} / \mathbf{m}^{\mathbf{3}}\right)\end{array}$ & $\begin{array}{c}\boldsymbol{w}, \\
(\%)\end{array}$ & $\begin{array}{c}\mathbf{L L}, \\
\mathbf{( \% )}\end{array}$ & $\begin{array}{c}\mathbf{P I}, \\
(\%)\end{array}$ & $\begin{array}{c}\boldsymbol{C}_{v}, \\
\left(\mathbf{c m}^{2} / \mathbf{s}\right)\end{array}$ & $\begin{array}{c}\boldsymbol{S}_{u} \\
(\mathbf{k P a})\end{array}$ & $\begin{array}{c}\boldsymbol{c} \\
(\mathbf{k P a})\end{array}$ & $\begin{array}{c}\phi \\
\left({ }^{\circ}\right)\end{array}$ & $\begin{array}{c}\boldsymbol{c}^{\prime} \\
(\mathbf{k P a})\end{array}$ & $\begin{array}{c}\phi^{\prime} \\
\left({ }^{\circ}\right)\end{array}$ \\
\hline 1.53 & 67 & 51 & 23 & $1.40 \mathrm{E}-04$ & 50 & 42.2 & 23.3 & 8.6 & 26 \\
\hline
\end{tabular}

Notes: $\rho=$ bulk density; $w=$ moisture content; $c_{v}=$ coefficient of consolidation; $S_{u}=$ undrained shear strength using Vane test; $c=$ cohesion (undrained, sheared at $2 \mathrm{~mm} / \mathrm{min}$.); $\phi=$ friction angle (undrained, sheared at $2 \mathrm{~mm} / \mathrm{min}$.); $c^{\prime}=$ cohesion (drained); $\phi^{\prime}=$ friction angle (drained) 


\subsubsection{Pile Installation}

All piles were positioned at a distance of about $1.5 \mathrm{~m}(>6 \mathrm{~d})$ center to center of the piles in order to prevent any disturbance and stress interference of the previously drilled hole (BS 8004). A mechanical diesel drilling auger was used to perform the bored piles excavation with $200 \mathrm{~mm}$ diameter and $1200 \mathrm{~mm}$ length (Figure 4.3a). All four piles were drilled at the same day and maintained under the same dimensions \& conditions during installation as shown in Figure 4.34.4, and were extended for $200 \mathrm{~mm}$ to reinforce the pile cap for the compression load test. In order to facilitate the function of the hook, two rings stirrups were used; one was fixed on the top of the pile $50 \mathrm{~mm}$ below the platform level and the second one was fixed $200 \mathrm{~mm}$ above the toe of the pile. These two rings were connected with a central pivot steel bar $10 \mathrm{~mm}$ dia. where the hooks were fixed around the bar and equally distributed (Figure $4.3 \mathrm{~b}$ ). The reinforcing steel cage was slowly and carefully lowered into the hole to avoid damages to the Hooks and the surrounding soil. In order to enable the joining of fixing Hook element, the top of the main ring was fixed and hanged to the shaft of the borehole during placement of the cage. The suspended hooks were released and hanged to the borehole shaft extremity before pouring the concrete.

The concrete used for the cast-in-place pile was prepared using a special sand-cementwater mixture with maximum aggregate size of $10 \mathrm{~mm}$. The concrete mix slump was $200 \mathrm{~mm}$. The process of pouring was executed manually by wheel borrow and buckets (Figure 4.4). All piles were poured at the same time and were left for 14 days before staring the test. Normal water curing was performed for the piles caps. 


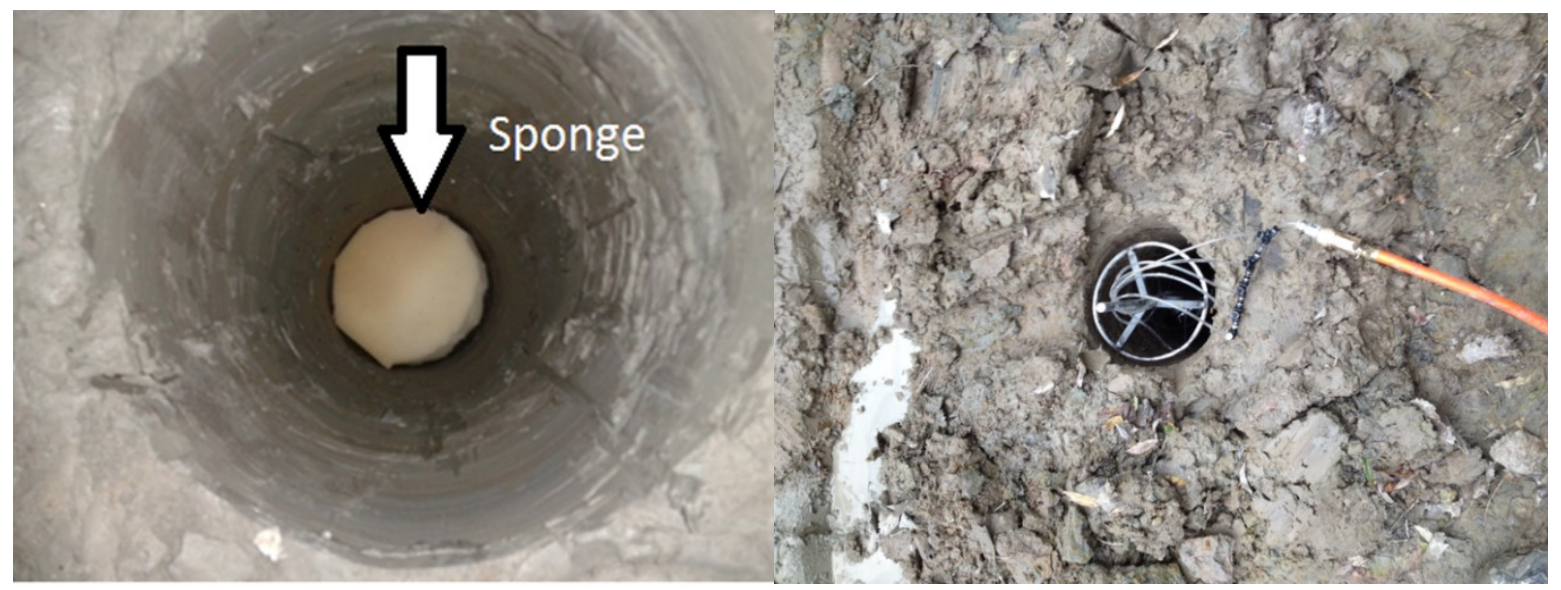

a)

b)

Figure 4.3: Steel cage for cast-in-place piles

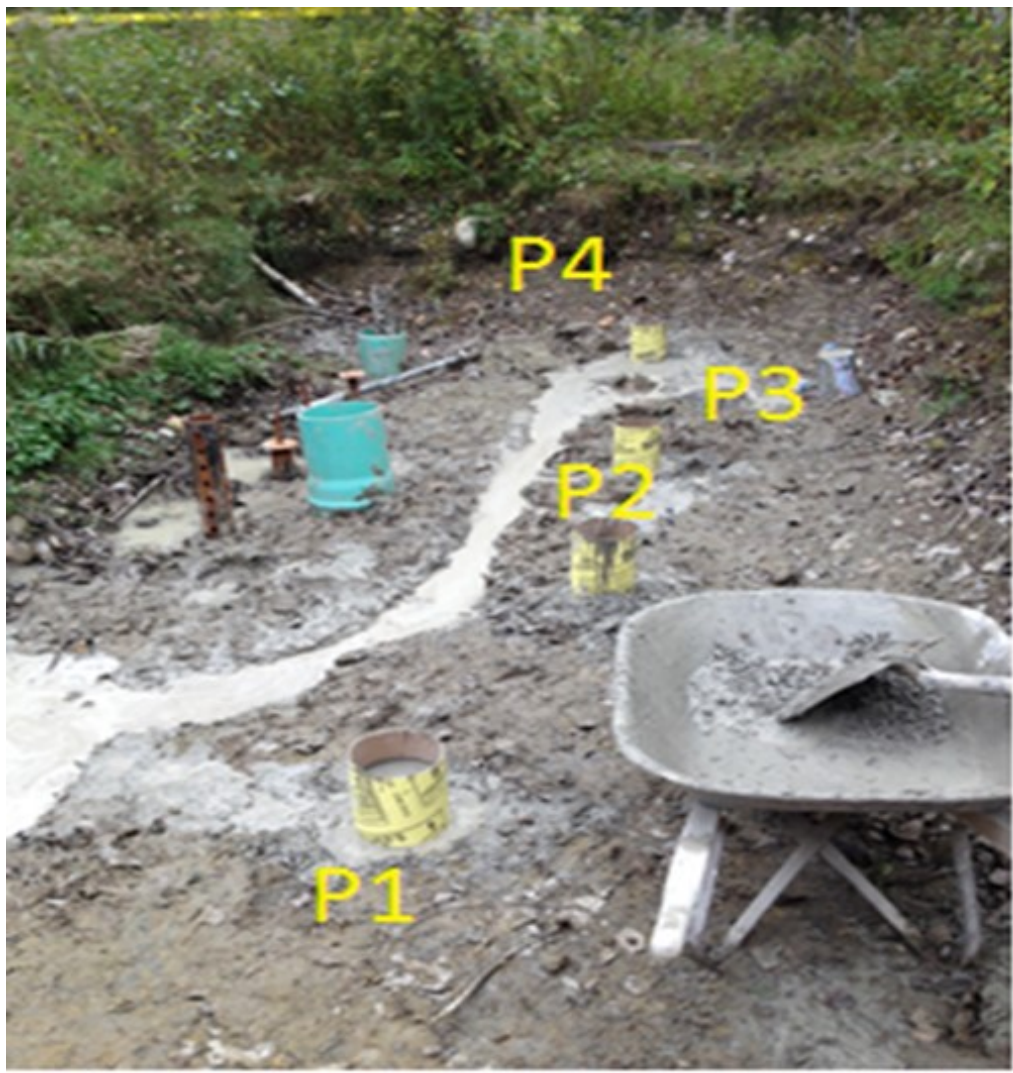

Figure 4.4: Preparation of cast-in-place piles in the field 


\subsubsection{Pile Test Setup}

A Platform was assembled at Gloucester Geotechnical testing site to apply monotonic axial loads (Figure 4.5). A testing platform base was constructed to ensure the stability of the reaction loads during the test., Three sets of horizontal beams were employed to hold the static load concrete block elements sizes of $1230 \times 620 \times 620 \mathrm{~mm}$ weighing around $58 \mathrm{kN}$. The center of this platform coincides at the same center of the pile and covers an area of $1.2 \mathrm{~m} \times 1.2 \mathrm{~m}$. Two dial gauges fixed against a datum reference beam supported in distance from the pile were used to record the pile head movement. Axial load was applied using a hydraulic jacking against kentledge. Force measurement was carried out using a conversion pressure to load at the jack Table (4.2), while ensuring proper alignment for pile head connection. A square frame kentledge support centralized to the center of the pile was erected for each pile. The kentledge consisted of concrete blocks with a total weight approximately equal to $58 \mathrm{kN}$. The pile settlement was recorded by means of dial gauges against a datum beam recording the settlement. The test commenced only when there was no settlement of the frame and the kentledge. 

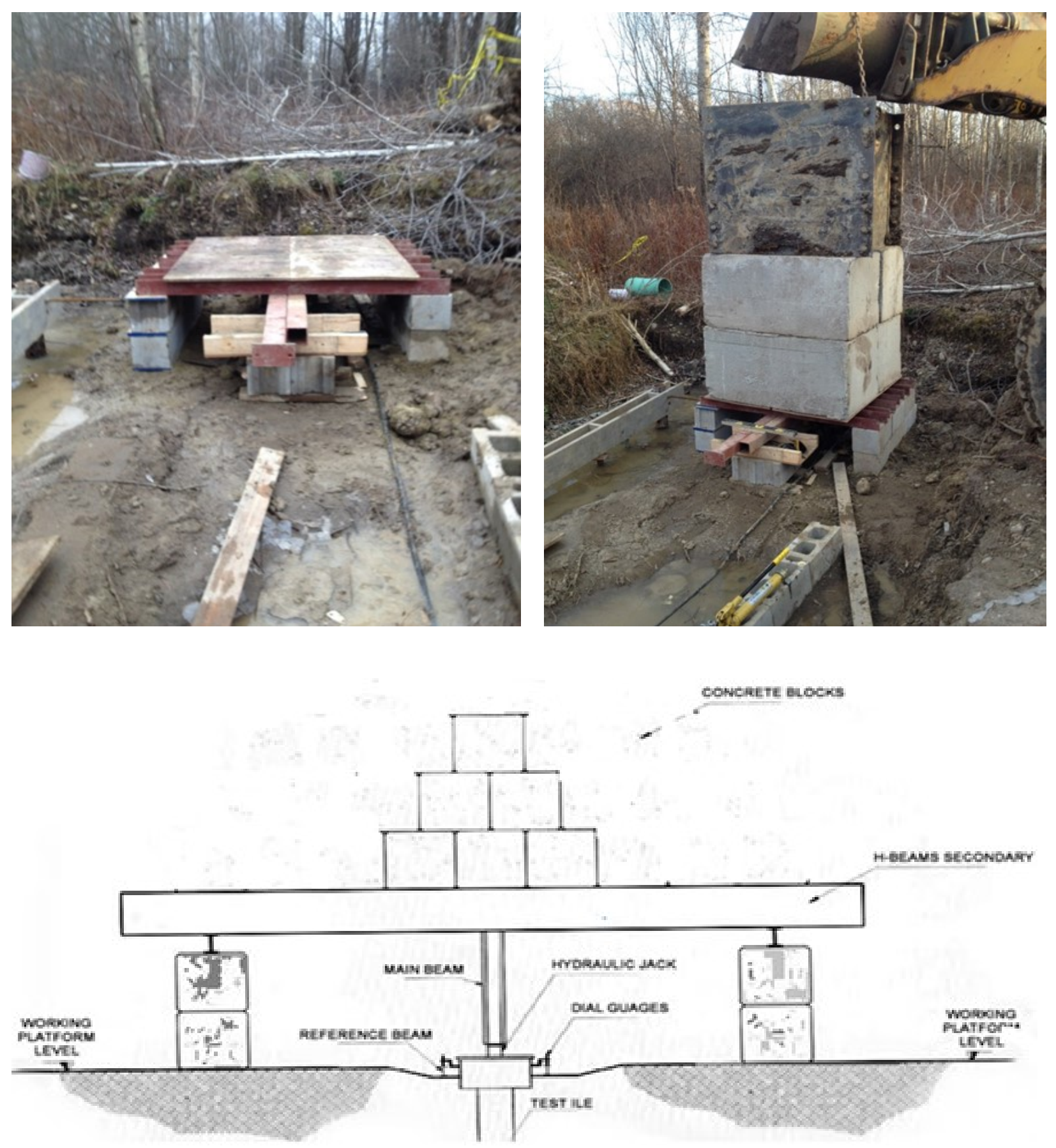

Figure 4.5: Test frame, reaction loads and schematic diagrams for static load test 


\subsubsection{Pile Load Tests}

The static compression maintained load test (MLT) was performed according to ASTM D1143 with a small modification on the duration of the time interval of the maintained load. The loading was applied using a hydraulically operated jack and a hydraulic calibrated pressure transducer. The applied force can be calculated by multiplying the recorded hydraulic pressure by the piston area of the jack. The piston area for the 21 -ton jack was $31 \mathrm{~cm}^{2}$. The load increment is shown in Table 4.2. The sequence of maintained loading and the minimum holding times for each load increment were as per the load chart mentioned below Table 4.2. The piles were loaded in two cycles: in the first cycle, the load increments were taken up to the estimated working load and in the second cycle the load was taken up to failure load.

Table4.2: The load increments used for pile load tests

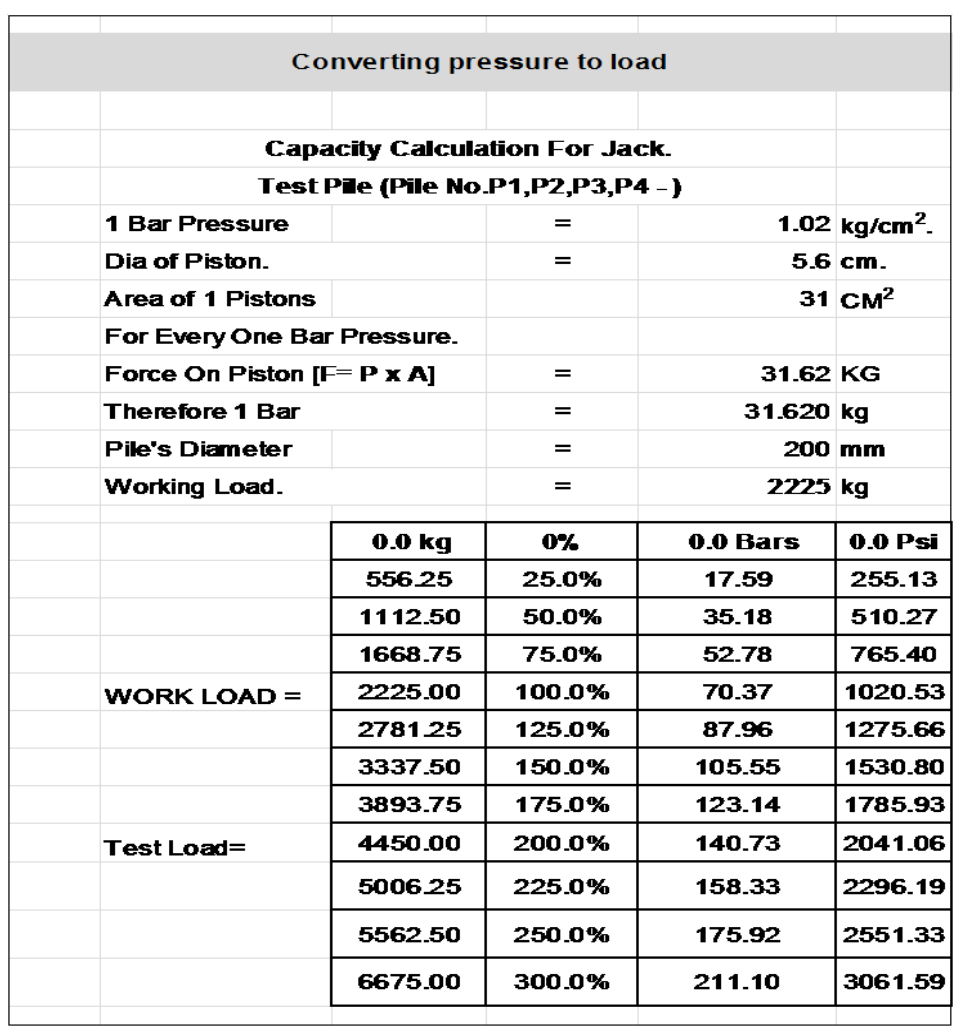


Table4.3: Pile test load chart

\begin{tabular}{lc} 
Loading $\%$ & loading time \\
\hline $25 \%$ & 10 minutes \\
50 & 10 minutes \\
75 & 10 minutes \\
100 & 30 minutes \\
75 & 5 minutes \\
50 & 5 minutes \\
25 & 5 minutes \\
0 & 10 minutes \\
100 & 30 minutes** \\
125 & 10 minutes \\
150 & 10 minutes \\
175 & 10 minutes \\
200 & 30 minutes* \\
150 & 5 minutes \\
125 & 5 minutes \\
100 & 5 minutes \\
50 & 5 minutes \\
0 & * Designated to estimated failure load \\
\multicolumn{2}{c}{}
\end{tabular}

Two micrometers capable of reading to $0.01 \mathrm{~mm}$ were used to record the pile settlement. The micrometers were attached with their tips resting on the pile head and the base micrometer was placed on the datum beams supported at least 1.2 meters (6d) (BS 8004) away from the test pile to avoid any loading influence. The failure criteria used to determine ultimate pile capacity was pile resistance at pile head displacement of $10 \%$ pile diameter according to "BS 8004 " or the load at which the settlement continues to increase without any further increase of load. For the piles tested here, the failure occurred before reaching the settlement of $10 \%$ of the pile diameter. 


\subsection{PILE LOAD TEST RESULTS}

This section presents the results of axial compression static load tests conducted on 4 piles installed in clay soil. As mentioned earlier the pile load tests were conducted in two stages. In the first stage, the piles were loaded up to their design load capacity equivalent to $22 \mathrm{kN}$. The design load was achieved by estimating the ultimate load capacity of the cast-in-place piles and dividing it by a factor of safety of 1.5 . The load-settlement curves for tests in stage 1 was used to compare the results of the hooked and unhooked piles at load test equal to the pile working load. In the second stage (stage 2), the piles were loaded up to their failure bearing capacity. This failure load was varied from $35 \mathrm{kN}$ for convenient cast-in-place pile to more than $53 \mathrm{kN}$ for the modified pile with 7 hooks. As it is evident from the results, the hook implementation has significantly increased the load carrying capacity of the piles tested here. Considering the undrained shear strength parameters of the soil (Table 4.1) and pile dimensions ( $\mathrm{L}=1.2 \mathrm{~m}$, $\mathrm{D}=0.2 \mathrm{~m}$ ), the bearing capacity of model piles used here would be about $43.6 \mathrm{kN}$ as per the theoretical equations discussed in section 4.2 .

\subsubsection{Results for Static Pile Load Test Conventional Pile (P1)}

A maintained static compression load increment test was conducted on pile P1 to evaluate the performance of the cast-in-place piles without hook and their conformance with design theoretical calculations. Figure 4.6 shows the load-displacement curves for pile P1 under both stage loadings. Under the working load test, the pile reached a maximum capacity of about $22 \mathrm{kN}$ at a displacement of $2 \mathrm{~mm}$. For the failure load test, the ultimate bearing capacity of $36 \mathrm{kN}$ was 
achieved at the displacement of $12 \mathrm{~mm}$. The obtained result at failure load test shows that the pile capacity calculated theoretically is almost the same as the failure load with a deviation of $1 \%$.

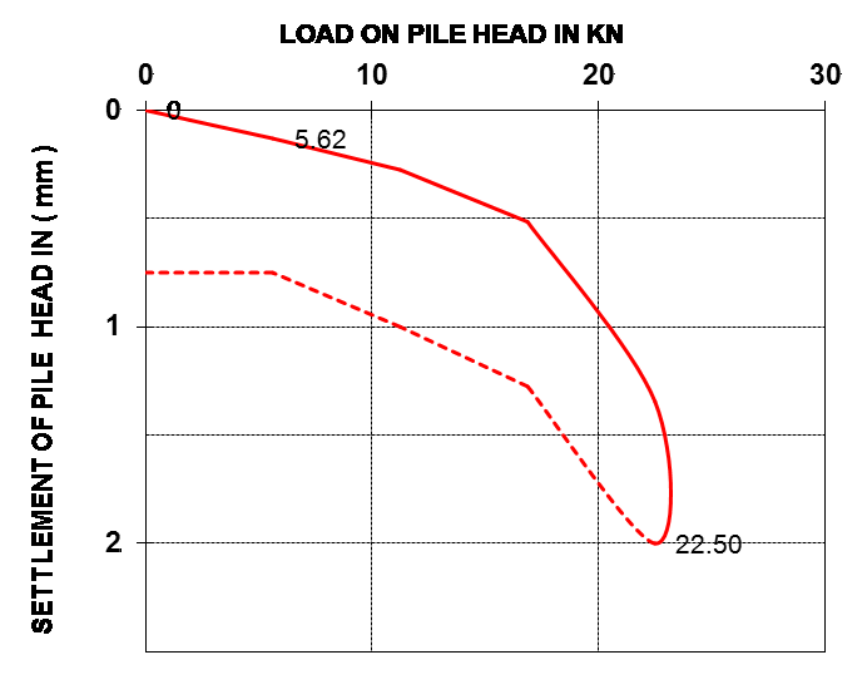

a)

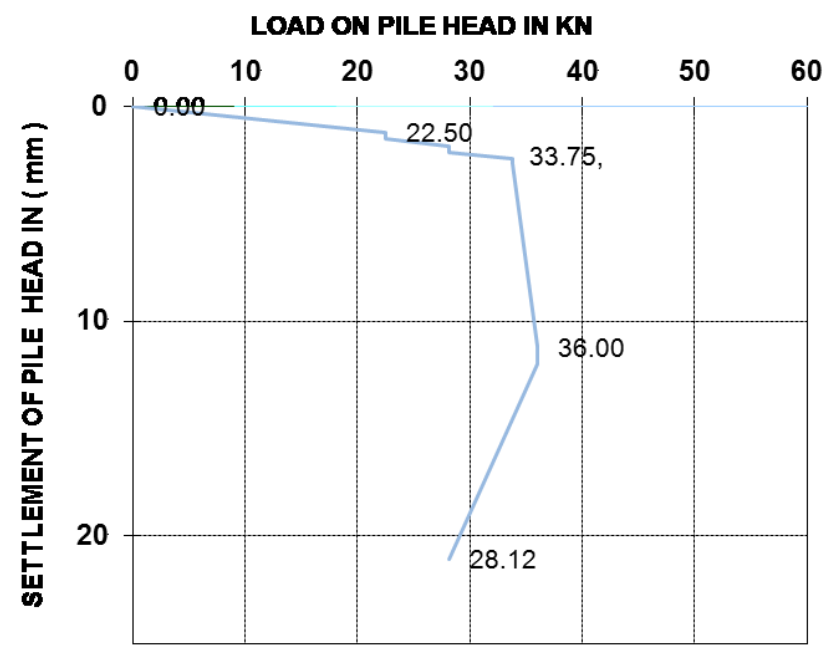

b)

Figure 4.6: a) Diagram of static load test up to working load for P1 (without hook), b) Diagram of static load test up to failure load for P1 (without hook)

\subsubsection{Results for Static Pile Compression Load Test on Modified Pile with 5 hooks (P3)}

Figure 4.7(a) illustrates the load-settlement behaviour for the hooked pile P3 (5 hooks) at design load state. The range of the Settlement for this hooked pile was shown to be negligible (less than $0.1 \mathrm{~mm}$ ) under the design load. This indicates the role of the hooks in improving the load carrying capacity and reducing the displacement of the pile, which could be related to the fusion and clutching between the hooks and the surrounding soils. Only a small movement of 0.01 was required in order to create a full suspension and total fixation of the hooks under the design working load. Figure 4.7(b) shows the load-settlement curve of pile P3 (5 hooks) under the failure load application. When subjected to axial compression at failure load, an ultimate bearing capacity of $50 \mathrm{kN}$ was achieved under a downward settlement of $5 \mathrm{~mm}$, the limit where the hooks had no 
more effect and lost its clutching phenomenon. This behaviour shows that implementing 5 hooks has increased the pile capacity from $36 \mathrm{kN}$ to $50 \mathrm{kN}$ while reducing the failure settlement from 12 $\mathrm{mm}$ to $5 \mathrm{~mm}$.

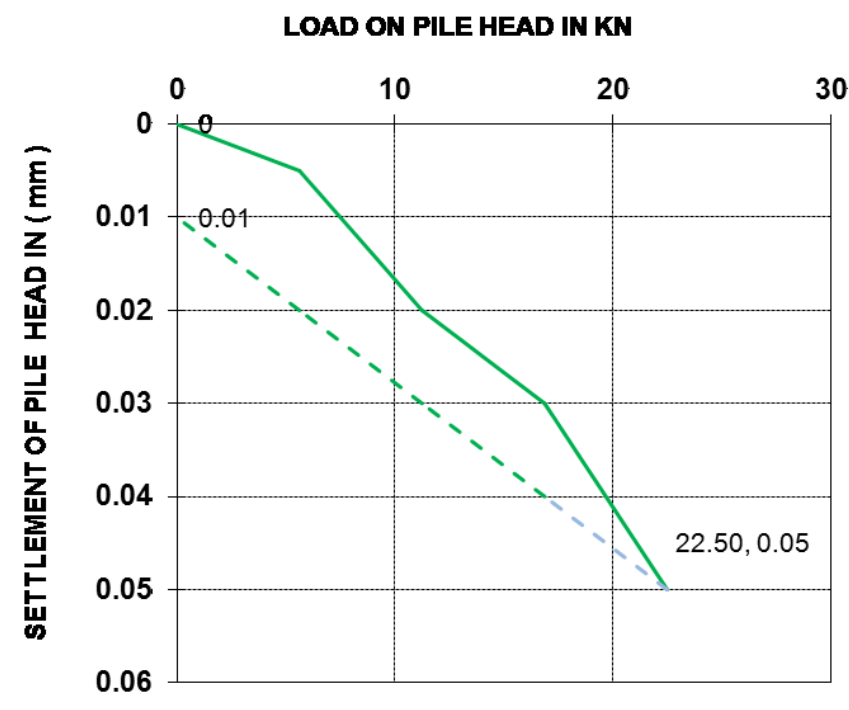

a)
LOAD ON PILE HEAD IN KN

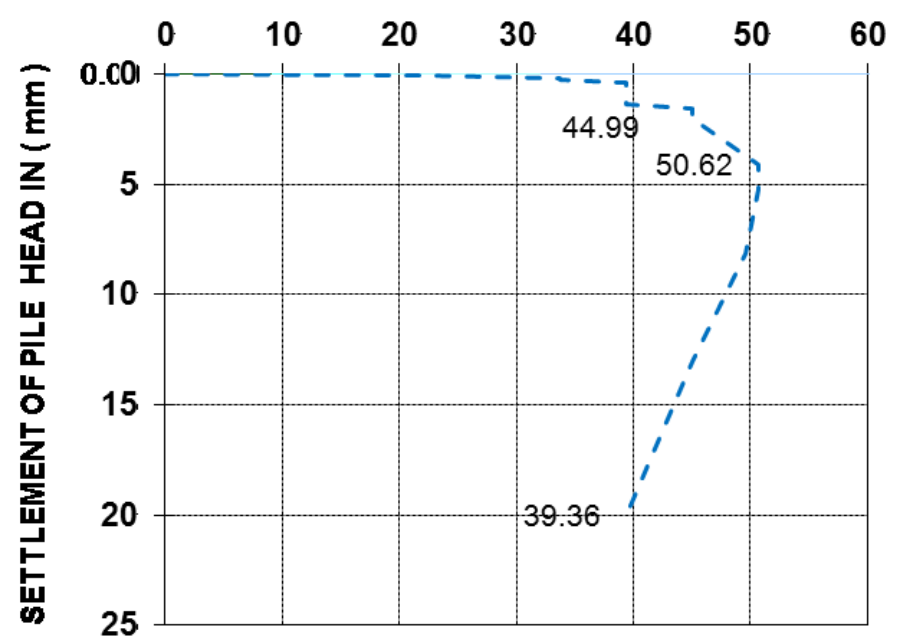

b)

Figure 4.7: Load-settlement curves for Pile 3 under the design load (a) and failure load test (b)

\subsubsection{Results for Static Pile Compression Load Test on Modified Pile with 7 hooks (P2)}

Figure 4.8 shows the load-settlement curves for the hooked pile P2 modified with 7 hooks under both design load and failure load conditions. The design load was achieved at a displacement of about $0.03 \mathrm{~mm}$, and upon removal of the load the load-settlement curves moved back to zero leading to no residual settlement. This shows that the pile behaviour under the design load was fully in elastic range and no plastic stress-strain behaviour was observed. This indicates the significant load transfer improvement of the pile when 7 hooks were added to the shaft of the pile. Under the failure load test condition, the reaction load of about $53 \mathrm{kN}$ was not sufficient to 
fail the pile. A bearing capacity of $53 \mathrm{kN}$ was achieved at a small settlement of $1.2 \mathrm{~mm}$, and up on the removal of the load a residual movement of less than $1 \mathrm{~mm}$ was recorded. This indicates that the ultimate bearing capacity has significantly been enhanced when 7 hooks were implemented on the pile. The observed behavior of this pile under axial loading showed that at working load the pile experienced no displacement after releasing the load and it was not failed under a load of 53 $\mathrm{kN}$.

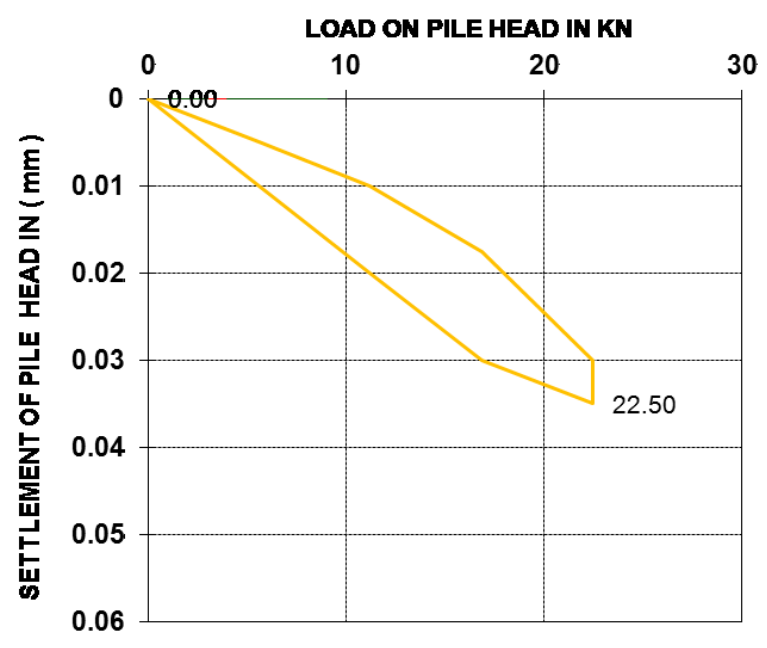

a)

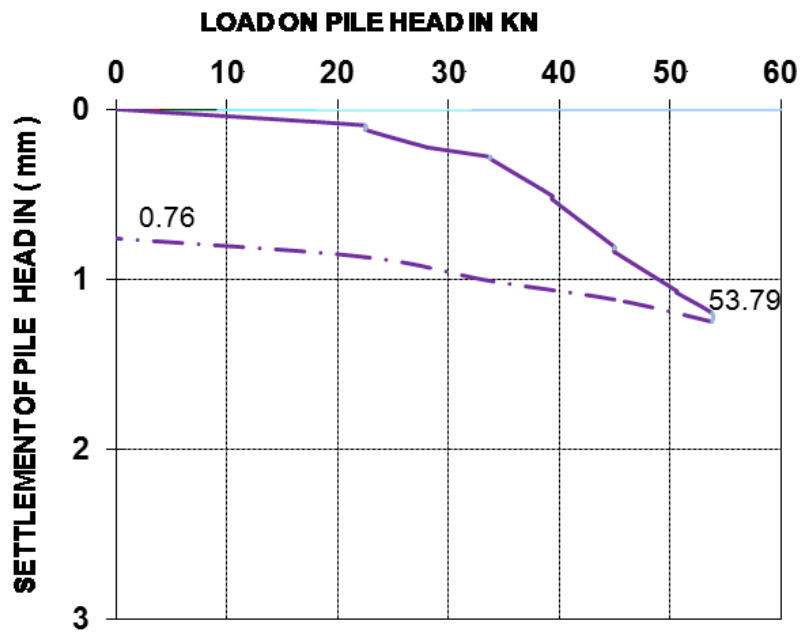

b)

Figure 4.8: Load-settlement curves for Pile 2 under the design load (a) and failure load test (b)

\subsection{ANALYSIS AND DISCUSSION}

\subsubsection{Repeatability of Results}

In order to evaluate the repeatability of the test results, two identical piles (P3 and P4) with 5 hookes embeded on their shaft was studied. Figure 4.9 shows the load-settlement of the two piles under failure load conditions. As it is evident from the curves, both piles showed a similar 
behaviour under pile load test. $\mathrm{P} 3$ reached a maximum bearing capacity of $50 \mathrm{kN}$ at a settlement of $4.95 \mathrm{~mm}$, while $\mathrm{P} 4$ showed an ultimate load capacity of about $50.5 \mathrm{kPa}$ at a settlement value of $5.09 \mathrm{~mm}$. The difference in the results between P3 and P4 under axial compression static load test up to failure load was found to be $0.5 \mathrm{kN}$ and a settlement difference of $0.1 \mathrm{~mm}$.
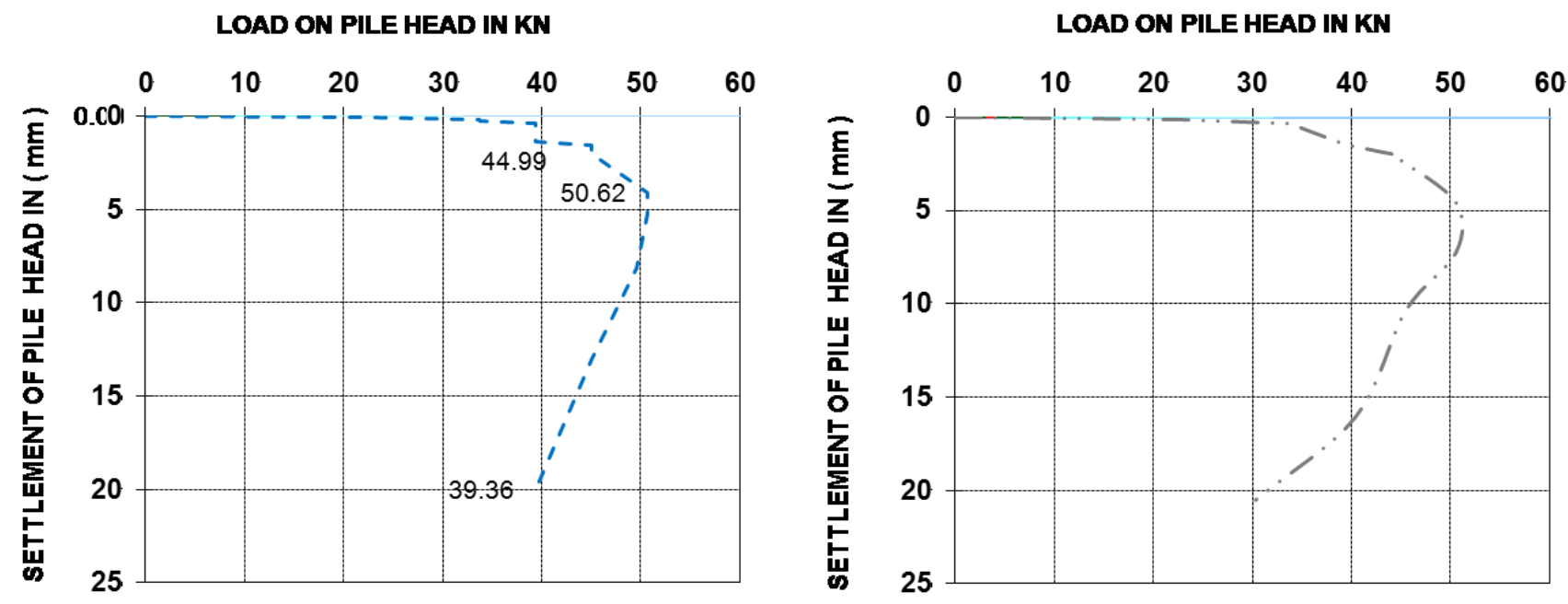

a) P3

b) P4

LOAD ON PILE HEAD IN KN

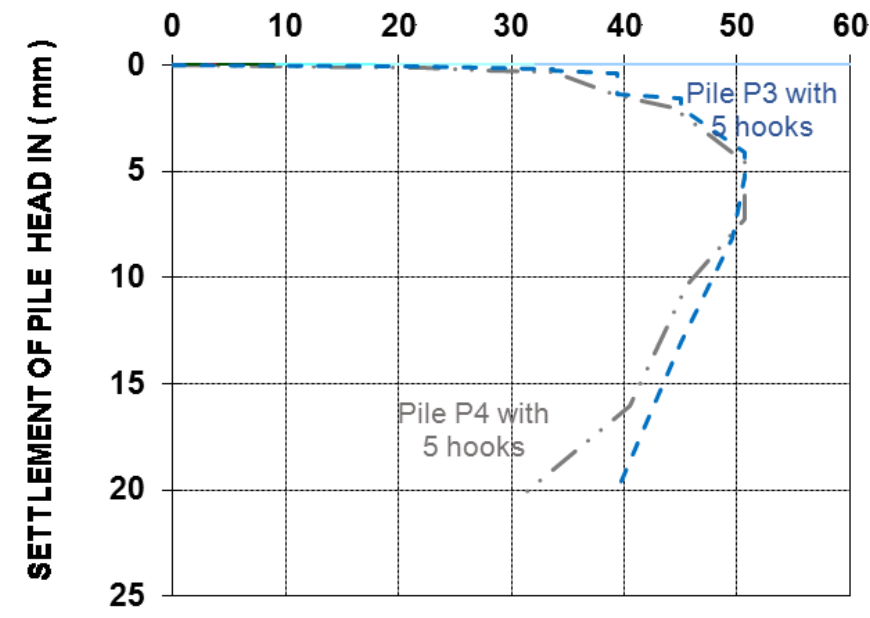

c)

Figure 4.9: Load-settlement curves for piles $\mathrm{P} 3$ and $\mathrm{P} 4$ under failure load tests 


\subsubsection{Effect of the Hook on the Shaft Resistance of the Piles}

The pile-soil interface resistance is normally developed by the shear strength at the interface of concrete and the soil. In the hooked pile, the interface resistance will also be affected by the hook provision, which creates a passive zone developed from the contribution of many hooks distributed in a way not to disturb the shaft extremities of the soil. The load-settlement curves for the piles with hooks (P3) and without hook (P1) are shown in Figure 4.10. As it is evident from the graph, the ultimate pile capacity at a $5 \mathrm{~mm}$ displacement has significantly increased from about $32 \mathrm{kN}$ for the convenient cast-in-place pile to $50 \mathrm{kN}$ when 5 hooks were implemented in the shaft of the pile. On the other hand, the conventional cast-in-place pile has experienced a settlement of about $12 \mathrm{~mm}$ prior to failure, while the modified pile did not experience any considerable movement considering the same load of P1 $(0.05 \mathrm{~mm})$ due to the existence of the passive hook zone surrounding the shaft. The existence of the hooks in P3 developed extra resistance of over $14 \mathrm{kN}$ and minimized the movement of the pile. 
LOAD ON PILE HEAD IN KN

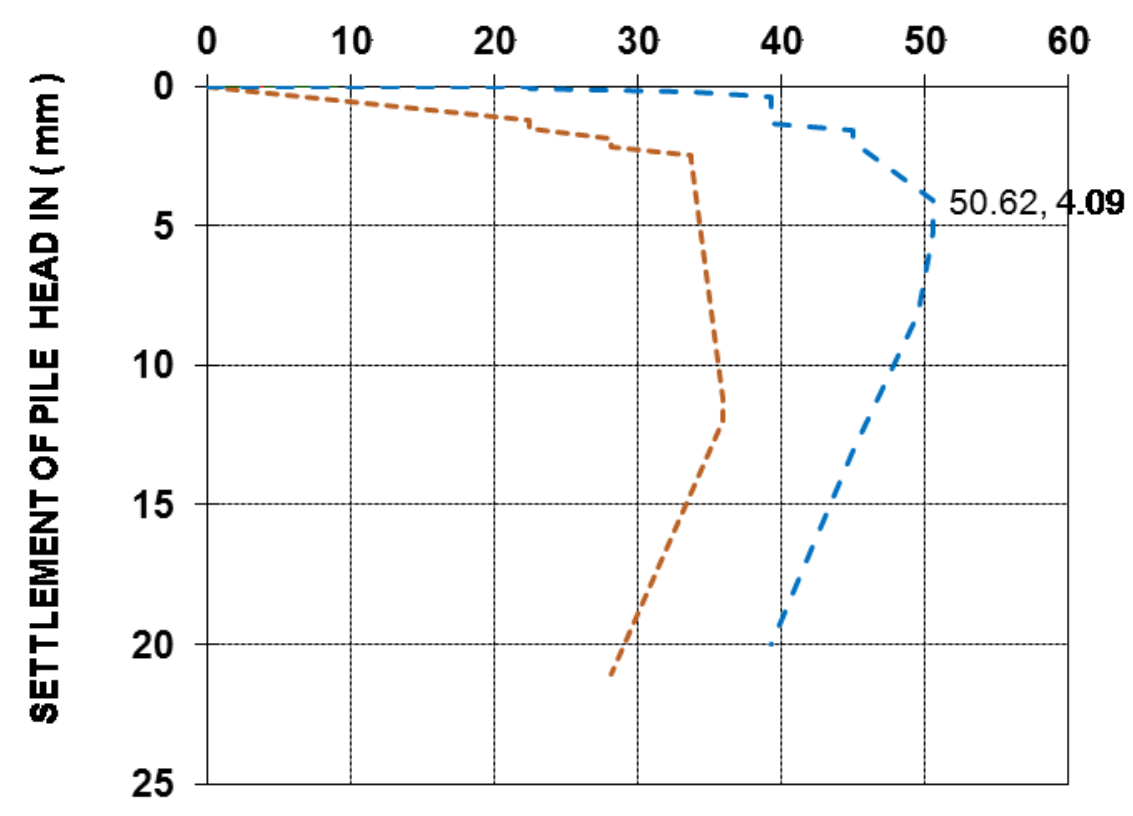

Figure 4.10: Results of axial compression static load test up to failure load for P1\&P3 (5hooks)

\subsubsection{Effect of the Number of Hooks on Pile Bearing Capacity}

In order to investigate the effect of number of hooks installed on the perimeter of the pile on load carrying capacity of the pile, results from pile number 2 (P2) with 7 hooks are compared with P3 with 5 hooks around its shaft. Figure 4.11(a) compares the result of pile load tests conducted on both piles when subjected to design working load of $22 \mathrm{kN}$. The pile head total settlement was reduced from $0.05 \mathrm{~mm}$ for the pile with 5 hooks to $0.03 \mathrm{~mm}$ when 7 hooks were used around the pile.

Figure 5.11(b) compares the ultimate load capacity of piles with 5 and 7 hooks. The maximum settlement of the pile with 5 hooks prior to the failure was about $5 \mathrm{~mm}$. This settlement was dropped to less than $0.76 \mathrm{~mm}$ when the number of hooks increased from 5 to 7 . From bearing capacity perspective, $\mathrm{P} 3$ has shown an ultimate bearing capacity of $50 \mathrm{kN}$, while the ultimate 
capacity of P2 was more than $53 \mathrm{kN}$. It should be noted that the real ultimate capacity of this pile would be higher than the $53 \mathrm{kN}$ measured here, as it was more than the weight of the dead load used for pile load test. This indicates that the contribution of extra two hooks played a major role in increasing the passive resistance of the pile as the spacing between the hooks is decreased and the effective zone of the passive resistance is increased. The plotted curves in Figure 4.11-b demonstrates the improvement of the hooked pile when increasing the number of the hooks for the reasons mentioned earlier in this text.

LOAD ON PILE HEAD IN KN

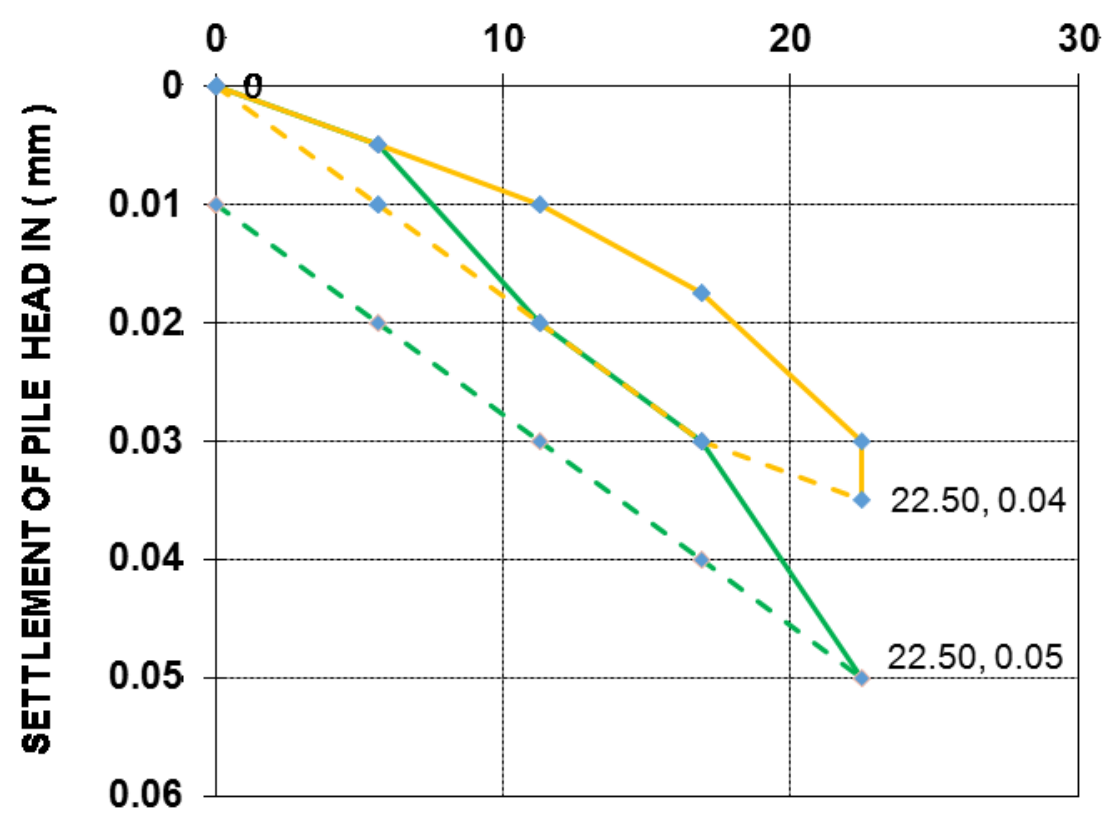

a) 


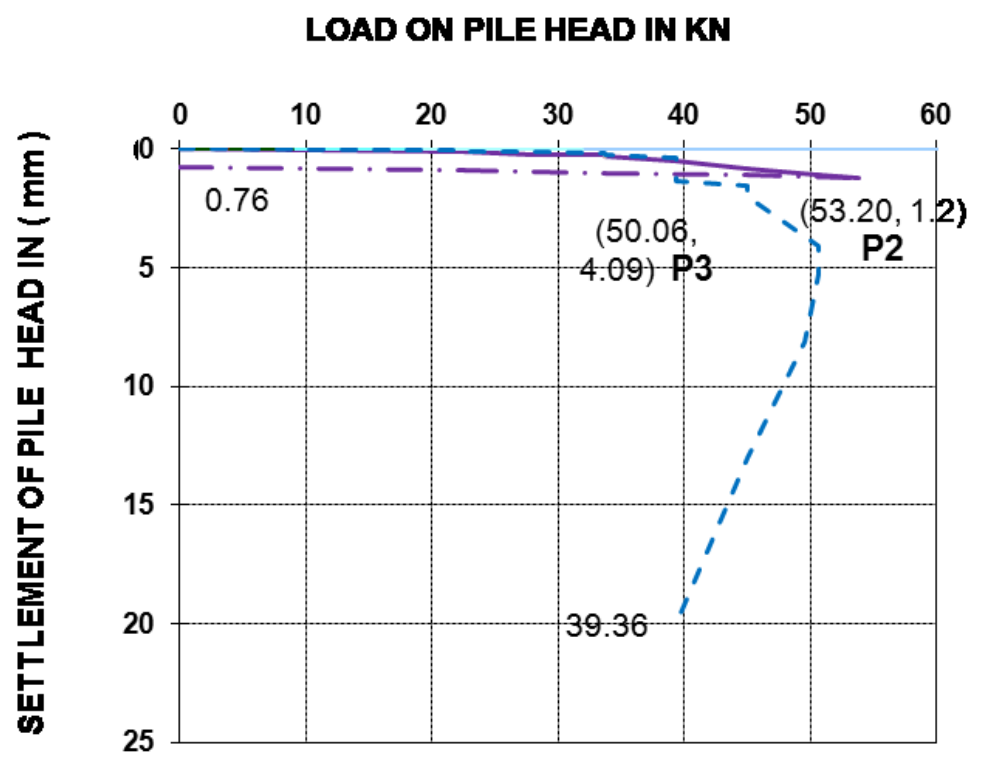

b)

Figure 4.11: a) Load-settlement curves at Working load for piles with 5and 7 hooks (P3) \& (P2)

b) Load-settlement curves at failure load for piles with 5and 7 hooks (P3) \& (P2)

\subsection{PERFORMANCE OF HOOKED PILE INTERFACE IN CLAY}

In order to investigate the effect of hooks on pile-soil interface behaviour, the interface resistance of plain concrete used in cast-in-place piles as well as the hooked concrete-soil interface is discussed here. As mentioned in section 4.2, the interface resistance of the hooked piles would be provided by the concrete-soil interface strength and the hook-soil resistance. This can be summarized as the following equation:

$$
\begin{gathered}
q_{f}=q_{c}+q_{\text {hooks }}=+\alpha C_{u}+\alpha_{h} C_{u} \\
Q_{\text {hook }}=q_{f} \pi d L=\left(q_{c}+\alpha_{h} C_{u}\right) \pi d L_{-}
\end{gathered}
$$


where $q_{f}$ is the ultimate lateral capacity of the pile, $q_{\text {hooks }}$ represents the shear resistance resulted from the contributions of the hooks passive reactions, and $q_{c}$ represent the concrete-soil interface strength. $\mathrm{Cu}$ is the soil undrained shear strength, and $\alpha$ is an empirical adhesion factor accounting for pile-soil adhesion, and $\alpha_{\mathrm{h}}$ represents the hook contribution in adhesion along the shaft. Considering the fact that a layer of sponge was placed under the toe of the pile, the measured bearing capacities here were assumed to be equal to the shaft bearing capacity of the piles. With this assumption the $\alpha$ value for the plain concrete pile (P1) can be calculated as follow:

$$
Q_{\text {plain concrete }}=\alpha_{p} C_{u p} \pi d L \quad \alpha=\frac{Q_{f}}{\pi \cdot d \cdot L \cdot C_{u}}
$$

where $\mathrm{Q}_{\mathrm{f}}$ is the measured bearing capacity in $\mathrm{kN}, \mathrm{L}$ is the pile length and $\mathrm{d}$ is pile diameter. Considering the soil undrained shear strength (Table 4.1) and pile dimensions, the $\alpha$ value would be about 0.95 , which is slightly higher than the values used for the design (0.9) in these types of soils. Using a similar assumption the interface friction angle provided by the hooks can be estimated as follow:

$$
\alpha_{\mathrm{h}}=\frac{Q_{f}-\alpha C_{u} \pi \cdot d \cdot L}{C_{u} \pi \cdot d \cdot L}
$$

The effect of hooks on pile-soil interface strength can also be investigated based on the results from direct shear tests discussed in Chapter 3. The shear strength parameters achieved from direct shear tests in laboratory and shear parameters produced from field compression static load tests locations are summarized in Table 4.4. The increase in interface apparent adhesion for the hooked piles estimated through comparison of the adhesion relative to the plain concrete in the direct shear tests that was estimated to be about $38 \%$ under undrained loading. The similar ratio was used here to estimate the rate of increase in apparent adhesion of the hooked piles (Table 4.4). 
Comparing the field pile static load test results for plain and hooked pile by substituting the values of the tests load results Qhook, $Q_{\text {plain, }}$ and using the hook contribution ratio obtained from the laboratory direct shear tests, the hook contribution qhook can be estimated as follow:

$$
\text { Hook contribution }=\frac{\alpha_{h} C_{u h}+\alpha_{p} C_{u p}}{\alpha_{p} C_{u p}}=\frac{P_{h}}{P_{p}}
$$

Since $C_{u h}=C_{u p}$, therefore, assuming $\alpha_{p}=1$ the apparent adhesion coefficient contributed by the hooks can be estimated as:

$$
\alpha_{h}=\frac{P_{h}}{P_{p}} \alpha_{p}-\alpha_{p}=\alpha_{p}\left(\frac{P_{h}}{P_{p}}-1\right)
$$

The apparent friction equation of the pile shaft with hook $=$

$$
Q_{\text {hooked }}=\left(\alpha_{p}+\alpha_{h}\right) C_{u p} \pi d L
$$

Considering the results of the hooks contribution in the interface direct shear test in laboratory, a similar rate of increase was observed in the pile load tests. Considering the rate of increase in shaft capacity for P3 with 5 hooks and P1 without hook $(50 \mathrm{kN}-36 \mathrm{kN})$, the normalized increase in pile shaft capacity would be proportionally related to the number of the hooks. These observations demonstrate that hooked piles would improve the shaft capacity of cast-in-place piles in clayey soils. More investigation is required to draw the contribution of both the apparent adhesion and friction coefficient in the hooked pile capacity. 
Table 4.4: Interface shear strength parameters for concrete/clay at field tests

\begin{tabular}{|l|c|c|c|c|c|}
\hline \multicolumn{1}{|c|}{ Interface } & Test location & ca (kPa) & $\alpha$ plain & $\alpha$ hook & $\alpha \mathbf{p}+\alpha \mathbf{h}$ \\
\hline Plain concrete & Direct shear test & 19 & 0.45 & - & 0.45 \\
\hline Hooked concrete & Direct shear test & $19+15^{*}$ & & 0.8 & 0.8 \\
\hline Plain concrete P1(0) & Field static load test & 46 & 0.95 & - & 0.95 \\
\hline Hooked concrete P2(7) & Field static load test & $46+24^{*}$ & 0.95 & 0.61 & 1.53 \\
\hline Hooked concrete P3(5) & Field static load test & $46+20^{*}$ & 0.95 & 0.53 & 1.44 \\
\hline Hooked concrete P4(5) & Field static load test & $46+20^{*}$ & 095 & 0.53 & 1.44 \\
\hline
\end{tabular}

$c_{a}=$ adhesion; $c_{u}=$ undrained cohesion; * Apparent adhesion contribution by the hooks

\subsection{SUMMARY}

Four different bored cast-in-place-piles were tested for axial compression static load tests 3 weeks after casting the piles. The mobilized shear strength parameters as well as piles ultimate capacities were summarised for evaluation. The following conclusions are highlighted below.

1- The ultimate capacity of the plain concrete pile measured here is almost equivalent to those estimated using conventional theoretical equations used for pile design in clay soils.

2- The inclusion of 5 hooks in the pile $\mathrm{P} 3$ increased the ultimate bearing plain concrete piles by about $14 \mathrm{kN}$, which represents a ratio of over $38 \%$ of the original pile capacity.

3- The presence of the hooks demonstrated a better performance of the pile in terms of displacement. Implementing 5 hooks in the cast-in-place pile (P3) reduced the residual settlement of the pile under the design working load from $0.75 \mathrm{~mm}$ to $0.01 \mathrm{~mm}$, which demonstrates a significant improvement in the ratio of fixation, 18 times less settlement compared to a pile without hooks. 
4- The shaft capacity increments in pile P2 compared to pile P3 showed that the pile shaft capacity may proportionally increase the passive resistance as the number of hooks increases. More investigation is required to find the optimum number of hooks as well as the influence area of the hooks. 


\section{CHAPTER 5}

\section{CONCLUSIONS AND RECOMMENDATIONS}

\subsection{SAMMARY AND CONCLUSIONS}

Cast-in-place pile with hook system is a new technique emitted by the need for new ways to strengthen the pile foundations in piling industry. The pile-soil interface behavior is of particular interest in sands and clays where shaft resistance plays an important role in resisting the applied load. This interface strength could be lower in cast-in-place piles due to the implementation of drilling mud, cavities, and other defects caused by different drilling methods. The hook system induced in this study was shown to be an effective approach to improve the bonding and hence the interface resistance in cast-in-place piles. The hooks installed around the perimeter of the pile act as an anchoring system and minimize the shaft displacement.

The research goal was to elaborate the influence of steel hooks placed around the cage in the friction zone between the pile and surrounding materials on enhancement of the pile capacity. This was examined through two stages of studies using direct shear tests and pile load tests for clay soils. In the first stage, prefabricated plain concrete and hooked concrete surfaces were sheared against sand and undisturbed clay specimens in a direct shear box apparatus. These tests were used to evaluate the difference between shearing parameters of the plain and hooked concrete interface. In the second stage, static pile load tests were conducted on both traditional cast-in-place piles and the hooked piles with 5 and 7 hooks. These tests were used to evaluate the 
difference in the pile behavior in terms of capacity and its related settlement. The following conclusions could be drawn from this research.

- The interface strength obtained for pile-soil specimens was found to significantly increase when passive inclusions using two hooks were implemented. Residual apparent friction angle for concrete-sand interface increased from $22^{\circ}$ to $29.5^{\circ}$ when two hook elements were used at the pile-soil interface. And the residual apparent friction angle for concrete-clay interface increased from $1^{\circ}$ to $16^{\circ}$. This could be related to significant increase in surface roughness when hooks were placed at the pile-soil interface.

- Inclusion of 5 hooks in the pile P3 increased the ultimate bearing capacity plain concrete piles by about $14 \mathrm{kN}$, which represents a ratio of over $38 \%$ of the original pile capacity.

- The presence of the hooks demonstrated a better performance of the pile in terms of displacement. Implementing 5 hooks in the cast-in-place pile (P3) reduced the residual settlement of the pile under the design working load from $0.75 \mathrm{~mm}$ to $0.01 \mathrm{~mm}$, which demonstrates a significant improvement in the ratio of fixation, 18 times more than when using a pile without hooks.

- Addition of 2 more hooks ( $40 \%$ increment in the number of hooks) in pile P2 compared to pile P3 showed that the pile shaft capacity may proportionally increase the passive resistance as the number of hooks increase. More investigation is required to find the optimum number of hooks as well as the influence area of the hooks.

A consistent and harmonious result was achieved from this study as shown in the loading diagrams presented in Chapter 4. In addition, a proportionate relation could be achieved by 
continuing this research to find the optimum number of hooks in a square meter of shaft area. Ultimately, the presence of the hooks at the interface of the pile shaft will give the piling foundation a concept of a new performance in shearing resistance between concrete cast-in-place piles and the surrounding soils. The advantage this hook system is the creation of a reinforced anchoring element within the load supporting area, which provides ultimate stability of the pile in addition to its capacity. This research shows that the hook system can provides the pile designers with an opportunity to improve their design while reducing the cost of pilling.

\subsection{RECOMENDATIONS}

This study is a preliminary research program to explore the effect of the hook system on enhancement of pile shaft capacity in clay soils. This research can be extended to examine the hook performance in different ground materials and to illustrate the construction methods in different types of soils. Accuracy in the implementation and installation of the hooks in place will guarantee the efficiency of the system and its best performance. In order to apply the hook system in the design, a design methodology along with prediction of an empirical formula based on basic soil characteristics is required. The current research can also be expanded to develop such methodologies for the design of hooked piles. A control system will be required for the total anchoring of the hooks along with the borehole shaft of the soil. 


\section{REFERENCES}

AFSHIN, A. and RAYHANI, M. T., Characterization of Pile Capacity over Time in Leda Clay. Geotechnical and Geological Engineering, Under Review for Publication.

ASTM D422, 2007: Standard Test Method for Particle-Size Analysis of Soils, ASTM International, West Conshohocken, PA, 2007, DOI: 10.1520/D0422-63R07.

ASTM D1143, 2007: Standard Test Methods for Deep Foundations Under Static Axial Compressive Load, ASTM International, West Conshohocken, PA, 2007, DOI:10.1520/D1143_D1143M-07E01.

ASTM D2435/2435M, 2011: Standard Test Methods for One-Dimensional Consolidation Properties of Soils Using Incremental Loading. American Society for Testing and Materials.

ASTM D2487, 2011: Standard Practice for Classification of Soils for Engineering Purposes (Unified Soil Classification System), ASTM International, West Conshohocken, PA, 2011, DOI: 10.1520/D2487-11.

ASTM D2573, 2008: Standard Test Method for Field Vane Shear Test in Cohesive Soil, West, ASTM International, West Conshohocken, PA, 2008, DOI: 10.1520/D2573-08.

ASTM D3080/D3080M, 2011: Standard Test Method for Direct Shear Test of Soils Under 494 Consolidated Drained Conditions, Annual Book of ASTM Standards, ASTM International, 495. West Conshohocken, PA, 2012.

ASTM D4318, 2010. Standard Test Methods for Liquid Limit, Plastic Limit, and Plasticity Index of Soils, ASTM International, West Conshohocken, PA, 2010, DOI:10.1520/D4318-10

ASTM D4945, 2012: Standard Test Method for High-Strain Dynamic Testing of Deep Foundations, ASTM International, West Conshohocken, PA, 2012, DOI: $10.1520 / \mathrm{D} 494512$.

ASTM D698, 2012: Standard Test Methods for Laboratory Compaction Characteristics of Soil Using Standard Effort (12 $400 \mathrm{ft}-\mathrm{lbf} / \mathrm{ft} 3(600 \mathrm{kN}-\mathrm{m} / \mathrm{m} 3)$, ASTM International, West Conshohocken, PA, 2012, DOI:10.1520/D0698-12.

BEREZANTSEV, V. G. et al. Load bearing capacity and deformation of piled foundations, Proceedings of the 5th International Conference, ISSMFE, Paris, Vol. 2, 1961, pp. 11-12.

BERTERO, V. V. and CHOI, J., 1962. Chemically pre-stressed concrete hyperbolic paraboloid shell model. Proceedings, International Association for Shell Structures, World Conference on Shell Structures, San Francisco, CA, pp. 145- 158 
BERTERO, V. V. and IRAGORRY MONTERO, G. J. 1964. Pre-cast chemically prestressed concrete frames. SESM Report No. 63-4, Department of Civil Engineering, University of California, Berkeley, CA, $25 \mathrm{p}$.

BLANCHET, R., TAVENAS, F., GARNEAU, R., 1980. Canadian Geotechnical Journal, 17(2): 203-224, 10.1139/t80-02

BOWLES, J. E., (1988), "Foundation Analysis and Deisgn", Fourth Ed., McGraw Hill Publishing Co., New York, $1004 \mathrm{p}$

BS 8004:1986, Section 7 Pile Foundations

BURLAND, J., 1973. Shaft Friction of Piles in Clay; A Simple Fundamental Approach. Ground Engineering, Foundation Publications Ltd., 6(3), pp. 30-42.

CANADIAN GEOTECHNICAL SOCIETY, 2007. Canadian Foundation Engineering Manual. 4th ed. Richmond, BC, BiTech Publishers Ltd.

CHU, L. M. and YIN, J. H., 2006. Study on soil-cement grout interface shear strength of soil nailing. Geomechanics and Geoengineering: An International Journal, 1(4), p. 259273

CODUTO, D. P., 2001. Foundation Design Principles and Practices. Upper Saddle River, New Jersey: Prentice-Hall, Inc. 2001.

CLOUGH G. W., DUNCAN J. M., 1971. Finite element analysis of retaining wall behavior [J]. Journal of the Soil Mechanics and Foundations Division, ASCE, 1971, 97(12): $1657-1672$.

FLEMING, W. G. K. and SIMPSON, B., 1988. Introducers to Informal Discussion on auger-injected piles, Proceedings of the Institution of Civil Engineers, Vol. 84, No. 1, 1988, pp. 1316-19.

FLEMING, W. G. K. and SLIWINSKI, Z., 1977. The use and influence of bentonite in bored pile construction, Construction Industry, Research and Information Association (CIRIA), Report PG3, 1977.

FLEMING, W. G. K. , WELTMAN, A. J., RANDOLPH, M. F. and ELSON, W. K., Piling Engineering. Halsted Press; 2nd edition (January 6, 1992)

GIRALDO, J. and RAYHANI, M.T., (2014). Influence of FRP on pile-soil interface strength in soft clays. ASTM Journal of Advances in Civil Eng. Materials, 2(1): 1-18.

GOH, A. T. C. AND DONALD, I. B., 1984. Investigation of Soil-Concrete Interface by Simple Shear Apparatus. Perth, Australia, fourth Australia-New Zealand Conference on Geomechanics. 
HEALY, P.R. and WELTMAN, A.J., 1980. Survey of problems associated with the installation of displacement piles. Construction Industry Research and Information Association (CIRA), London, Report PG8, 1980.

HOBBS, N. B. and ROBINS, P. 1976. Compression and tension tests on driven piles in chalk, Geotechnique, Vol. 26 (1), 1976, pp. 33- 46.

HORVATH, R. G., 1983. Department of Civil Engineering and Engineering Mechanics, McMaster University, Hamilton, Ont., Canada L8S 4L7, Report accepted July11, 1983

HORVATH, R.G., 1978. Field load test data on concrete-to-rock bond strength for drilled pier foundations, University of Toronto, publication 78-07, 1978

JOHNSTON, I. W., LAM, T. S. K. AND WILLIAMS, A. F., 1987. Constant Normal Stiffness Direct Shear Testing for Socketed Pile Design in Weak Rock. Geotechnique, 37(1), pp. 83-89.

KISHIDA, H. 1. and UESEGUI, H., 1987. Tests of the interface between sand and steel in simple shear apparatus. Geotechnique, 37(1), pp. 45-52.

KULHAWY, F. H. and GOODMAN, R. E., 1980. Design of Foundations on Discontinuous Rock, Proceedings of the International Conference on Structural Foundations on Rock, Sydney, 1980, Vol. 1, pp. 209-20

KULHAWY, F.H., 1984. Limiting tip and side resistance, fact or fallacy, Symposium on Analysis and Design of Pile Foundations, American Society of Civil Engineers, San Francisco. Proceedings, pp. 80-98.

KULHAWY, F.H. and GOODMAN, R.E., 1987. Foundations in rock, chapter 15 of Ground Engineering Reference Book, ed. F.G. BELL, Butterworth, London, 1987

MEYERHOF, G.G., 1976. Bearing Capacity and Settlement of pile Foundations. Proceedings of the American Society of Civil Engineers, GT3, March 1976, pp. 197-228.

MEYERHOF, G. G. and MURDOCK, L. J., 1953. An investigation of the bearing capacity of some bored and driven piles in London Clay, Geotechnique, Vol. 3, No. 7, 1953, pp. 267-82.

MEYERHOF, G. G., 1992. Various authors, Proceedings of the conference on recent large-scale fully-instrumented pile test in clay, Institution of Civil Engineers, London, 1992.

LEMOS, L. J. L. and VAUGHAN, P. R., 2000. Clay-Interface Shear Resistance. Geotechnique, 50(1), pp. 55-64.

LUPINI, J. F., SKINNER, A. E. and VAUGHAN, P. R., 1981. Drained Residual Strength of Cohesive Soils. Geotechnique, 31(2), pp. 181-213. 
O'ROURKE, T. D., DRUSCHE, 1. S. J. and NETRAVALI, A. N., 1990. Shear Strength Characteristics of Sand-Polymer Interfaces. Journal of Geotechnical Engineering, 116(3), pp. 451-469.

OSTERBERG. J. 0. and GILL, S. A., 1973. Load transfer mechanism for piers socketed in hard soils or rock. Proc. 9th Can. Syrnp. on Rock Mechanics, Montreal, P.Q., pp. 235262.

OVANDO-SHELLEY, E., 1995. Direct shear tests on Mexico City clay with reference to friction pile behaviour. Geotechnical and Geological Engineering, 13, pp. 1-16

PELLS, P.J.N. and TURNER, R.M., 1979. Elastic solutions for design and analysis of rock socketed piles, Canadian Geotechnical Journal, Vol. 16, pp. 481-7.

PELLS, P.J.N. and TURNER, R.M. 1980. End bearing on rock with particular reference to sandstone, Proceedings of the International Conference on Structural Foundations on Rock. Sydney, 1980, Vol. 1, pp. 181-90.

PECK, R. B. 1958. A study of the comparative behavior of friction piles. Highw. Res. Spec. Rep. 36, 1-78.

PECK, R. B., HANSON, W. E. and THORNBURN, T. H,. 1974. Foundation Engineering, 2nd edition, John Wiley, New York, 1974.

POTYONDY, J. G., 1961. Skin friction between various soils and interface and construction materials. Geotechnique, 11(4), pp. 3-18.

POULOS, H. G. and DAVIS, E. H., 1980. Pile Foundation Analysis and Design. New York: John Wiley and Sons, Inc, 1980

POULOS, H.G., 1989. Pile Behaviour-Theory and Application, Geotechnique, Vol. 39 (3), 1989, pp. 365-415

RANDOLPH, M. F. and WROTH, C. P., 1982. Recent developments in understanding the axial capacity of piles in clay, Ground Engineering, Vol. 15, No. 7, 1982, pp. 17-25.

ROSENBERG, P. and JOURNEAUX, N.L., 1976. Friction and end bearing tests on bedrock for high capacity socket design, Canadian Geotechnical Journal, Vol. 13, 1976, pp. 324-33

RAO, K. and VENKATESH, K., 1985. Uplift Behaviour of Short Piles in Uniform Sand. Soils and Fountations - Japanese Society of Soil Mechanics and Foundation Engineering, 25(4), pp. 1-7.

SHEIKH, S. A. 1974. Expanding cement and its application. M. A.Sc. thesis, Department of Civil Engineering, University of Toronto, Toronto, Ont. 
TIMUSK, J., and SHEIKH, S. A. 1977. Expansive cement jacks. Journal of the American Concrete Institute, 74(2), pp. 80-85.

SHEIKH, S. A., O'NEIL M. W. and MEHRAZARIN, M. A., 1984. Department of Civil Engineering, Universe of Housfon-Universify Park, Housfon, TX 77004, U.S.A. Received March 9, 1984

SHERWOOD, D. E. and MITCHELL, J. M., 1989. Base grouted piles in Thanet Sands, London, Proceedings of the International Conference on Piling and Deep Foundations, London, Vol. 1, pp. 463-72, Balkema, Rotterdam, 1989.

SILVESTRI, V., KARAM, G., TONTHAT, A. and ST-AMOUR, Y., 1989. Direct and Simple Shear Testing of Two Canadian Sensitive Clays. Geotechnical Testing Journal, 12(1), pp. 1121.

SKEMPTON, A. W., 1951. The bearing capacity of clays. Building Research Congress, pp. Div. I, pp. 180.

SKEMPTON, A. W., 1964. Long term stability of clay slopes. Geotechnique, 14(2), pp. 77-102.

ST JOHN, H. D., RANDOLPH, M. F., MCAVOY, R. P., and GAL-LAGHER, K. A. 1983. The design of piles for tethered platforms. Proceedings of the Conference on the Design and Construction of Offshore Structures. Institution of Civil Engineers, London, 1983. pp. 53-64.

STARK, T. and EID, H. T., 1994. Drained Residual Strength of Cohesive Soils. Journal of Geotechnical Engineering, 120(5), pp. 856-871.

TAHA, A. M., 2010. Interface Shear Behaviour of Sensitive Marine Clay - Leda Clay. Thesis, University of Ottawa, Ottawa, Ontario, Canada.

TAVANAS, F. A., 1971. Load Test Results on friction pile in sand, Canadian Geotechnical Journal. (Vol 8). 221-226.

TAYLOR, P. T., 1966. Age effect on shaft resistance and effect of loading rate on Load Distribution of Bored Piles, Ph.D. Thesis, University of Sheffield, October 1966.

THORBURN, S. and THORBURN, J. Q., 1977. Review of problems associated with the construction of cast-in-place concrete piles, Construction Industry Research and Information Association (CIRIA), London, Report PG2, 1977.

TOMLINSON. M. J., 1957. The adhesion of piles driven in clay soils. Proceedings, Fourth International Conference on Soil Mechanics and Foundation Engineering, London, Vol. 2, pp. 66-71. 
TOMLINSON, M. J., 1994. Pile Design and Construction Practice. New York: E \& FN Spon, an Imprint of Chapman \& Hall, $4^{\text {th }}$ Edition, 1994

TOMLINSON M. J. with contributions by R. Boorman, 1995. Foundation Design and Construction. Harlow, England, Addison Wesley Longman Ltd, 1995.

VESIC, A., 1977. Design of Pile Foundations - Synthesis of Highway Practice No. 42.Transportation Research Board - National Cooperative Highway Research Program. Washington.

WELTMAN, A. J. and HEALY, P. R., 1978. Piling in 'Boulder Clay' and other glacial tills, Construction Industry Research and Information Association (CIRIA), Report PG5, 1978

WILLIAMS, A. F. and PELLS, P. J. N., 1981. Side resistance rock sockets in sandstone, mudstone and shale, Canadian Geotechnical Journal, Vol. 18, 1981, pp. 502-13.

WYNNE, C.P. A., 1988. Review of Bearing Pile Types, Construction Industry Research and Information Association, Report PGI, 2nd edn, 1988.

YIN ZONG-ZE, ZHU HONG, XU GUO-HUA, 1994. Numerical Simulation of the Deformation in the Interface between Soil and Structural Material[J]. Chinese Journal of Geotechnical Engineering, 1994, 16(3): 14-22. (In Chinese) 


\section{APPENDIX A}

\section{Laboratory shear box and Pile load field tests photos}

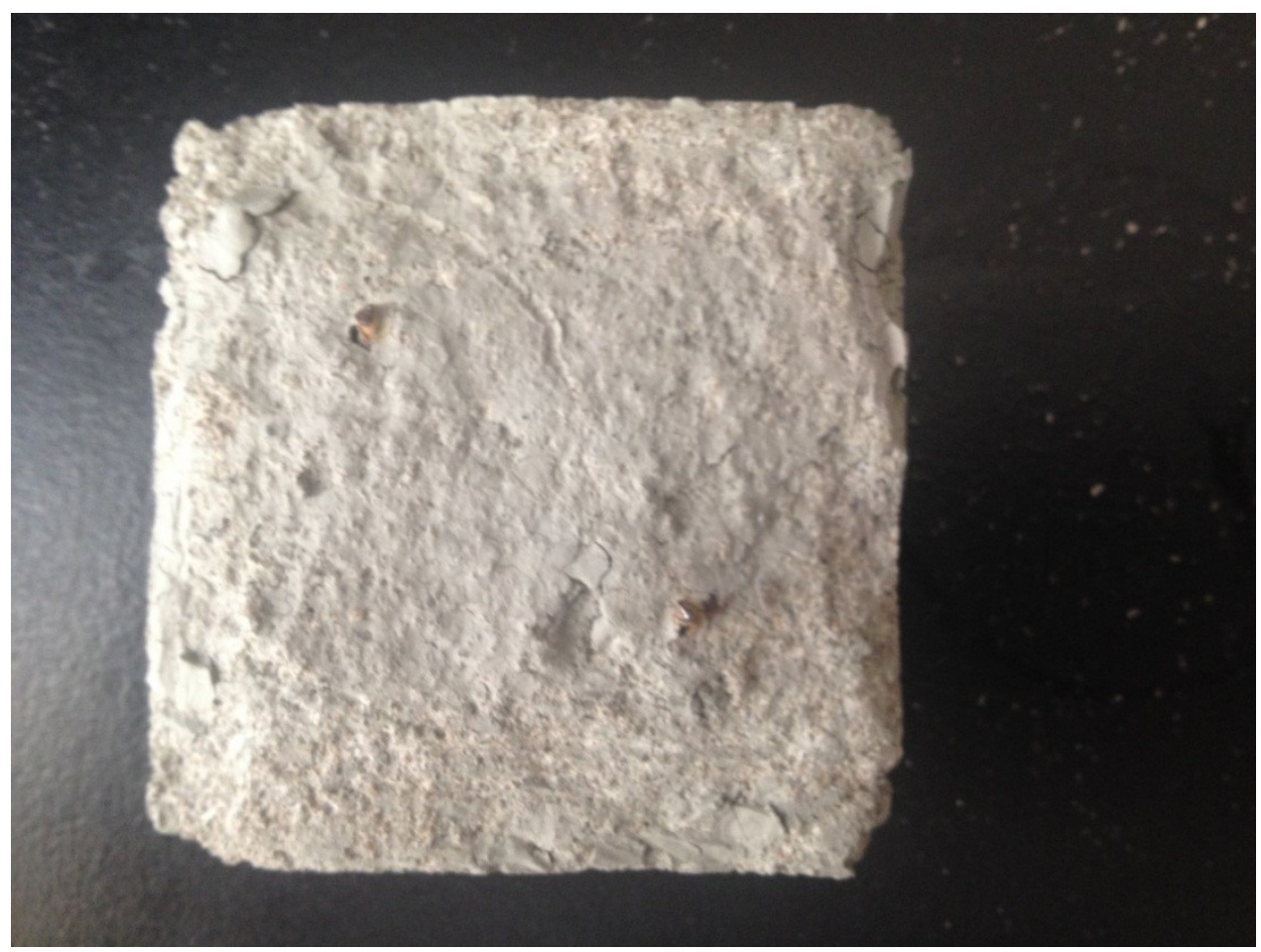

Figure 1 - Laboratory test concrete interface with 2 hooks removed from the shear box 


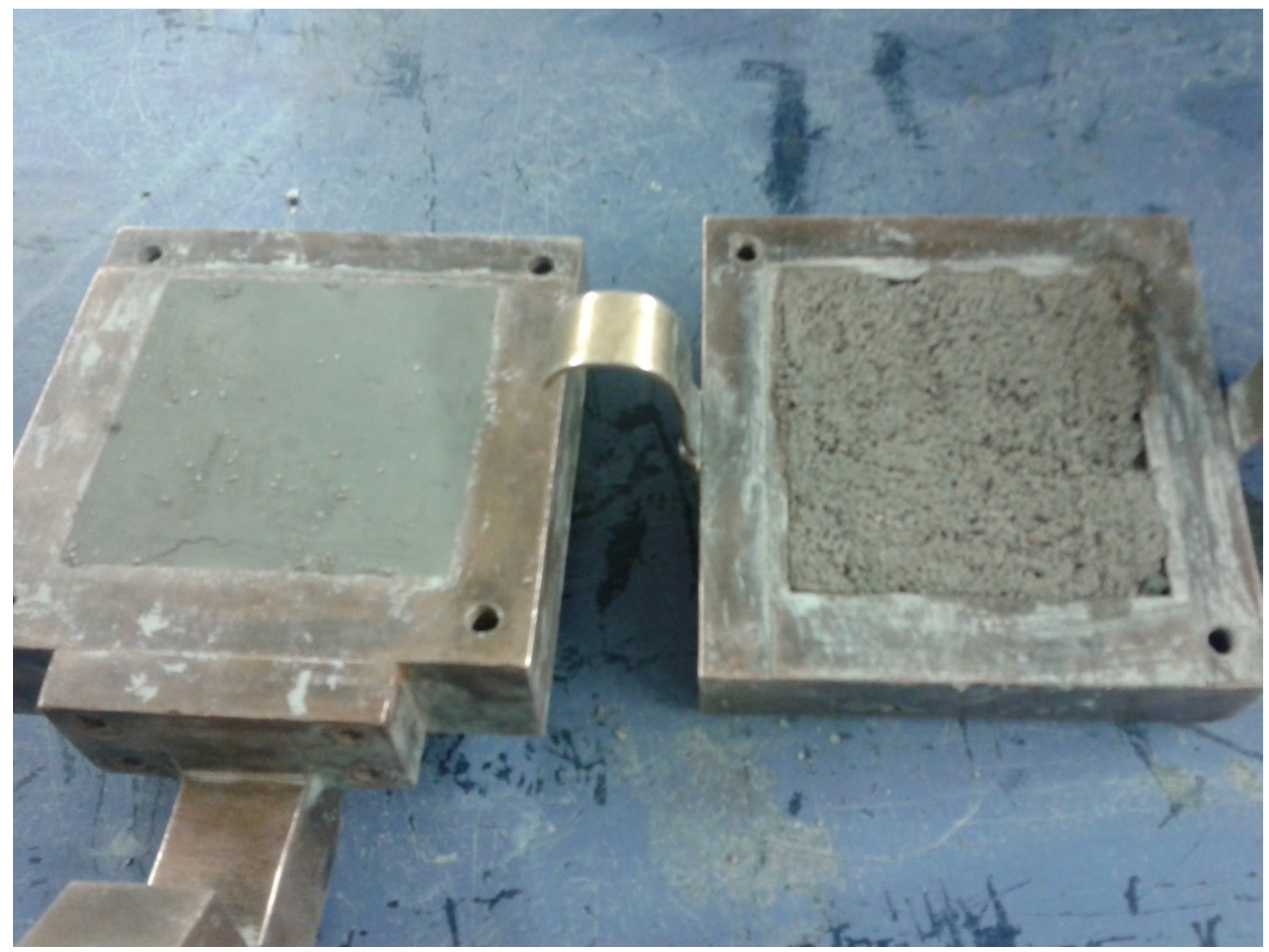

Figure 2 - Laboratory test concrete-clay interface with no hooks 


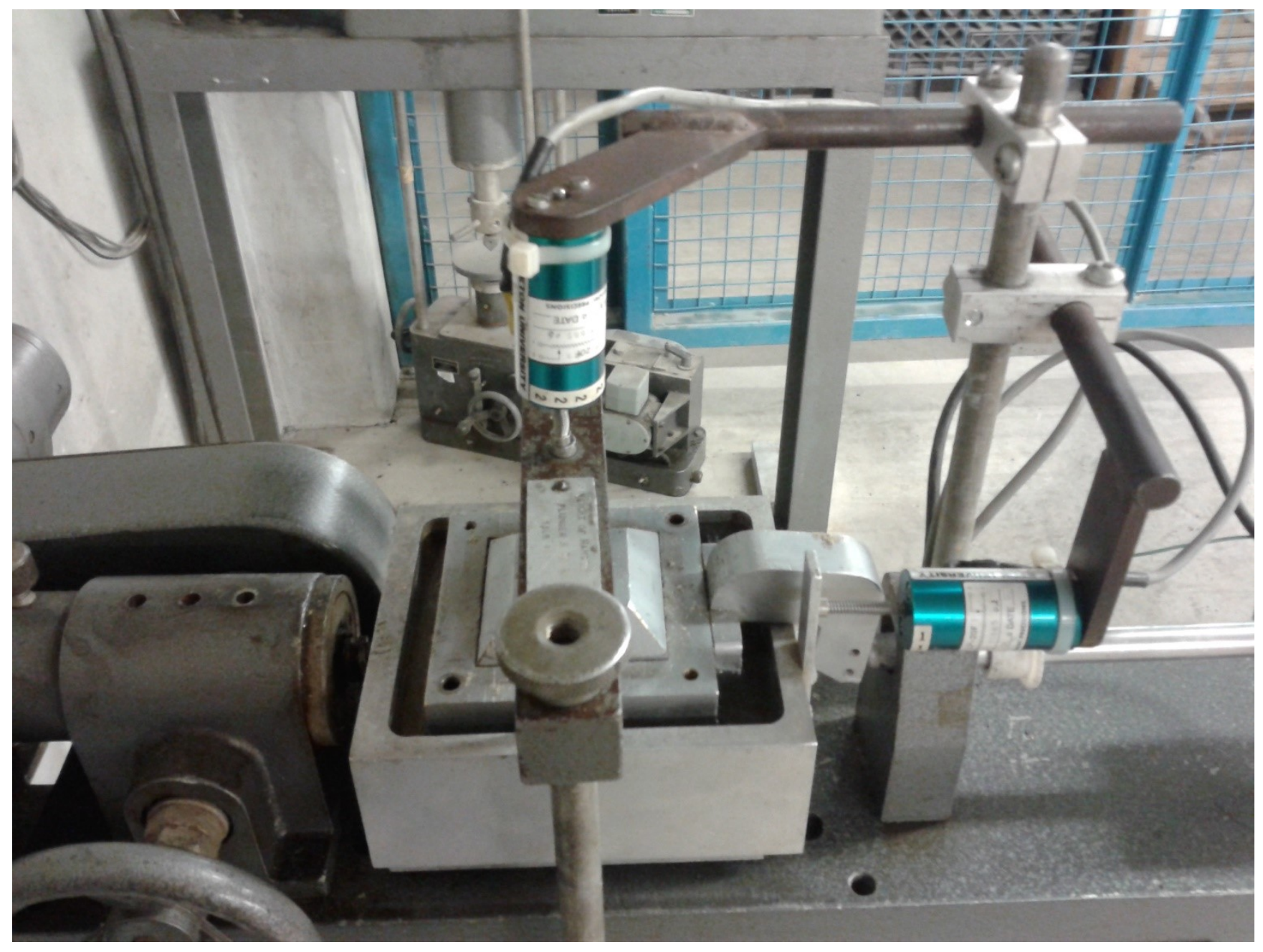

Figure 3 - Shear box test apparatus 


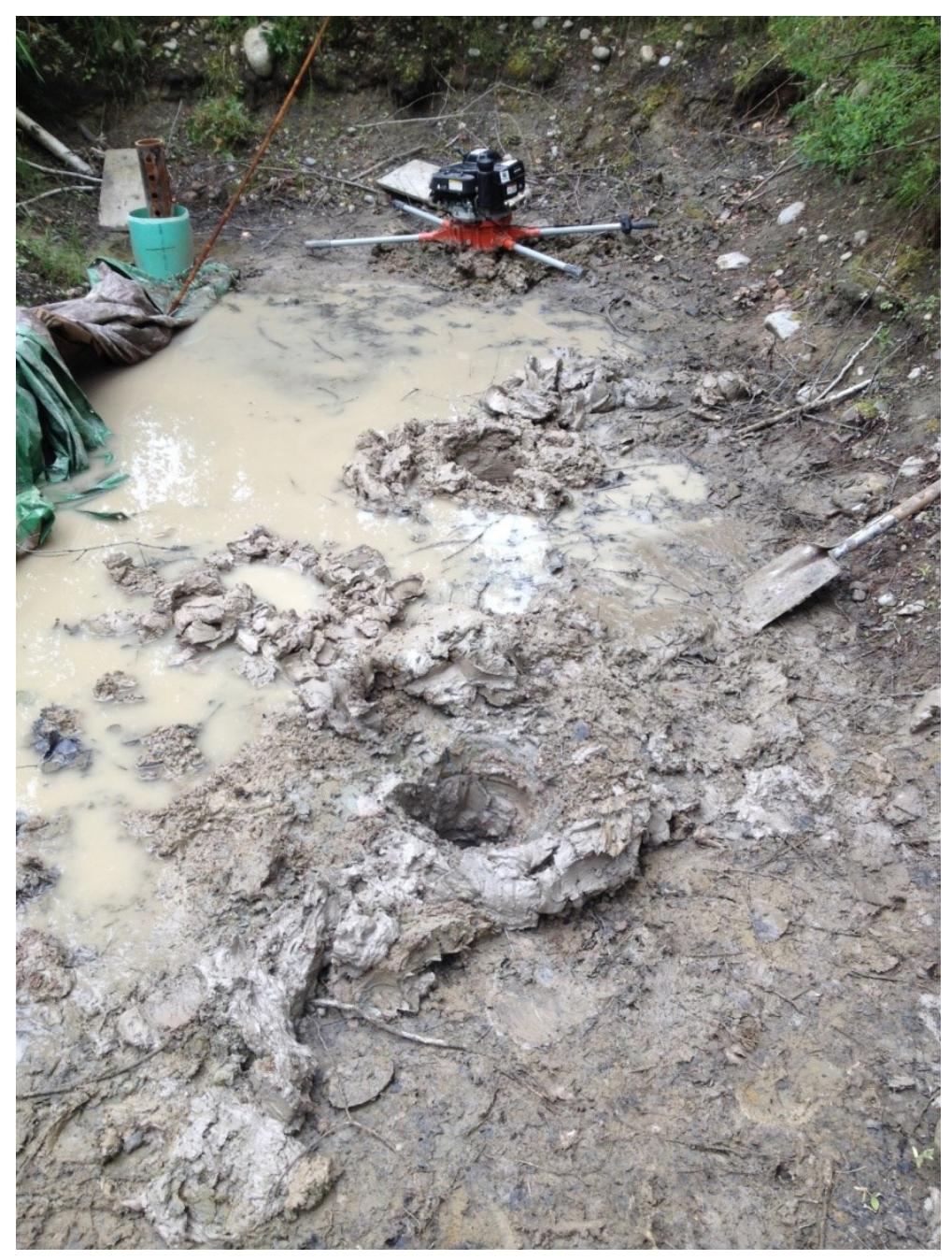

Figure 4 - Drilling the hole shaft of the pile using mechanical auger 


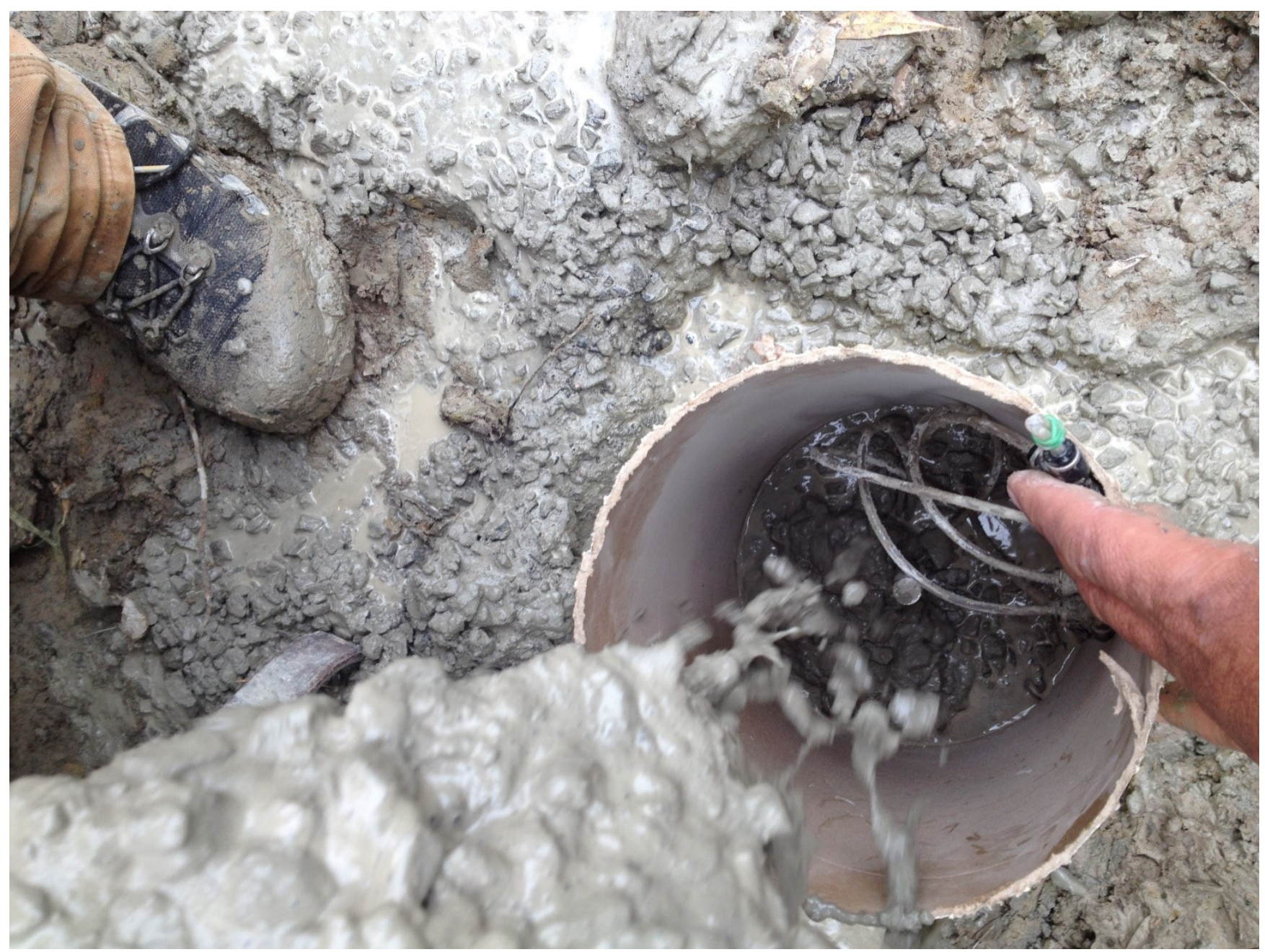

Figure 5 - Pouring concrete in the holes of the piles using ready mix concrete 


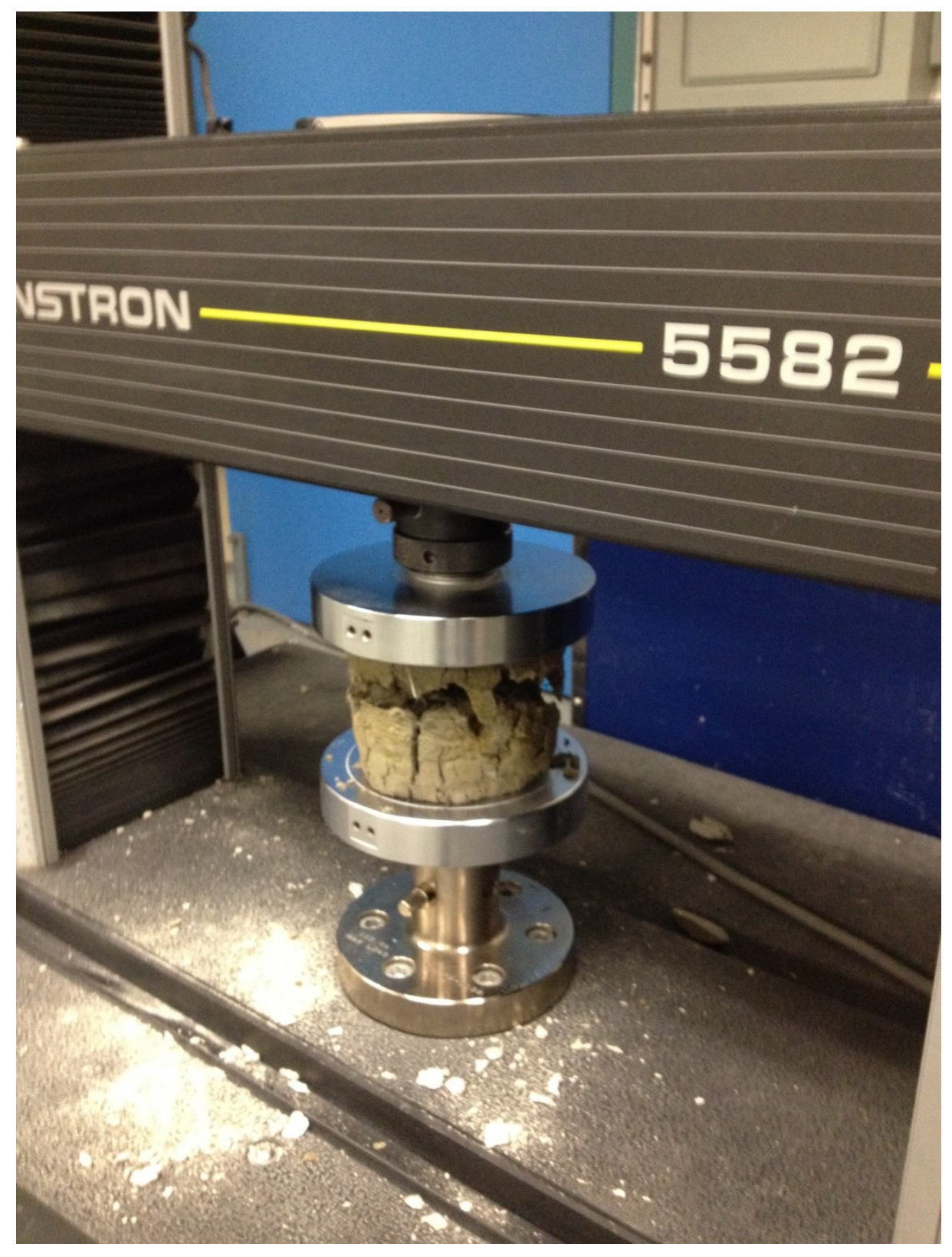

Figure 6 - Unconfined compression test for clay sample taken from the site 


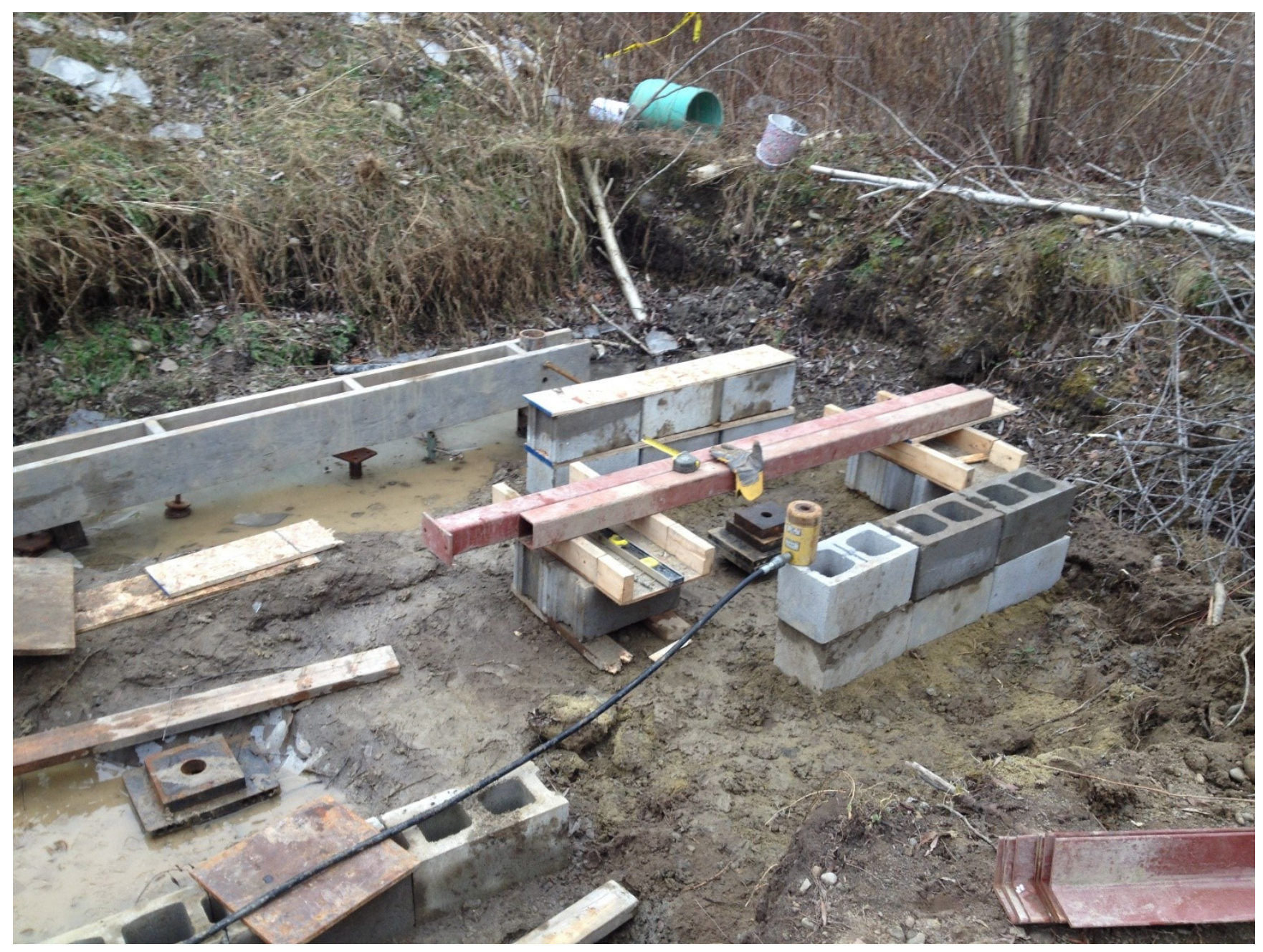

Figure 7 - Platform set-up 


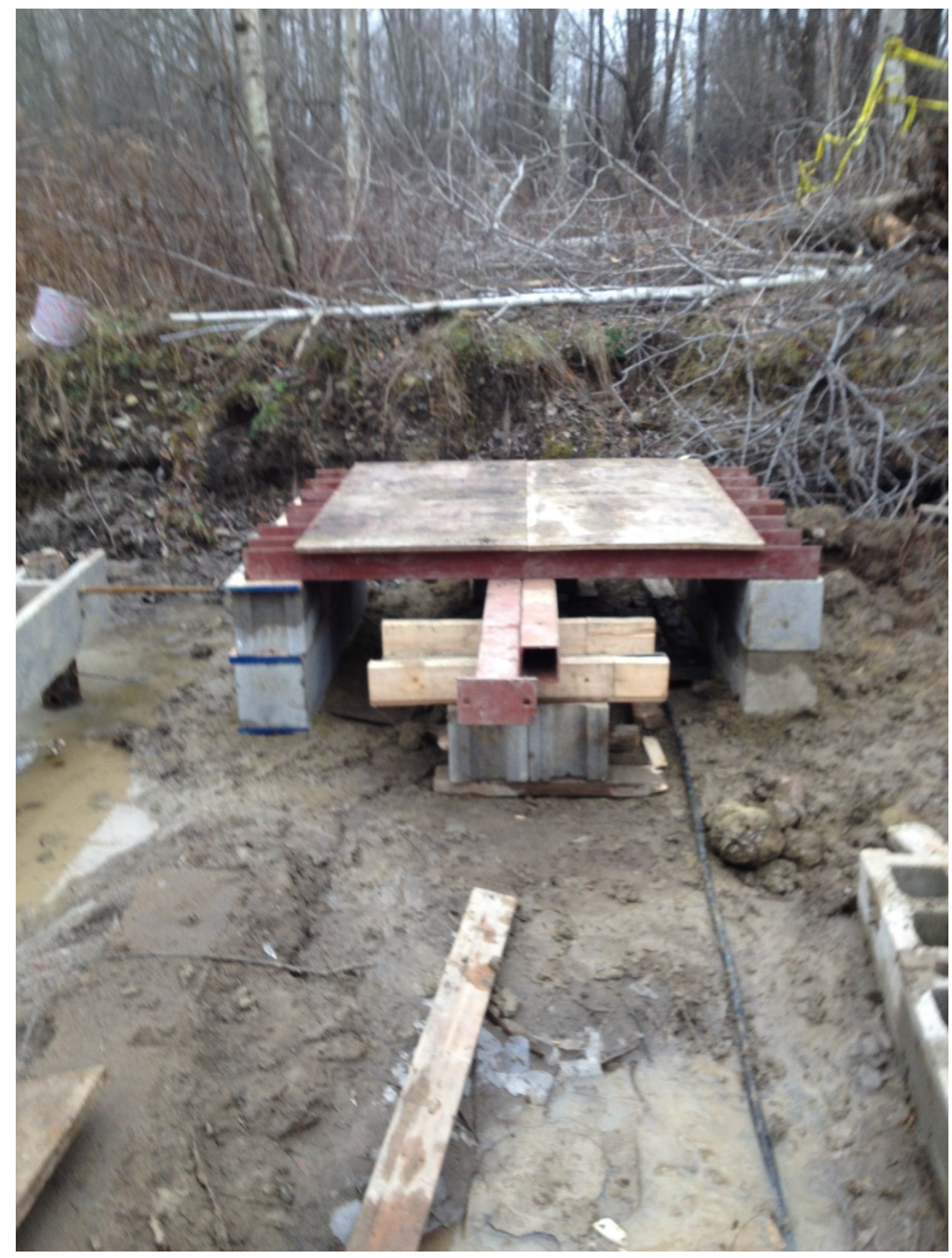

Figure 8 - Platform set-up completed 


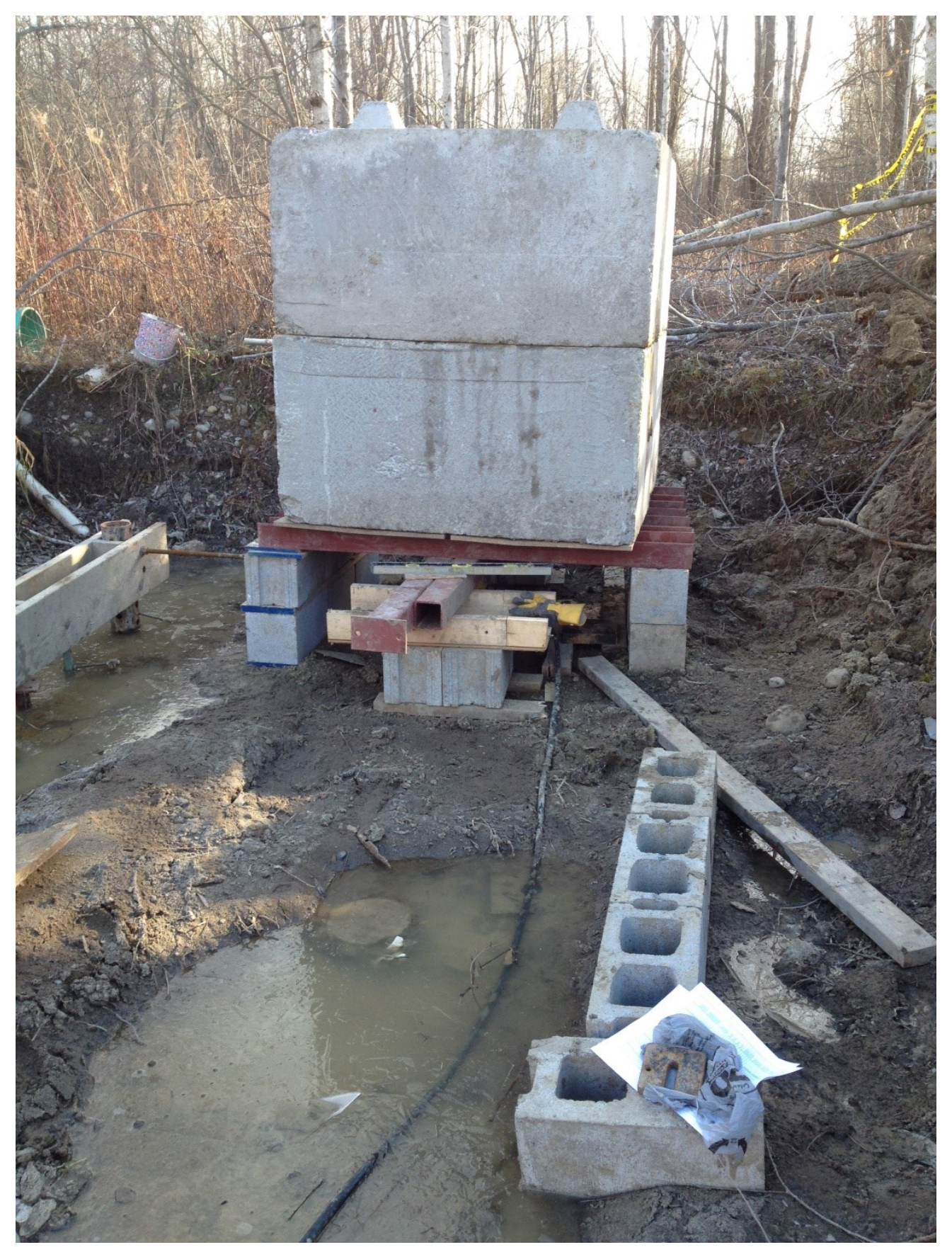

Figure 9 - Test set-up completed 